\title{
Muerte, despedazamiento y apoteosis de Rómulo: un estudio sobre la realidad histórica del primer rey de Roma
}

\author{
Death, dismemberment and apotheosis of Romulus: \\ a study about the reality of the first king of Rome
}

\author{
Ángel luis CAsquillo Fumanal*
}

\begin{abstract}
RESUMEN
El descuartizamiento de Rómulo y su apoteosis celestial con el nombre de Quirino no son dos variantes de la muerte del primer rey de Roma, que se excluyan mutuamente, sino dos versiones que hay que armonizar. Augusto Fraschetti (2002) y Andrea Carandini (2006 y 2007) quieren reducir la historicidad del relato sobre la muerte de Rómulo sólo a su despedazamiento, que interpretan como un reparto de la soberanía de Roma entre los senadores y las curias. Pero, siguiendo la tesis de historiador antropólogo Angelo Brelich (1960), hay que recalcar que el despedazamiento del cadáver regio, lejos de tener algo que ver con el reparto de la soberanía en Roma, se remonta a un ritual de inmortalización de la función regia en la Grecia prearcaica (Dioniso) y en el antiguo Egipto
\end{abstract}

(Osiris).

\section{PALABRAS CLAVE}

Rómulo, despedazamiento, apoteosis, Quirino, carácter regio, sucesión, Dioniso,

Osiris.

\begin{abstract}
The tearing to pieces of Romulus and his apotheosis in heaven with the name Quirinus are not variants, mutually autoexcluding, of the death of the first king of Rome. Augusto Fraschetti (2002) y Andrea Carandini (2006 y 2007) reduce the historicity of the narration of the death of Romulus only to his tearing to pieces, that they interprete as an appropriation of the Rome sovereignty by the senators and the curias. But, following the thesis of the historian anthropologist Angelo Brelich (1960), it must be emphasized that the dismemberment of the royal corpse, far from being related to the distribution of the sovereignty, retroacts a ritual of immortality of the regal function in prearchaic Greece (Dionysos) and Egypt (Osiris).
\end{abstract}

\section{KEYWORDS}

Romulus, dismemberment, apotheosis, Quirinus, regal character, succession, Dionysos, Osiris.

* I.E.S. «Juana de Castilla». Madrid. C/Valdebernardo, 3. 28030-Madrid. E-mail: luiscfumanal @ hotmail.es 
«Es necesario que los historiadores estén dispuestos a admitir, en ciertos casos, su incapacidad para llegar a conclusiones seguras, porque los elementos de información son insuficientes. Los historiadores deben estar dispuestos a sentenciar, como si fueran jueces: No ha lugar, faltan pruebas».

ARNOLDO MOMIGLIANO

«Oggi, la stessa enunciazione dei problemi relativi alla storia arcaica di Roma in termini di ipercritica (o, subordinatamente e in modo sostanzialmente subalterno, di "ipocritica") può considerarsi definitivamente inattuale: il discorso si è spostato su un terreno nuovo, la cui stessa problematica è sostanzialmente diversa (...): alla storia eticopolitica ed "événementielle" (che pure resta importante, ma per quanto riguarda Roma arcaica difficilmente pratticabile) si va sostituendo una storia "antropologica", interessata a problemi in parte alternativi» (F. COARELLI, Foro Romano, 1983, p. 301).

\section{INTRODUCCIÓN}

La cuestión de la historicidad de Rómulo y la datación de la fundación de Roma siguen siendo piedra de toque para la credibilidad de toda la historia antigua de Roma. La obra de Augusto Fraschetti y de Andrea Carandini en los últimos años ha puesto de relieve el problema de la historicidad de Rómulo, el fundador de Roma, y la historicidad de los primeros tiempos de la monarquía de Roma.

Dentro de la cuestión de la historicidad de Rómulo está encerrado el problema de la verosimilitud del carácter regio que el relato tradicional le atribuía. Es sabido que la historiografía hipercrítica niega la existencia misma de Rómulo. Por su parte, la historiografía etrusquizante de Roma, haciendo remontar a los etruscos el origen de la monarquía romana, niega a Rómulo el carácter de rey y fundador de la Urbe. Su muerte, su descuartizamiento y apoteosis, no son ajenos al problema mismo de la regalía de Rómulo. La interpretación de tal desmembramiento puede de algún modo conllevar la historicidad del carácter regio y de la personalidad misma de Rómulo.

La muerte, descuartizamiento y apoteosis de Rómulo está rodeada de conjeturas y de discrepancias desde el momento mismo en que historiadores y anticuarios de Roma la incluyeron en el relato tradicional. De ahí la importancia de los pasos que se imponen en este tema: 1. Establecer el texto tradicional. 2. El estado de la cuestión : antigüedad del relato y su interpretación. Los autores antiguos que hacen mención al desmembramiento y/o a la divinización de Rómulo son por orden de antigüedad Ennio, Cicerón, Tito Livio, Dionisio de Halicarnaso, Ovidio y Plutarco.

Ennio nos ofrece —entre el año 250 y el 200 a.C.- el más antiguo de los documentos conocidos acerca de la suerte póstuma de Rómulo. El testimonio de Ennio abarca desde la condición divina de Rómulo, fundamentada ya en su propio na- 
Muerte, desplazamiento y apoteosis de Rómulo: un estudio sobre la realidad...

cimiento («ioh sangre emanada de los dioses!»)1, y confirmada tras su presupuesta ascensión a los cielos («Rómulo pasa el tiempo sin fin en el cielo con los dioses») ${ }^{2}$, hasta la mención de Quirino, cuya identificación con Rómulo no afirma expresamente, y la veneración sagrada que recibe en unión de su esposa Hersilia: "Yo te venero a ti, Quirino, y a ti Hora, esposa de Quirino»3. La ascensión de Rómulo a los cielos, implica, a su vez su caracterización como rey bueno y benemérito por excelencia ${ }^{4}$. Véase el contraste con el belicoso y cruel rey Tulo Hostilio, quien a pesar de ser transportado por una tormenta a los cielos no recibió el trato apoteósico del mismo Rómulo.

Los versos de Ennio que proclaman a Rómulo divinizado como «guardián de la nación romana» pueden ser usados para confirmar la naturaleza benemérita del rey que fundó Roma ${ }^{5}$. Pero tomados en su contexto más bien definen el estatuto post-mortem de Rómulo. En ese sentido el texto parece una citación de «Los Trabajos y los Días» de Hesíodo: En la descripción del estatuto de los hombres de la generación dorada, la llamada «edad de oro», Hesíodo atribuye a ese linaje, dotado de carácter regio, la función de perpetuarse como «daimones» protectores (phylakes) de los hombres que les sobreviven 6 . Encontramos aquí, pues, una alusión de Ennio a un fondo mitológico sin duda muy anterior a él.

Ya en el siglo final de la república romana, Cicerón trata de este asunto considerándolo desde una doble perspectiva: la inmortalización de Rómulo y su identificación con Quirino. Los textos fundamentales son: De Republica (II,10), libro inmediatamente anterior al año 52 a.C., y el tratado sobre las Leyes (De legibus I, 3-4), libro escrito a partir de 52 a.C. Dejamos aquí de lado algunas citaciones de menor calado 7 . El libro De Republica y el De Legibus merecen una consideración especial.

1 «o sanguen dis oriundum» (ENN. Ann. fr. 59,4 ed. Segura).

2 «Romulus in caelo cum dis genitalibus aeuom degit», (ibid. fr. 57).

3 «<Teque>, Quirine pater, ueneror Horamque Quirini» (ibid. fr. 58).

4 Ver A. Fraschetti, Romolo il fondatore, ed. Laterza, Roma-Bari, 2002, p. 96.

5 Ver el texto en ENN. Ann. fr. 59 ed. Segura: «La congoja embarga sus corazones al mismo tiempo que entre ellos hablan de este modo: -iOh Rómulo, divino Rómulo (Romule die), cuán grande guardián de la patria te engendraron los dioses! (qualem te patriae custodem di genuerunt) ¡Oh padre, oh fundador, oh sangre emanada de los dioses! Tú nos condujiste dentro de los confines de la luz». Se trata de una evidente alusión a la desaparición de Rómulo en la laguna de Capras y a su posterior ascensión a los cielos.

6 El texto completo de Hesíodo es el siguiente: «Mas desde que la tierra cubrió (kalypse) a esa generación, ellos se convierten en daemones puros, buenos, supraterrestres (epichthonioi), alejadores del mal, guardianes de los hombres mortales, (...) dadores de riqueza: aun ese honor de reyes tuvieron" (HES. Erga 121-126. Constituye un tratamiento ya clásico del pasaje hesiódico Jean-Pierre Vernant, «El mito hesiódico de las razas. Ensayo de análisis estructural» en Revue de l' Histoire des Réligions (1960), pp. 21-54; artículo contenido en Mythe et pensée chez les grecs, ed. Maspero, Paris 1965 (ver la edición castellana: «Mito y pensamiento en la Grecia Antigua», ed. Ariel, Barcelona 1983, pp. 21-51; cfr. también pp. 52-88). En cuanto a la promoción de los hombres de la edad de oro - generación regia, como Rómulo- al estatuto de démones "guardianes" de los hombres, Vernant se remite al estudio de Victor Goldschmidt, "Theologia", Revue des études grecques LXIII,1950, pp. 33-39.

7 Hay que añadir breves alusiones en Officiis 3,41 (pace vel Quirini vel Romuli dixerim: «dígalo yo con permiso de Quirino o, lo que es lo mismo, Rómulo») y en el De natura deorum II,62 (Romulum quem quidam eundem esse ac Quirinum putant: «Rómulo que algunos piensan ser el mismo que Quirino»). 
En su tratado sobre las «Leyes» Cicerón dialoga con su íntimo amigo Ático. A éste, que pone en duda la autenticidad de una leyenda poética aludida por Cicerón (acerca de una supuesta «encina de Mario» en Arpino), le contesta que responderá a su pregunta, si antes él se atreve a decirle «si es cierto que Rómulo, después de muerto..., le dijo a Próculo Julio que estaba divinizado y que su nombre era Quirino (se deum esse et Quirinum vocari), y ordenó que se le construyera un templo en aquel sitio». Ante la persistente actitud dubitativa de Ático, Cicerón le encarece a no pararse a «investigar con excesivo rigor las tradiciones de esta clase» (quae isto modo memoriae sunt tradita). Texto este último fundamental, que no carece de una cierta ambivalencia, puesto que, a) por un lado muestra una indudable ironía de Cicerón con respecto a algunos tipos de tradición -téngase en cuenta sobre todo el sentido peyorativo del isto modo-; y, por otro lado, alude a una memoria (¿oral?) recibida de los antiguos acerca de la divinización de Rómulo, mientras que nuestros testimonios directos no son anteriores a Ennio. ¿A qué antigua tradición puede referirse Cicerón? Una cierta aproximación a la respuesta la encontramos precisamente en el propio tratado «De Republica».

En el «De Republica» Cicerón mantiene una actitud de fe total en relación a la inmortalidad de Rómulo y su identificación con el dios Quirino, temas que, como hemos visto, en el De Legibus pasó a tratar con cierta ironía. El texto ciceroniano empieza afirmando que la perfección de la obra política de Rómulo llegó a tan alto grado (tantum est consecutus), que «habiendo desaparecido tras un oscurecimiento del sol, fue considerado digno de ser contado en el número de los dioses» (deorum in numero collocatus putaretur). Y eso le parece a Cicerón tanto más digno de admiración porque los hechos relativos a la biografía de Rómulo, coetáneos de la fundación de Roma (secundo anno olympiadis septimae, 751 a.C.), sucedieron en un tiempo en que la humanidad ya no era propicia a creer fácilmente en mitos ni en fábulas. Lo más interesante del texto es que Cicerón se atreve a retrotraer la fe en la inmortalidad de Rómulo hasta el momento mismo de su muerte, que no elude fechar con la precisión que se pediría a un historiador:

«En el mismo año en que aquél (Rómulo) murió, nació Simónides, en la Olimpíada cincuenta y seis; con lo que se puede entender más fácilmente que ya entonces se creía en la inmortalidad de Rómulo, cuando ya la vida de los hombres (ilustres) era tratada y conocida».

El texto de la «República» a que nos acabamos de referir está muy corrompido ${ }^{8}$. La Olimpíada cincuenta y seis se celebró en el año 552 a.C. Y sabemos que el aludido poeta griego Simónides vivió efectivamente por esa época y que, como decían los antiguos floreció (floruit) alrededor del año 520 a.C. (630).

8 El texto latino restaurado de Cicerón dice así: Quo <vero> ille mor<tuus e eodem <est an>nno na<tus Si>moni<des, ol<lympia<de sex>ta et quin<quag>esima, <quo $f>$ acilius <intell>igi pos<sit $t u<m$ de Ro>muli iam immortalitate creditum... Evidentemente el nombre de Simonides, en vez de Semónides, resulta de la conjetura $(<S i>m o n i<d e s>)$ de los restauradores del texto. Pero nada se les puede reprochar a éstos, pues su conjetura $-(<S i>$ moni $<$ des $>)$ y no $(<S e>$ moni $<d e s>)$ - es la que se deduce irremisiblemente de la cronología (cincuenta y seis olimpíada= 552 a.C.) suministrada por Cicerón, que es quien ineludiblemente se equivoca. 
Muerte, desplazamiento y apoteosis de Rómulo: un estudio sobre la realidad...

Ignoro en qué fuente Cicerón encontró el dato de esa coincidencia cronológica entre la muerte de Rómulo y el nacimiento de Simónides, que contradice lo dicho más arriba acerca de la coetaneidad obvia entre le vida de Rómulo y la fundación de Roma (según Cicerón en el 751 a.C.) Parece como si Cicerón $-\mathrm{y}$, siguiéndolo a él, los restauradores del texto- hubiera podido confundir el nombre y, consiguientemente, la cronología de Simónides con la del poeta yámbico Semónides de Amorgos, que floreció en el 630 a.C. y cuyo nacimiento debió haber sido hacia el año 675, menos de cien años después del hipotético nacimiento de Rómulo.

Dos cuestiones nos asaltan a este propósito: 1) ¿Por qué la fe en la inmortalidad de Rómulo habrá de coincidir con la fecha del nacimiento de Simónides?, ¿hubo algún texto de este poeta griego relativo a Rómulo?, y 2) ¿Podemos exigir en Cicerón para el caso de Rómulo la misma precisión cronológica, que damos por comprobada en el caso de Simónides? Evidentemente no nos es necesaria. De lo que, en todo caso debemos tomar nota (a propósito de un texto tan corrompido y un panorama tan confuso), es de que Cicerón no reduce la fe en la inmortalidad de Rómulo a una mitología tardía y de elaboración reciente. Él cree que esa fe es casi contemporánea con los hechos.

Y da como prueba de ello (además de la poco clara alusión a Simónides) lo que nosotros no pasamos de calificar de epidodio meramente legendario: la intervención de Próculo Julio, «quien a requerimiento de los senadores, para apartar de ellos la sospecha por la muerte de Rómulo» (qui impulsu patrum, quo illi a se invidiam interitus Romuli pellerent), se presentó ante la asamblea (in contione, es decir en la laguna de Capra) asegurando que había visto a Rómulo en la colina que por tal razón «ahora se llama Quirinal», pues Rómulo le había dicho que «era un dios y quería ser llamado Quirino" (se deum esse et Quirinum vocari), mismo texto (!) éste último que en «Las Leyes» y que allí tratará con gran dosis de ironía.

Ya en época augústea contamos con el doble testimonio de Dionisio de Halicarnaso y de Tito Livio, más una breve alusión de Apiano. Dionisio de Halicarnaso, griego que escribe en griego y que llegó a Roma en el año 29 a.C., nos cuenta en sus "Antigüedades Romanas» el desenlace de la vida mortal de Rómulo, del que aporta una triple versión (DIONYS. II, 56). Según un tipo de narración, que Dionisio califica de «más fantasiosa» (mythodestera), Rómulo desapareció durante una acampada del ejército que él había convocado (ekklesiázonta) en el Campo de Marte: De repente sucedieron fenómenos sobrenaturales, pues el día se oscureció en medio de una gran tempestad de truenos y Rómulo desapareció de la vista de todos; cuando la calma se recobró, el trono apareció vacío y se creyó que Rómulo había sido arrebatado a los cielos por su padre Marte. Los que presentan la versión para Dionisio «más creíble» (pythanotata) son quienes dicen que Rómulo murió a manos de sus propios conciudadanos - se menciona en concreto a los patricios reunidos en el senado (en el «Vulcanal», precisará Plutarco), es decir, a los senadores-; la causa del asesinato habría sido que distribuyó sin consultar al pueblo las tierras conquistadas a los Veyentes, que privilegió a los antiguos ciudadanos frente a aquellos recientemente adscritos y que inflingió a los condenados castigos de una crueldad inaudita: toda una serie de circunstancias 
que coalescían para que hubiera llegado a parecer que Rómulo ejercía el poder «no a la manera de un rey sino a la manera de un tirano» (DIONYS. II,56,5). Pero los senadores no se contentaron con asesinar a Rómulo, sino que, -en la lógica de Dioniso- para tapar su crimen, «después de reducir a pedazos el cuerpo, con la intención de impedir que el cadáver fuera visto», salieron del senado llevando oculto (kryptontas) bajo su toga el trozo que a cada uno le había correspondido, y después de esto lo ocultaron a escondidas bajo tierra ${ }^{9}$ (DIONYS. II, 56, 10-13). Según la tercera versión fueron los nuevos ciudadanos de Roma los que, descontentos, asesinaron y despedazaron a Rómulo, en este caso en el campo de Marte; versión menos interesante, pero que demuestra que el mismo Dionisio no elude combinar elementos de la primera versión (laguna de Capra, campo de Marte) y de la segunda versión (despedazamiento) en una suerte de versión mixta: despedazamiento o, lo que es lo mismo, ocultación del cadáver (habida en el Volcanal), pero en el Campo de Marte (escenario de la apoteosis). Apiano, que también escribe en griego, ya en el siglo II d.C., se adhiere a la segunda versión de Dionisio de Halicarnaso, cuando -refiriéndose al asesinato de César- dice: «(Los conjurados) pensaron entonces en la curia (de Pompeyo) como lugar (del crimen), suponiendo que los senadores, aunque no habían sido antes informados, se pondrían de su lado cuando vieran de qué empresa se trataba, lo mismo que según se decía sucedió en el caso de Rómulo, convertido de rey en tirano» (APPIAN. B.C. 2,114.476?).

El historiador latino Tito Livio escribió su famosa Historia de Roma «Ab urbe condita» entre los años 30 a.C. y 9 d.C. Pero sabemos que en concreto la publicación del primer grupo de cinco libros - donde está contenida la vida Rómulose llevó a cabo en el tiempo que media entre la concesión del título de Augusto a Octaviano (27 a.C.) y la segunda clausura del templo de Jano (25 a.C.). Teniendo en cuenta que la llegada a Roma de Dioniso de Halicarnaso y el inicio de la composición de su obra fue en el año 29 a.C., es difícil saber si uno de ambos autores puede depender del otro y cuál de ellos. En el caso de Tito Livio es más razonable limitar su dependencia a Asinio Polión y a toda la tradición analística romana, cuya vulgata en la época estaba constituída por el historiador del 200 a.C. Fabio Píctor.

Livio hace preceder su relato de la muerte de Rómulo de una especie de afirmación programática en la línea de Ennio sobre la indudable cualidad de rey benemérito de Rómulo: «Esto fue lo realizado por Rómulo a lo largo de su reinado tanto en el terreno de la paz como en el de la guerra, sin que nada de todo ello sea incompatible (absonum) con la creencia en su origen divino y en su propia divinidad, que le fue reconocida tras su muerte» (T.LIV. I, 15,6). Sin embargo, Livio no deja de hacer notar que Rómulo fue más querido por la multitud que por los padres senadores (ibid. I, 15,8). Luego viene el relato detallado de la muerte y ascensión

9 Las palabras griegas de Dioniso de Halicarnaso relativas al enterramiento de Rómulo («ocultar bajo tierra»), aun no siendo las mismas, parecen remitir a los términos que Hesíodo (loc. cit.) usa a propósito de la regia generación de oro: $\kappa \alpha \tau \alpha \gamma \alpha \iota \alpha \kappa \alpha \lambda \nu \psi \varepsilon$ «debajo la tierra cubrió». Del sentido que puede tener tal coincidencia ( $\gamma \varepsilon \rho \alpha \varsigma \beta \alpha \sigma \imath \lambda \eta ı v$, HES. Erga 126) hablaremos más abajo. 
Muerte, desplazamiento y apoteosis de Rómulo: un estudio sobre la realidad...

de Rómulo a los cielos ${ }^{10}$. Livio coloca la prodigiosa desaparición de Rómulo en el Campo de Marte, junto a la laguna de Capra $(I, 16,1)$, mientras pasaba revista al ejército. Una tempestad de nubes y rayos lo hacen desaparecer de la vista de sus hombres: "A partir de entonces nunca Rómulo estuvo ya en la tierra» (ibid. I, $16,1)$. Viene a continuación el llanto de la juventud romana; y sigue la afirmación -inspirada en el texto de Ennio - de que, aunque «al principio por iniciativa de pocos», al fin todos declaran a Rómulo dios nacido de un dios, rey y padre de la nación romana. $\mathrm{Y}$ acaba el pasaje con un texto, cuyo sentido hay que relacionar con Ennio y que —como hemos dicho más arriba- hay que hacer remontar a Hesíodo: todos piden al divinizado Rómulo que «vele siempre propicio por su progenie romana» (ibid. I, 16,3).

Llegado a este punto del relato, Livio informa de que «no faltaron entonces quienes formularon la tácita acusación de que el rey había sido despedazado por mano de los senadores (discerptum regem patrum manibus); surgió, en efecto, un rumor tan confuso como éste (haec quoque sed perobscura fama); pero el miedo y la admiración que Rómulo suscitaba acalló aquel rumor» (ibid. I, 16,4). Tal admiración llevó a todos a dar crédito precisamente al testimonio de Próculo Julio, quien se presentó ante la asamblea (in contionem) diciendo que se le había aparecido Rómulo, descendido del cielo (aunque no se menciona la identificación con Quirino), y le había anunciado la futura grandeza de Roma. «Es admirable - concluye Tito Livio- cuánta fe se dio al anuncio de aquel hombre, y cómo la creencia en la inmortalidad de Rómulo contribuyó ante la plebe y el ejército a sobrellevar la ausencia de Rómulo» (ibid. I, 16,8).

Algunas décadas después de Tito Livio el poeta épico Ovidio recoge en sus «Fastos» (II, 475-512) la leyenda de la muerte, despedazamiento y apoteosis de Rómulo. Ovidio resume en lo sustancial el mismo relato que Ennio y Cicerón, y que Tito Livio, su probable fuente histórica: Tormenta prodigiosa y desaparición de Rómulo en la laguna de Capra («Capreae paludem», v.491), consiguiente exaltación (venit in astra, v.478; astra petebat, v.496), explícita identificación con Quirino (se trata de la fiesta de las Quirinalia, 17 de Febrero) y el testimonio enaltecedor de Próculo Julio acerca del exaltado (novum...Quirinum, v.507). Añade también la información aportada por Dionisio de Halicarnaso y, ya con todas las cautelas, por Tito Livio — que la califica de «rumor»- de la intervención presuntamente criminal de los senadores en la muerte de Rómulo. Pero Ovidio no vacila en ser contundente en su valoración: «En el momento del luto se extendió la falsedad de la intervención de los Padres en el crimen» (Luctus erat falsaeque Patres in crimine caedis, v.497). Pero la negativa de Ovidio a creer en la culpabilidad de los senadores

10 Nada obsta el que, como quiere Patrick Marchetti, («Autour de Romulus et des Lupercalia», en Les Études Classiques LXX, 2002, pp. 83-84) el texto de la desaparición y ascensión de Rómulo a los cielos (T.LIV. 1,16) haya sido intercalado en medio de otro texto perteneciente a la vulgata de Fabio Píctor, que saltaría coherentemente desde T.LIV. 1,15,6 (ver más arriba) a T.LIV. 1,17. Eso nada más afecta al análisis literario del texto. Pero la vulgata de Fabio Píctor no era la única tradición ni necesariamente la más antigua sobre el fin de la vida mortal de Rómulo; y Tito Livio estaba en el derecho de enriquecerla intercalando cualquier otro texto que él considerara más explícito y rico en detalles, sin que ello presuponga que ha de tratarse de un texto más reciente y, como si dijéramos, una desautentificación del relato. 
(frente a su ingenua credulidad en cuanto a la exaltación de Rómulo) no fue compartida por todos los historiadores sucesivos.

Entre finales del s.I y principios del s. II d.C. el polifacético escritor griego Plutarco escribió sus «Vidas Paralelas». En la «Vida de Rómulo» (PLUT. Rom. 27-29), como es natural, se ofrece un relato, que sigue muy de cerca a Dionisio de Halicarnaso (y en algunos detalles a Livio). La muerte y desaparición de Rómulo tiene lugar exclusivamente en las nonas quintiles (7 de julio). Plutarco, como Dioniso, da dos versiones del hecho. En la primera versión Plutarco hace hincapié en la trasformación de Rómulo de buen rey en tirano: por su actitud tiránica los senadores lo asesinaron en el templo de Vulcano, despedazaron su cuerpo, y cada uno se llevó escondido bajo su vestimenta un trozo de cadáver. Según otra versión, la desaparición de Rómulo tuvo lugar entre los extraordinarios fenómenos meteorológicos ya consabidos, mientras Rómulo tenía una asamblea (ekklesían), como en Tito Livio, junto a la laguna de Capra. Los senadores invitaron al pueblo a venerar a Rómulo como a un dios: «se había convertido de buen rey en dios propicio» (ibid. 27,8). Pero algunos continuaban acusando a los «patricios» de engañar al pueblo con patrañas. Y es entonces cuando Próculo Julio se presenta «en el foro» (contra Cicerón: in contione) anunciando, como en Tito Livio, la apoteosis de Rómulo y la futura grandeza de Roma.

\section{ESTABLECIMIENTO DEL TEXTO}

Tal es el panorama global que presentan los testimonios antiguos acerca de la muerte y divinización de Rómulo. Historiadores y arqueólogos actuales extraen del texto conclusiones divergentes.

Lo normal es poner de manifiesto que todo lo que dicen Ennio, Cicerón, Dionisio de Halicarnaso, Tito Livio y Plutarco acerca de la desaparición final de Rómulo se resume en dos variantes absolutamente incompatibles y completamente distintas entre sí11. Según una variante la muerte de Rómulo sucede ante el ejército reunido junto a la laguna de Capras; según la otra, sucede ante los senadores en el lugar habitual de reunión (en el templo de Vulcano según la versión de Plutarco). La primera variante presupone un reinado intachable de Rómulo, que lo conduce a un final apoteósico; la segunda variante acusa a Rómulo de un final de reinado tiránico y da así paso al tiranicidio operado por los senadores. Tito Livio, que presenta una versión mixta, reduce el despedazamiento de Rómulo por los senadores a un «oscuro rumor» desmontado por la intervención de Próculo Julio.

\section{1. ¿Cómo organizan y reconstruyen el texto los actuales «scholars»?}

Empecemos por Andrea Carandini, quien a mi juicio es el que hace las aportaciones más explícitas dividiendo el relato en dos esquemas de verdad/falsedad

11 Ver sobre todo Augusto Fraschetti. Romolo il fondatore. Laterza, Roma-Bari 2002, p. 96. 
correspondientes a su valoración de ambas tradiciones, que él llama «variantes»: a) la primera «variante» —la del asesinato y desmembramiento de Rómulo, que tiene lugar en el Vulcanal, sede entonces del senado, celebrada durante las fiestas llamadas Quirinalia (17 de febrero) - es calificada por Carandini de «meno frequente, attestata in epoca piú tarda, ma verosimilmente piú risalente e autentica»; b) la segunda «variante» —la de la apoteosis, que tiene lugar en la laguna de Capra, campo de Marte, luego celebrada durante las llamadas Nonas Caprotinas (7 de julio) - es calificada por Carandini de «piú frequente e attestata in epoca piú antica, ma probabilmente meno risalente e autentica» (Carandini 2006, 314).

Pero la separación del despedazamiento de Romulo y de su apoteosis a los cielos en dos versiones distintas parece labor exclusiva de la historiografía racionalista griega: Dionisio de Halicarnaso en el s. I a.C. y un siglo después en menor grado Plutarco, que sigue y parafrasea a Dionisio (no sin cierta confusión entre ambas versiones). La tradición estrictamente latina, Cicerón, Tito Livio y Ovidio (que parecen seguir a Ennio) une en un solo escenario el despedazamiento/ asesinato de Rómulo y su apoteosis. En efecto: es precisamente a propósito de la apoteosis de Rómulo a los cielos en la laguna de Capra cuando Cicerón, Tito Livio y Ovidio mencionan la sospecha acerca de la muerte de Rómulo a manos de los senadores. Ovidio y el calendario de Palemon Silvio confirman el dato llamando Quirinalia a una fiesta en que se trata precisamente de la desmembración de Rómulo. El calendario de Palemón no puede ser más explícito al unir ambos acontecimientos: "Quirinalia, quo die Romulus occisus a suis". Si la desmembración de Rómulo (occisus) no está irremediablemente unida a su apoteosis, ¿por qué la fiesta de su desmembración se llama Quirinalia, siendo Quirino no otro — como más abajo tendremos ocasión de reafirmar- que Rómulo ascendido a los cielos?...

Parece relativamente claro que muerte y apoteosis de Rómulo no tienen por qué ser dos «variantes de la leyenda» (la variantes se autoexcluyen dentro de un mismo autor, que opta por una u otra de ellas; por eso son variantes). Muerte y apoteosis de Rómulo pueden ser pasos sucesivos de una misma leyenda. Es precisamente la labor de redacción de los autores del texto la que ha optado por: o bien unir la muerte no violenta de Rómulo a su apoteosis, o bien separar de la apoteosis su asesinato ritual. Pero la versión mixta de Tito Livio demuestra que despedazamiento de Rómulo y apoteosis no son incompatibles. Dejamos para más adelante explicar por qué, tratándose de un mismo acontecimiento legendario, la fiesta se celebraba en dos escenarios diversos.

El mismo Carandini, al trazar el estado de la cuestión, aduce los precedentes que responden a su valoración de ambas tradiciones: Según el clasicista y antropólogo comparatavista Angelo Brelich, una leyenda como la de la apoteosis de Rómulo no surge de la nada y de la noche a la mañana, por lo que «la variante (sic) dell'apoteosi risulterebbe piú antica di quella relativa all'uccissione» (Carandini 2006, p. 315). De hecho, el relato más antiguo conservado, el de Ennio (y Cicerón?), sólo hace alusión a la apoteosis de Rómulo. En tal sentido ilustres filólogos, como Schwegler, Otto y Cook, han defendido como auténtico el mito de la muerte 
y despedazamiento de Rómulo, seguido de su exaltación, en base a la comparación con mitos griegos (Penteo, Licurgo, Orfeo y Dioniso - sin decir nada de Osiris-). Angelo Brelich, un historiador, comparativista, es quien con más convicción ha defendido la posibilidad de combinar las dos versiones del final de Rómulo, que a algunos les parecen antitéticas e irreconciliables: la de la muerte por desmembramiento de Rómulo y la de su apoteósica ascensión a los cielos.

Otros muchos autores han defendido que hay que separar el despedazamiento de Rómulo de su apoteosis,

- o bien porque la desmembración y desaparición del cadáver excluye su ascensión a los cielos: Fraschetti insiste, sin dar las razones pertinentes, en que la apoteosis de Rómulo en forma de Quirino sólo se puede entender si aquel asciende a los cielos «con todo su cuerpo» (Fraschetti 2002:96 y 108),

- o bien porque el despedazamiento ritual de Rómulo no sería más que una racionalización posterior de su excesivamente prodigiosa apoteosis.

Sin embargo, no faltan quienes, olvidando que la apoteosis es el estrato más antiguo del relato de la muerte de Rómulo, no le conceden mucha más antigüedad que al motivo mismo del despedazamiento ritual de Rómulo: «Alcuni studiosi (Wissowa, Dumézil, Kock e Latte) hanno considerato l'idetificazione di Romolo con Quirino come un motivo mitico "dimostrabilmente" tardo, tardo-repubblicano, comunque non anteriore al III secolo a.C. Infatti solo dal III secolo l'identificazione diventa un motivo dominante nel pubblico colto e quindi nella tradizione letteraria, artistica, monetale e calendariale ...» (Carandini 2006, p. 315.).

\section{2. ¿Qué conclusiones se pueden sacar de ahí?}

Es evidente que hay que distinguir la fe de los romanos - más o menos contemporáneos de Rómulo- de los hechos mismos. Hechos de carácter prodigioso, de los que está hecha la mitología, como aquéllos que constituyen la apoteosis (inmortalidad, divinización, ascensión a los cielos) no armonizan con las categorías lógicas del pensamiento actual, que les niega posibilidad física; y tales hechos carecen, por eso, evidentemente de base histórica. Pero eso no obsta para que puedan haber alimentado la fe de los contemporáneos de Rómulo (ver Cicerón supra), de la que se nutre el relato legendario. Por eso, concluimos que no es signo de rigor histórico prejuzgar que la versión de la apoteosis de Rómulo, aunque «attestata in epoca piú antica», es "probabilmente meno risalente e autentica» (ver supra) por el hecho de que cuadra ya poco con el expediente racionalizador de los autores que a partir del s. III a.C. nos transmiten el relato tradicional de la vida de Rómulo; y por el hecho de que - se supone - tampoco cuadraba con la racionalidad que se quiere proyectar a la época misma de Rómulo, para la que Carandini tiene preparada, como se verá más adelante, una interpretación pretendidamente razonable del despedazamiento de Rómulo. 
Muerte, desplazamiento y apoteosis de Rómulo: un estudio sobre la realidad...

Está cargado de sentido el afirmar, como hace Brelich, que una leyenda como la de la apoteosis de Rómulo no surge de la nada y de la noche a la mañana. Un punto de partida como éste puede apoyarse en las consideraciones del propio Cicerón, quien en el pasaje ya citado de su tratado sobre la «República» arguye que, si bien debemos tomar los tiempos posthoméricos -en que vivió Rómulo-como una época llena ya de poetas y de músicos, y ya alejada de fábulas de apoteosis y fantasías de inmortalidad propias de tiempos entonces ya pretéritos, se ha de hacer una excepción en el caso de Rómulo precisamente a causa de «su estirpe y de su virtud» (vis ingenii atque virtutis, CIC. R.P. II, 10).

El despedazamiento lejos de ser un expediente racionalizador es uno de los temas predominantes de la mitología clásica y muy bien pudo ser recreado para Roma - a imitación de mitos griegos y egipcios - ya en tiempos muy cercanos a la muerte de Rómulo, como el mismo Cicerón sugiere a propósito del mito de apoteosis. Luego en el texto hay que hacer armonizables la mal llamada «variante» de Capra con la mal llamada «variante» de la curia o Vulcanal).

\section{INTERPRETACIÓN ACTUAL DEL TEXTO}

Augusto Fraschetti (2002) se inclina por una interpretación racionalizante del desmembramiento: la asumpción de una parte del cadáver de Rómulo por cada uno de los Padres significa la recuperación -en el interregno- de la soberanía regia por parte de los jefes de las curias. Los pasos lógicos que intenta recorrer son los siguientes:

3.1. La versión del desmembramiento de Rómulo es incompatible con la de su apoteosis: La ocultación y enterramiento de los pedazos del cadáver de Rómulo por los senadores desmiente su ascensión al cielo: "questo macabro e orrendo 'aphanismòs' nella documentazione in nostro posseso sembra escludere in linea di principio, e almeno in origine, ogni ipotesi di 'divinizzazione dopo la morte'» (Fraschetti 2002:97). Prueba de ese «aphanismòs» y del enterramiento del cuerpo de Rómulo es la tumba, situada en el Comicio, de cuya existencia nos documenta Varrón ${ }^{12}$ : En tal sepulcro se suponía que el cadáver de Rómulo debió estar íntegro e indiviso, pues el Pseudo-Acrón excluye -algo que Fraschetti primero y luego Carandini pasan disimuladamente por alto- no sólo la apoteosis sino también el mismo desmembramiento («discerptus»). Y éste, como veremos más abajo, resulta esencial en la teoría que con mínimas diferencias orquestarán Fraschetti y Carandini. Aún más: lo que importa dejar bien asentado es que la permanencia in situ del cadáver no es óbice para la apoteosis y exaltación a los cielos del «rey», si

12 «Ad avviso di Varrone sarebbe esistita una tomba che si sarebbe trovata nel Comizio 'dietro' o "davanti' ai rostra, la tribuna degli oratori... I commentatori di Orazio ricordavano infatti una notizia di Varrone a proposito degli 'ossa di Quirino" ('nefas videre'), quelli che "ignorano da sempre il vento e il sole"..." (Fraschetti 2002:100). La cita está tomada de Horacio Ep. XVI, 13-14, a la que hay que añadir los comentarios del Pseudo-Acrón a este pasaje horaciano: «hoc sic dicitur, quasi Romulus sepultus sit, non ad caelos raptus aut discerptus. Nam Varro post rostra fuisse sepultum Romulum dicit». 
- como veremos con toda evidencia en el caso de Egipto- es el alma (ba) la que vuela a las estrellas y no el cuerpo que queda embalsamado en la tumba.

3.2.1. El punto clave en la muerte de Rómulo sería su desmembración y la división del cadáver entre los senadores asesinos. Estos senadores actúan como jefes de las curias, y es en la soberanía —antes, por encima y más allá del reydonde Fraschetti quiere centrar el meollo de toda esta cuestión de la muerte y despedazamiento de Rómulo: Fraschetti, citando a Burkert, quiere ver en el despedazamiento de Rómulo un ritual que repita el sacrificio del toro en los Montes Albanos durante las Fiestas Latinas, (un toro que representaba a Júpiter) y cuya repartición y consumición entre los asistentes significaría el reparto de soberanía entres los populi Albenses ${ }^{13}$.

Según Fraschetti, de la misma manera que en los Montes Albanos, el despedazamiento de Rómulo por los Senadores significaría un apoderarse de la soberanía, que ostentaba Rómulo, con vistas al «interregnum» y sobre todo de los «auspicios», que son en las altas magistraturas, como reyes y cónsules, el signo mayor del poder. Así Fraschetti: «gracias al descuartizamiento del cuerpo del fundador los patricios, para poder ejercer el cargo de inter-rex colectivamente y para siempre, se apoderaron de lo más precioso que contenía aquel cuerpo, es decir, los auspicios» ((2002: 113). Y, dado que en el interregno (tanto en época monárquica como republicana) los senadores ejercían el poder todos a turno, se trataba, según Fraschetti, de aprehender de forma personalizada una parte del cadáver de Rómulo: «Desmembrando el cadáver de Rómulo, los patricios pensaron 'dividir' de hecho los auspicios y la auctoritas" (ibid. 114). Fraschetti es claramente consciente de que antes de este momento nunca los senadores habían ostentado este poder, pues antes de la creación del senado por Rómulo no existían ni Padres ni patricios. Rómulo había sido el único depositario y el detentor originario. Por eso, Fraschetti cree seguir a Plutarco, cuando éste dice que los patricios habían asesinado a Rómulo, no queriendo recuperar el poder, sino «volendo che il potere passasse nelle loro mani» (2002: 112).

Dos graves objeciones surgen al considerar los argumentos de Fraschetti en su interpretación del desmembramiento de Rómulo como forma de asumir la auctoritas que se ejercía en el interregno por medio de la dispensación de los auspicios:

La primera objeción se debe a la relación material entre la muerte y desmembramiento de Rómulo y la asumpción misma de sus poderes. Tal concepción resulta de una materialidad crasa poco acorde con los tiempos de Rómulo (ni siquiera los nuevos faraones miles de años antes requerían una ritualización tan material para asumir el $k a$ - o poder faraónico - de su predecesor). Cicerón en su «República» nos avisa de que la época de Rómulo (s. VIII a.C.) no eran ya tiempos

13 Ver W. Burkert 1962: 367-369, citado en Fraschetti 2002: 106. Pero no es necesario ni hacer tan irracional el hecho de participar en la soberanía, que viene dado suficientemente por la común participación en el cuerpo social del banquete; ni es necesario racionalizar tanto adelantando tamaño sentido de reparto de la soberanía en aquélla época, siglo VIII a.C., tanto tiempo antes de la democracia ateniense. 
tan asilvestrados como los anteriores a Homero y ya quedaba atrás «todo aquel desvarío derivado de una vida agreste ${ }^{14}$ :

¿De dónde deducían lo senadores patricios que la asumpción del poder que iba asociado a la ostentación de los auspicios estaba en relación con la fagocitación de las carnes de Rómulo? No hay nada en la religión romana que nos conduzca en esa dirección. ¿Por qué esa proyección mítica a Rómulo de una asimilación física del dema auspicial de Rómulo, se coman, como sugieren algunos (Burkert), o no se coman físicamente las carnes de Rómulo? De hecho -lo que es un serio revés para la tesis de Fraschetti- Dionisio de Halicarnaso, el autor que crea y hace hincapié en la versión del desmembramiento de Rómulo y la separa de la versión de la apoteosis, no da ninguna base para interpretar el despedazamiento de Rómulo como un simbolismo de la repartición del poder auspicial entre los senadores en previsión del interregno; se limita «novelar» el asunto: Los senadores lo que pretendían era poder ocultar el cadáver de Rómulo, que dividido en trozos podía ser fácilmente escondido entre las togas en el momento de salir del edificio... De hecho asociaban tan poco la posesión de ese pedazo de Rómulo a los auspicios que, una vez evadidos de la sede del senado, se limitaron a enterrar tranquilamente cada uno su pedazo de cadáver.

Y, ¿por qué era necesaria la muerte por homicidio ritual de Rómulo?, ¿no bastaba esperar a su muerte natural...? Si no se mezclan los temas, habría que concluir que el asesinato ritual de Rómulo era superfluo para asumir su poder sobre los auspicios, algo que podía hacerse de forma no violenta tras su muerte natural, repartiendo entonces (y consumiendo o no) su cadáver. Pero los temas de hecho se mezclan; y aquí entra en juego el dato - tardío (no aparece en Ennio)— del carácter tiránico del «último» Rómulo, que según Apiano, convenientemente citado por Fraschetti, tuvieron en cuenta los asesinos de César, cuando creyeron que, como en el caso de aquél, el asesinato de César sería contemplado por los senadores y por toda la población como una gesta no encaminada al beneficio partidario de sus asesinos sino al beneficio de toda la polis ${ }^{15}$. Pero sobre el carácter tardío y secundario de este aspecto del asesinato de Rómulo hablaremos más abajo.

3.2.2. Carandini (2002, 2006 y 2007) da un paso más adelante sobre lo que ya le había ofrecido Fraschetti. Para Carandini el reparto de los trozos del cadáver de Rómulo no significa meramente la conquista o primer apropiarse del poder auspicial, sino la recuperación de una soberanía que las gentes patricias ya ostentaban antes de la fundación de Roma. Para Carandini el consumir de las carnes de Rómulo es superfluo, pues el poder auspicial no reside mágicamente en el "dema» Rómulo, sino que ya era poseído por los patres antes que lo depositaran en el fundador de

14 CIC. Rep. II, 10

${ }^{15}$ El texto completo de Apiano (Bella Civilia II,114,476) es el siguiente: «Bruto y Casio escogieron el edificio del senado (para asesinar a César), porque pensaban que los senadores, aunque no hubieran sido advertidos previamente (de la conspiración), participarían de buen grado cuando contemplasen los hechos. Se decía que le había sucedido lo mismo a Rómulo, cuando se convirtió en tirano; y pensaban que esta empresa, como aquélla, también llevada a cabo en el senado, no parecería realizada como si se tratase de una insidia, sino como algo en beneficio de la ciudad». 
Roma. Carandini no cree, al contrario que Fraschetti (2002), que el descuartizamiento del toro sacrifical, que simbolizaba al rey Latino, identificado con Jupiter Latiaris, en los Montes Albanos, pueda ser el modelo de Rómulo despedazado y divinizado. El tema del dema - a lo Frazer (1908) y más exactamente a lo Jensen (1948) - es decir, el tema del poder oculto en las carnes del toro, que contendrían la soberanía de los 30 populi albenses, o el poder oculto en los pedazos de Rómulo, que contendrían mágicamente el poder auspicial, no convencen con razón el «buon senso" de Andrea Carandini. El reparto de las carnes de Rómulo no es para él tanto un acto físico, cuando un acto simbólico, un «signo». Carandini ve más lógico seguir el paradigma bíblico del descuartizamiento de una concubina o de una pareja de bueyes, que debidamente troceados, por un levita (Jueces 19-21) y por Samuel (Sam $1,11,7)$ respectivamente, fueron enviados por mensajeros a las 12 tribus de Israel, simbolizando así —en forma de mera alegoría - la soberana corresponsabilidad de cada una de las 12 partes del reino (que «fueron a la guerra como un solo hombre»). Los 30 trozos de Rómulo representan el Quirino en que Rómulo - al margen de todo movimiento de ascensión a los cielos- se convierte: Quirino representa en su origen - que Carandini hace remontar a la Roma preurbana, es decir pre-romúlea- la unión de las 27 curias proto-urbanas (igual número que los 27 santuarios de los Argei). Rómulo, más tarde identificado con Quirino, aumenta las curias de 27 a 30, igual que los 30 populi albenses, y añade la nueva organización no sólo unitaria sino también centralizada en la figura del rey (Carandini 2006:338).

Hay, sin embargo, un desequilibrio en la comparación que Carandini hace del despedazamiento de Rómulo con los 12 trozos de mujer del levita y con los bueyes enviados por Samuel a las Doce Tribus de Israel: En el tiempo bíblico a que los fragmentos citados por Carandini nos remiten, Israel era ya un reino conformado y orgánicamente constituido. Sin embargo, Tito Livio definía de solitudines, «parajes solitarios» los territorios que rodean el recodo del río Tíber en que encalló la cesta que contenía a los gemelos Rómulo y Remo ${ }^{16}$. Nada en el relato tradicional (ni en Livio ni en ningún otro autor) permite presuponer, ni sobre el Palatino ni sobre el complejo sagrado Foro/Capitolio, una organización proto-urbana, anterior a Rómulo, de naturaleza tal que constituyera un sistema curial al que hubiera de retornar la soberanía.

Carandini comparte, con los que niegan la labor fundadora de Rómulo y cualquier monarquía latina en Roma antes de la monarquía etrusca, el principio de que Roma no nace de repente ${ }^{17}$. Pero Carandini, que cree en Rómulo, interpreta ese

16 Vastae tum in his locis solitudines erant (T.LIV. I,4,6). La perspectiva de Tito Livio difiere de la que expresa Cicerón acerca de la población de aquellos mismos territorios algunos años después, en la adolescencia de Rómulo y Remo: Omnes... tum eos agros, ubi hodie est haec urbs, incolebant (CIC. Rep. II,2). La realidad no había cambiado tanto si tomamos en cuenta que Cicerón (ibid.) describe el territorio como un «lugar silvestre» y a los habitantes de la región como «gentes feroces» que llevaban una "vida salvaje». Nada que ver con la perfecta organización curial que Carandini parece reivindicar para aquellos momentos previos a la fundación de la ciudad por Rómulo.

17 Formación (gradual) de Roma y fundación (puntual) son términos manejados habitualmente como conceptos opuestos. Ver, por ejemplo: "All'idea della fondazione della città è stata preferita [...] quella di formazione, a prescindere di chi potesse essere l'eventuale fondatore» (A.Carandini. Remo e Romolo. Einaudi, Torino 2006, p. 228). 
principio en el sentido de anticipar a Rómulo una cierta forma de estructuras políticas en una Roma proto-urbana, una Roma pre-romúlea: Roma no nace de la nada, al contrario de lo que afirma la vulgata analística seguida por Tito Livio, sino que fue fundada dentro de un centro proto-urbano habitado ya por los Quirites (Carandini 2006:125). Para documentar ese centro proto-urbano Carandini se remite a su hipótesis de un Septimontium anterior a la Roma Quadrata de Rómulo, que la tradición ignora y la arqueología latina, o bien ignora, o bien como Varrón, hace posterior a la Roma Quadrata. Pero la vulgata afirma que Roma nace «ex nihilo sui», pero no de la nada absoluta: nace de unos pastores que pertenecen al entorno politico de Alba Longa, que contaba con reyes, que a su vez debían contar con sus rudimentarias instituciones políticas. Ése es el centro proto-urbano (testimoniado por la vulgata analística) en el que crece Rómulo y del que nace Roma ${ }^{18}$. La vulgata analística, insisto, solamente presupone que Roma nace «ex nihilo sui», es decir, de nada de lo que después sería la constitución de Roma: los Quirites, las curias, el senado, etc., de cuya existencia en Alba Longa nada sabemos y nada podemos presuponer. Carandini presupone, igual que antes había hecho Fraschetti, sin ninguna base documental, la preexistencia a Rómulo del sistema de curias, cuya creación el relato tradicional atribuye al fundador de Roma: Los senadores asesinan, descuartizan y se reparten los trozos de Rómulo, «riconducendo con la violenza l'unità del potere regio alla pluralità tradizionale delle ripartizioni communitarie e dell'abitato o curie» (Carandini 2006:343). Pero, ¿de qué «tradición» puede documentar Carandini que se remonte a los tiempos de antes de Rómulo? Él, de sí mismo, se ha reconstruido una Roma proto-urbana, pre-romúlea, que reúne -ien el siglo VIII a.C.!- características utópicas de las que no pudo gloriarse, ni siquiera varios siglos después, la democracia ateniense: una comunidad originaria que se siente depositaria de la soberanía y la legitimidad, de las que hace generosa entrega: las curias a los senadores («l'aristocrazia legittimata dalla communità», p. 340); los senadores al rey. Pero la historia de la soberanía es la inversa . La soberanía, como su nombre indica, nació de «soberanos» que se impusieron sobre el pueblo. Han sido las democracias, y sobre todos las democracias contemporáneas las que, con buen criterio, han invertido los términos y han «devuelto» al pueblo una soberanía que «in principio» fue arrancada al margen de todo proceso de legitimidad ... En la política históricamente hablando el todo fue anterior a las partes; el soberano precedió a los depositarios de la soberanía. Así fue en los estados prístinos (en Mesopotamia, en Egipto), así fue en Roma.

El relato tradicional, y el mismo Dioniso de Halicarnaso, nos hacen suponer más bien lo contrario de lo que Carandini por su cuenta y riesgo afirma. Es Rómulo

18 Aquí Carandini es contundente en reafirmar el carácter habitado y en rudimentario desarrollo político independiente (proto-urbano) del entorno tiberino del Palatino, que él se niega a considerar un simple territorio agrícola de Alba Longa («un pastizal de Amulio»: Esto sería "un dato exclusivamente mítico -anche se vero nella fantasia dei Romani» (Carandini 2006:297). Pero seguramente (al tratar de evitar tomar por exclusivamente mítico o exclusivamente histórico todo el relato tradicional de los orígenes de Roma) lo que conviene distinguir es el carácter meramente legendario del nombre de Amulio y el carácter definitivamente histórico de la configuración agreste (cf. Cicerón, Tito Livio, etc.), a mediados del siglo VIII a.C., de lo que algún decenio después sería el complejo urbano Foro-Capitolio-Palatino. 
en persona quien crea las «partes» o instituciones que constituyen el todo político llamado Roma. Para Carandini, sin pruebas — sólo una mera conjetura que él llama «ricostruzione» (p. 341) — esas partes ya preexistían. ¿Cómo y desde cuándo? En todo caso, territorios adyacentes al Tiber, a la altura del Palatino, podían estar organizados como un apéndice de la estructura política albense. Pero, ¿acaso cada uno de los 30 populi albenses eran algo más que una parte periférica -amorfa- del conglomerado político que era Alba Longa?, ¿acaso existían curias en el entorno político de Alba Longa?, ¿de dónde nacen las curias?

El sistema de curias, sea anterior o sea instituido por Rómulo, ¿supone una cesión de soberanía que los Padres recuperarán con el despedazamiento de Rómulo? No, la soberanía es ostentada por el rey, Rómulo primero y luego él en unión de Tito Tacio, en nombre de todos los ciudadanos de Roma, llamados a partir de un cierto momento Quirites. Y los Quirites sobrepasan el mero estatuto de las curias, que son el terreno restricto de las patricios. Nada en el texto permite suponer que las curias habían ofrecido a Rómulo una soberanía que ahora iban a recuperar. Ni en Alba ni en lugar alguno (¿en Etruria?) había otra cosa que monarquía hereditaria (recuérdese a Tanaquil, la esposa de Tarquino, guardando el trono para Servio). Pero aquí se abre una interrogación esencial: ¿Quiénes son los Quirites?

Hay algo que ofrece pocas dudas: El reinado conjunto de Rómulo y Tito Tacio da ocasión a la ciudad geminada (geminata urbs), cuyos habitantes aceptan el nombre de Quirites y se distribuyen en treinta curias. Pero, a partir de ahí, Fraschetti da su propia respuesta: «Benché Livio faccia derivare l'appellativo Quirites dalla città sabina di Cures, si osservi come questa derivazione etimologica non sembri mutare, neppure nel raconto liviano, al meno a livello di sequenza narrativa, lo stretto rapporto dei Romani in quanto Quirites con le curie istituite da Romolo» (Fraschetti 2002: p. 40).

Fraschetti se ahorra, con razón, el caer en la tentación de hacer derivar Quirîtes de curĭa (<co-uiria, «asociación de varones»), étimo en el que no hay ninguna base para la -i- larga de Quirites. Pero no es cierto que, independientemente de la etimología, los Quirites, que incluyen a todos los ciudadanos de Roma, se deban identificar con los miembros de las curias, que sólo incluyen a los patricios ${ }^{19}$. Au-

19 A propósito de las curias, A.Fraschetti cita de forma imprecisa a Robert E. A. Palmer 1970 sin concretar páginas. Pero Palmer deja claro en el texto que en las curias no entran todos los ciudadanos, al contrario de lo que sucede en cuanto al término Quirites: «The Quirites, a term by which was then (en la época monárquica) understood all 'cives Romani', participated in Quirinalia whereas at Fornacalia only 'curiales' celebrated with their curias” (Palmer 1970:161). Es evidente la conclusión de que 'curiales' (patricios) es un término más restrictivo que Quirites (patricios y plebeyos). Tal concepción de la pertenencia a las curias era ya entonces un tópico en los manuales al uso, que no se puede abandonar sin un acervo de pruebas fehacientes. Por ejemplo , Jacques Ellul, entre los que estudian las antiguas instituciones, dice que «sólo pertenecían a las curias los miembros de las gentes» (1967:183); y los miembros de las «gentes» eran, como es sabido de sobra, exclusivamente patricios. Eso consta incluso en la historiografía más pro-plebeya, como fue la historiografía soviética: S.I. Kovaliov (1948<1975>:55-56) no duda en referirse a las curias como «divisiones de las gentes», gentes que él denomina sin vacilar «gentes patricias». Misma tesis en un vademecum, como Hacquard, "Guide Romaine Antique», Hachete. Paris 1952: 20: «La réunion des Comitia Curiata constitue l'assamblée solennelle du peuple, populus. Le po- 
Muerte, desplazamiento y apoteosis de Rómulo: un estudio sobre la realidad...

gusto Fraschetti se equivoca al hacer de las curias una institución ajena a divisón de órdenes entre patricios y plebeyos: Afirma erróneamente que «a las curias se pertenecía por nacimiento», con lo que «una misma curia podía contener ... tanto patricios como plebeyos» (2002:44). A la curia se pertenecía por nacimiento, pero por nacimiento noble. Precisamente en base al nacimiento (noble) las curias sólo comprendían ciudadanos patricios.

Los Quirites no existen por el hecho de que existan las curias. Como demuestra el texto de Dionisio de Halicarnaso (II,7) —que no encuentra ningún obstáculo en anticipar la creación de las curias por Rómulo antes de la fusión de latinos y sabinos-, de la existencia de las curias no se sigue para los romanos el título de Quirites. Tal título se debe a la incorporación a Roma de una masa de población sabina (procedente sobre todo de Cures) ajena - iella sí!— a la distinción patricia (los sabinos accederían al orden patricio por el solo hecho de ocupar los cargos públicos de Roma y adquirir el rango de Patres).

Lo más lábil en toda esta construcción teórica de Fraschetti reside en la función que se atribuye al nombre mismo de Quirino. Si Rómulo a su muerte pasa ser identificado con Quirino, es —según Fraschetti- porque a este último, a Quirino, corresponde el patrocinio de las curias que por mano de los Padres senadores acceden a la soberanía a la muerte de Rómulo. Quirino debe entenderse como el dios de los Quirites (y los Quirites como los componentes de las curias). Y todo ello en base a una, si no declaradamente falsa, sí al menos muy discutible etimología. Es verdad que no hay que excluir que el nombre de las curias provenga de vir, «varón», pertenencia que en el caso que nos ocupa (ver supra) queda restringida a los patricios. Pero ni Quirites ni Quirino están irremisiblemente emparentados con vir ni con curia. Fraschetti, mal documentado, afirma lo contrario con apodíctica seguridad:

«No le ha resultado difícil a André Magdelain contradecir y casi subvertir (capovolgere) la hipótesis avanzada por Georges Dumézil a proposito de un Quirino 'agrario' y en cuanto tal divinidad de la 'tercera función' indoeuropea, reivindicando con fuerza sus características de dios de la comunidad de Qurites a partir de su propio nombre ( ${ }^{\star}$ Covirino) indudablemente conectado a *co-viria, la curia» (2002: 103).

Pero la etimología que le suministra A. Magdelain (y, antes, P. Kretschmer) está muy lejos de ser cierta. Muy a pesar suyo, si Fraschetti se hubiera informado personalmente, habría comprobado que los autores en los que se basa Magdelain no derrochan ni claridad ni unanimidad en este asunto. Los antiguos se limitaron a hacer remontar Quirites a la ciudad sabina de Cures (a Curibus) y Quirino al panteón sabino, aun el el caso de que hubiera recibido veneración en Roma antes del

pulus est formé par les patriciens seuls (ou par patriciens et clients?)». Nada obsta que —según Fraschetti arguye- Tito Livio $(I, 43,10)$ diga que en los comicios curiados se votaba viritim, es dedir, «hombre a hombre, individualmente", dado que los individuos que componían el comicio curiado eran todos patricios. En el contexto que nos ocupa, «viritim» quiere decir que, puesto que en el comicio curiado de la monarquía correspondía "a cada hombre un voto», ello marcaba la diferencia con el comicio centuriado de la república, formado por patricios y plebeyos, donde se votaba centuriatim, es decir, que correspondía «a cada centuria un voto», lo que otorgaba primacía a los patricios, pues copaban las primeras clases, donde estaban enroladas la mayoría de las centurias. 
rapto de las sabinas y de la paz con los sabinos. Ni los filólogos modernos ni los contemporáneos han añadido nada sólido sobre este punto. Y algunos, en concreto, han negado cualquier viabilidad al intento de hacer remontar Quirino a viry a ${ }^{*}$ co-viria, aun en el caso posible (no sé si probable) de que «curia» derive de *coviria $^{20}$. Y con estas premisas toda la argumentación de Fraschetti (a quien sigue Carandini 2007:13, ver infra) se cae por tierra.

Por su parte, Carandini hace remontar a la Roma proto-urbana, anterior a Rómulo, también la existencia de los Quirites ${ }^{21}$. Media verdad y medio error: Sí, los

20 Augusto Fraschetti (no sé si siguiendo a A. Magdelain) se acoge a la autoridad de P. Kretschmer, a la que califica de «todavía fundamental». Pero, aunque Kretschmer haya afirmado que Quirinus provenga de *co-virinus $\rightarrow \mathrm{y}$ Quirites de *co-virites - se trata de una tesis oscura y no unánimemente aceptada, ni mucho menos. Al menos, si hemos de creer a Ernout-Meillet, que en su Dictionnaire Étimologique de la Langue Latine (Klinksieck, 1962) asegura a propósito de Quirinus (s.v.), después de referirse a Kretschmer (1920), que «'étymologie par *co-virī est insoutenable» (s.v.). En efecto, las dificultades surgen tanto por la morfología del prefijo cum- como por la cantidad de la larga de la palabra llana Quirînus. a) por la morfología del prefijo, que (ante semiconsonante) debería ser con- (<cum), esperándose así un con-uirinus (como conuiva, conuincere, etc.) que no sincoparía en Quirinus; los que se remontan a *Co-uirinus en lugar de ${ }^{*}$ Con-uirinus, reivindican gratuitamente un prefijo $\mathrm{co}$ - (<cum), cuya aparición es exclusiva de las formaciones ante vocal (como co-adiuvare, co-operare, etc.). b) por la cantidad, el resultado normal de un compuesto de viro-, "varón», precedido del prefijo con- (<cum), hubiera sido *Convirĭtes - *Convirĭnus. Para la formación de una -i- larga ( ${ }^{*}$ Convirītes- ${ }^{*}$ Convirīnus) es necesaria (en vez de viro-) una raiz del tipo virio-, según acertadamente argumenta Deecke, Falisker 86: «-I- aus Kontraktion von -ii- aus -io-», que justifica Samnītes (frente a Equĭtes de equo-) en base a Samnio- (Samnium). ${ }^{*}$ Convirĭtes $-{ }^{*}$ Convirĭnus (y no *Convirītes- ${ }^{\star}$ Convirīnus) hubiera evolucionado en todo caso a *Quirĭtes - ${ }^{*}$ Quirĭnus (como equites de equo- y dominus, de domo-, etc.. Para conseguir ese tema en -io-, Kretschemer propugna un antiguo * Co-uiriom (de donde también surgiría el colectivo curia en antiguo plural neutro ), que naturalmente no encuentra. Pero se apoya en el volsco covehriu- (toticu covehriu sepu, Ley de los Velestri, pueblo volsco), que interpreta como tota publica contione sciente; "sabiéndolo toda la reunión de varones". Contra volsco covehriu- correlacionado con uiro- surgen (además de la ilógica variante co- en vez de con-) otras dos objeciones: 1 ) la - $h$ - del radical no se explica por viro-, y 2) igual que en el caso del osco vereiia (ver vereiai Púmpaianaí, interpretado como «civitati Pompeianae», en Kretschmer, loc.cit. p.150), la -e- en lugar de -i- hace esta etimología insegura en relación a uiro-; «varón». Con razón Ernout-Meillet (s.v. curia) no está seguro de la etimología de «curia», y concluye que el volsco covehriu es una palabra de oscura etimología. A falta de seguridad en una nueva etimología de Quirites-Quirinus, parece más sabio remitirse a la etimología tradicional, tal como nos la entregaron los anticuarios romanos, que no dudaron - con sorprendente unanimidad - en relacionar ambas palabras con los sabinos. Eso conlleva dejarse calificar como «renovador de la hipótesis varroniana", lo que no deja de ser un honor. Después de todo, Varrón alguna vez tiene razón; el mismo Kretschmer le sigue a veces; y le sigue precisamente en la segunda parte del artículo que aquí estamos criticando (pp.152-157), cuando deriva de Quirites el verbo quiritare. Dice Varrón: «Se dice que da gritos de auxilio (quiritare), el que implora a gritos la protección de los Quirites" (VARR. L.L. 6,68). Pero el traductor comenta: «Falsa etimología popular (retomada, sin embargo, por algún importante autor moderno)» (L. A. Fernández Miguel, en Varrón. La Lengua Latina. Libros V-VI. Gredos, Madrid 1998, p.333). Conclusión: si uno puede equivocarse siguiendo a Varrón, obviamente también se puede equivocar no siguiéndolo. Y, sobre todo, uno se equivoca siguiéndolo cuando no hay razón para hacerlo. En todo caso, nada mejor que mantener la «hipóteisis varroniana», si ésta es sólida.

21 Carandini afima: «I Quirites fanno dunque inizialmente riferimento — sempre secondo la nostra tesi- a una realtà proto-politico-istituzionale piú antica di quella rappresentata dalla città di Roma nella prima età regia. I Quirites sembrano dunque preessiste al populus Romanus, che pare aggiungersi in un secondo momento, a partire dall'età romulea, ma che figurando all'inizio della formula appare gerarchicamente predominante rispetto ai Quirites» (Carandini 2006:125). Y añade: «Al sistema di Quirino e del 'Septimontium' — no sappiamo se già con la presenza di un 'populus'/esercito- è succeduto il sistema di Romolo (e di Roma), il quale avrebbe perfezionato il precedente ampliandolo da 27 a 30 curie" (Carandini 2006:129). Volveremos a continuación sobre el tema de la definición y extensión de las curias, que está lejos de resultar claro. 
Quirites son anteriores a Roma, pero seguramente — como afirma la analística y la antigua arqueología latina - preexistentes en la proto-historia de los sabinos, no en Roma, pues las noticias nos han transmitido que los Quirites vinieron de Cures con el pueblo sabino que se instaló en Roma tras el legendario rapto de las sabinas. Por eso, está perfectamente justificado el orden jerárquico que establece la conocida fórmula de Populus Romanus Quiritium, contra lo que impondría la lábil tesis de Carandini. En su obra del 2007 «Cercando Quirino», Carandini insiste en la idea de que las curias son una institución proto-urbana de Roma, anteriores a Rómulo, y en otra idea, ya expresada en el 2006 (ver nota 21), la idea de que Quirino es el dios de las curias, también él anterior en Roma a la constitución romúlea. Lo primero que hace Carandini es asentar la existencia de Quirino en Roma antes de la apoteosis de Rómulo: Si Rómulo es asimilado a él, eso significa que Quirino ya existía (Carandini 2007:12). Sin duda, Varrón atribuye el primer culto a Quirino en Roma a la época en que aún vivía Tito Tacio, quien como sabemos murió antes que Rómulo. Pero el texto de Varrón (L.L., 5,74) sólo prueba que Quirino era un dios ya cuando murió Rómulo, lo que podemos aceptar de buen grado, pues su apoteosis se podía hacer asimilándolo a un dios ya existente, como el faraón muerto se asimilaba Osiris (cf. infra). Pero del texto de Varrón no se sigue que Quirino perteneciera ya a la Roma proto-urbana, anterior a Rómulo, sino todo lo contrario: El mismo Varrón y otros autores nos dan a entender que Tito Tacio trajo a Quirino consigo desde Cures, pues el nombre Quirino está sin duda emparentado con el de los Quirites, y éstos vinieron con Tito Tacio desde Cures ${ }^{22}$. Y es sabido que la llegada de los sabinos a Roma se produjo después de la fundación de la Urbe por Rómulo. Lo que nos permite concluir que Quirino no fue un dios romano en la época proto-urbana de Roma.

Eso nos lleva a rechazar la ecuación que Carandini establece entre Quirino, en tanto que (según él) dios proto-urbano de Roma, y las curias, institución según él anterior a la constitución romúlea, que habría conferido el poder regio a Rómulo y que había de recobrar tal poder asesinando y desmembrando a Rómulo. Quirino es el dios de los Quirites - que abarcan a toda la población de Roma-. Pero Quirino no es, ni siquiera etimológicamente, el dios de las curias, como quiere Carandini:

22 Para la relación entre Quirino y Quirites, ver OVID. Fast. II, 475-480: «El tercer día (17 de Febrero) está dedicado a Quirino. Éste, que fue antes Rómulo, tiene este nombre (Quirino), bien sea porque la lanza fue llamada 'curis' por los antiguos sabinos - y en virtud de la lanza el dios guerrero ascendió a los cielos (venit in astra), bien sea porque los Quirites pusieron este nombre a su rey, o bien sea porque él (Rómulo-Quirino) anexionó Cures a los romanos». Las tres etimologías están elencadas en Paul-Fest p. 43 L., aunque con una más o menos lógica aclaración (son los Quirites los que derivan su nombre de Quirino, y no viceversa. Pero eso no es seguro). Todos los autores modernos asienten a la segunda-tercera etimología suministrada por Ovidio (Quirites<Quirino<Cures; o Quirino<Quirites<Cures). Así, por ejemplo, Sabbatuci 1988:63-s. Para la llegada de los Quirites desde Cures, ver el mismo Ovidio (loc. cit., 480) y,sobre todo, Varrón L.L., VI,68: «Los quirites (Quirites) tienen su denominación por los de Cures (Curenses)»: de aquí vinieron en compañía del rey Tacio para entrar en alianza con nuestro estado" (ver también V,51). La misma etimología en Tito Livio, quien no deja de presuponer que los Quirites no están presentes en Roma hasta la alianza de Rómulo con los sabinos : «Formada así una ciudad gemela de latinos y sabinos (ita geminata urbe), para conceder algo a los sabinos, (los ciudadanos romanos) fueron llamados Quirites por Cures» (T:LIV. 1,13,5). 
«El secreto de Quirino fue desvelado, casi hace un siglo, por el lingüista P. Kretschmer, quien sostuvo que Quirinus deriva de ${ }^{*}$ Co-virinus, porque es el dios protector de los barrios del habitat de Roma o 'curias', derivado de *co-viriae, que son los conjuntos de hombres que habitan tradicionalmente en aquellos barrios, tenidos por emparentados entre ellos y llamados Quirites, de *Co-virites» (Carandini 2007:13).

Carandini comete el mismo error que antes había cometido Fraschetti dando como segura y definitiva la hipótesis de Kretschmer (1920) sobre la derivación de Qurites-Quirinus a partir de ${ }^{\star}$ Co-virites - ${ }^{*}$ Covirinus, y se equivoca, por tanto, dando por buena la relación etimológica de Quirino con las curias. Quirino, según la tradición, toda la tradición historiográfica romana, es un dios sabino; y falta base argumental para insistir, como hace Carandini (2007:20) en que «es un dios de la comunidad indígena», refiriéndose al territorio romano anterior a la fusión latino-sabina. Y está muy claro, que si esa comunidad proto-urbana fuese el Septimontium -que Carandini adelanta a la fase pre-urbana de la fundación de Roma- no incluiría a los sabinos (que no ocupan «montes» sino "colles»), a los que en la fase septimoncial la historiografía tradicional sitúa en el collis Quirinalis y en el Capitolio, constituyendo allí una colonia rival del Septimontium.Y, no incluyendo a los sabinos, no incluiría a su dios Quirino, cuya identidad sabina Carandini reiteradamente esquiva.

No podemos, pues, acogernos a la teoría de Fraschetti y Carandini, débilmente fundamentada, de que el despedazamiento de Rómulo debe ser hermenéuticamente separado de su ascención a los cielos, para ser entendido -en un exceso de carga democrática para la Roma naciente- como un expediente simbólico que habría de significar la conquista de los auspicios o la recuperación de la soberanía por parte de los senadores. Hemos de buscar, por necesidad, otras vías de interpretación; hemos de buscar un punto de partida en otras teorías que Fraschetti y Carandini, con mayor o menor razón, han desestimado.

A. Schwegler (1853) fue el primero que escribió ya en edad contemporánea sugiriendo que el despedazamiento de Rómulo no puede ser entendido como un episodio histórico, más o menos inspirado en un acontecimiento de la vida normal, sino que hay que buscar una vía de interpretación de tal despedazamiento como un acontecer ritual basado en el correspondiente mito. Y así es como, tras Schwegler, se buscó material en la mitología clásica para una correcta interpretación del despedazamiento y apoteosis de Rómulo. Georges Frazer (1911-1918, VI 97 ss.; VII 236 ss.) coloca a Rómulo en la estela de los que, como Osiris (faraón muerto y padre del nuevo faraón), son despedazados en un rito de inmortalidad, que Frazer -empeñado en una teoría múltiple de dioses que simbolizan la resurrección de la vegetación- pone exclusivamente en relación con la fertilidad de la naturaleza (basada en la inmortalidad del rey).

Walter Burkert (1962:366), comentando la suerte futura de esta teoría de Frazer, pone el eslabón entre la suerte de la naturaleza y el destino del rey: «El rey es 
garantía y condición tanto del orden cósmico (la naturaleza, la fertilidad) como del orden estatal». Así la persistencia de la dinastía faraónica (ver Teología Menfita en H. Frankfort $<1948>$ ) se convierte en la persistencia de la naturaleza y su regeneración. Este párrafo que sigue va a resultar fundamental en toda mi futura teorización:

«La fundación de una ciudad es una repetición de la Cosmología; Y de esta manera puede ser entendido también el desmembramiento del fundador de la Urbe, Rómulo. Cuando el Primer Rey (véase el caso de Osiris, mítico primer rey de Egipto) es descuartizado en sus miembros, se forma la ciudad en su ordenamiento, en su articulación y en su interdependencia. Los senadores, los patres, en primer lugar son simplemente los cabezas de las grandes familias por separado; cuando se narra cómo cada uno de ellos tomó en posesión un trozo del Primer Rey, eso significa que todos ellos en conjunto forman el cuerpo de Roma, que la totalidad de Roma se compone de sus gentes, y coexiste en su cooperación. Rómulo en cierta manera parece ser el equivalente de 'el Romano', pero pater Romanus se refiere al Senado. Es sorprendente que la sucesión carnal de Rómulo no juega ningún papel práctico en la saga romana; pero muy próximo a eso está el hecho de que el Primer Rey (der Urkönig, el rey primordial), está presente en su dinastía. Rómulo no sobrevive de esta manera (Romulus lebt nicht in dieser Weise fort) (porque no tiene heredero carnal)), y sin embargo se debe esperar que el fundador de alguna manera vuelve a existir en su fundación. Si uno se lo plantea así, el mito del desmembramiento le ofrece la respuesta. Una primitiva saga indo-germánica perdura en él: el mito de forma significativa ha perdido libremente su sentido cósmico, pero ha mantenido en cierto modo su función política. En este contexto el desmembramiento no es ningún castigo, sino la necesaria metamorfosis, a través de la que el rey sobrevive; precisamente con esto es con lo que se puede conectar un culto regio, por muy paradójico que nos parezca: Aniquilamiento y apoteosis coinciden en este punto" (BURKERT 1962: 367-s.).

Y, siguiendo a Wissowa y a Latte, Burkert amplía este mismo culto regio al rey Latino, que en Alba Longa era venerado como lupiter Latiaris, al que en las Fiestas Latinas se sacrificaba un toro blanco — probable sustituto de un primitivo sacrificio del propio Latino-. Como parte del sacrificio el toro era despedazado y consumido entre los comensales, representantes de las comunidades latinas, de los 30 populi albenses. Igualmente el rey sabino de Roma Tito Tacio, que compartía el trono con Rómulo, fue asesinado en Lavinio con un cuchillo sacrifical en probable sustitución de una víctima bovina, a imagen del rey Latino. El despedazamiento y consumición de la víctima, expreso en el caso de Latino, velado en el caso de Tito Tacio (y ausente en el caso de Rómulo) constituyen, en palabras de Wissowa y de Latte, una autética communio sacrorum, expresión del «comercio entre las ciudades latinas» 23 .

La segunda parte de la interpretación del mito del destino de Rómulo presentada por Burkert se aparta sorpresivamente de la primera. El mito del despedazamiento de Rómulo, que Burkert había presentado como un camino hacia la «supervivencia» (Überleben) e inmortalidad del rey, deja de ser en esa segunda parte

23 Wissowa 1912:124-s.; y Latte 1960:144-s. 
una vía hacia la apoteosis o divinización del rey — de la que la inmortalidad es condición y nota específica-, puesto que los dioses no son sino los «inmortales». En esa línea la apoteosis y divinización de Rómulo no es más que un expediente de los Julios, aupados a los cargos religiosos, para preparar la exaltación de su estirpe (la gens Iulia, descendiente del albalongano lulus, el hijo de Eneas), es decir, su propia exaltación ${ }^{24}$. Pero es poco verosímil, quizás absolutamente inverosímil, que en el año 73, cuando Cayo Julio César, casi un adolescente en la terminología latina, fue elegido pontífice, o en el año 63 cuando el joven César fue elegido Pontífice Máximo, tuviera ya un plan que le llevara a preparar su propia exaltación imperial, que desde luego no pudo ser vislumbrada al menos antes del paso del Rubicón. Es igualmente inverosímilmente raro que Cicerón, poco amigo de César, contemplara atónito esa operación mitopoética de los Julios y que el en año 52, cuando en sus «Leyes» y en su «República» alude a la apoteosis de Rómulo en Quirino, ignore que Próculo Julio — que vino de Alba Longa predicando la ascensión de Rómulo a los cielos- no sea más que un «tapado» propagandista de la gens lulia; y, por el contrario, cometa la ingenuidad de afirmar que se trata de una tradición entregada a la memoria ancestral (quae isto modo memoriae sint traditae, Leg. I,3), y que tal tradición puede remontarse a la época inmediatamente posterior a la desaparición de Rómulo y en concreto al poeta Simónides en la cincuenta y seis Olimpíada (Respublica II,10; cfr. supra). Burkert, pues, acaba olvidando que, como él mismo no ha dudado en afirmar (ver supra), en el mito del descuartizamiento de Rómulo «aniquilación y divinización» van inseparablemente unidas. Es posible que César haya encontrado aprovechable en su propio beneficio la idea de la divinización de Rómulo (al fin y al cabo un antepasado suyo, un descendiente de Julo) y que, por tanto, «la haya sabido fomentar e incluso él mismo la haya extendido por el mundo» 25 ; pero eso no implica necesariamente que él mismo la haya inventado.

Por la misma época que Burkert, el etnólogo italiano Angelo Brelich (1960) había abordado el tema de la muerte y apoteosis de Rómulo con parecidos presupuestos, pero llega a diferentes resultados que Burkert en cuanto a la datación originaria del mito de Quirino. Siguiendo el método comparativista, Brelich toma como punto de partida la tesis del dema, que comparte con A. Jensen, basada en la etnografía de las más antiguas civilizaciones: Los demas son antiguos personajes que, habiendo fundado en la edad mítica las principales instituciones de un pueblo, a la muerte son despedazados para que de los fragmentos de su cadáver debidamente dispersos y sembrados reciba la vegetación fertilidad abundante. Brelich detecta los mismos contenidos en el mito de Rómulo-Quirino: Por un lado Quirino: de lo que se sabe de las fiestas en las que interviene el flamen Quirinalis, el dios está íntimamente relacionado con la siembra, maduración y torrefacción del grano de cereal; por otro lado Rómulo, el primer rey de Roma y fundador de sus principales instituciones, muere despedazado y después es identificado con Quirino. Tal esquema,

${ }^{24}$ Ver Burkert 1962:371-s., y sobre todo la frase que lo resume todo: «Nun ist aber die Romulus-Quirinus-Idee, wie die Gestalt des lulius Proculus anzeigt, überhaupt ein Stück iulischer Familientradition prësentiert worden».

${ }^{25}$ Ver Burkert 1962:373, quien cita datos de esta propaganda política cesariana en W.WEBER. 1936, nota 398 . 
Muerte, desplazamiento y apoteosis de Rómulo: un estudio sobre la realidad...

según Brelich, como todo lo que responde a la figura de dema, sería de origen muy antiguo y carecería de toda lógica atribuir el mito de identificación de Rómulo a Quirino a una labor mitopoética reciente, como la época de los Julios.

Dario Sabattucci (1984) se ha sumado a los que ven el el mito de RómuloQuirino una línea de expresión ritual de origen antiguo. En concreto Sabatucci ha apuntado a la estructura misma de Osiris y se ha sumado a la línea iniciada casi un siglo antes por Georges Frazer.

De todo lo argumentado contra Fraschetti y Carandini a propósito del título de Quirites (y de Quirino) como proviniente de *co-uiri, al contrario de curia, que sí podría provenir de uir, se deduce en positivo lo siguiente:

Quirites. Quirites es un título de probable origen sabino, que podría ser (en la Sabina, no en Roma!) anterior a Rómulo y a la fundación de Roma, pero que a Roma llega con la ciudad ya fundada y tras la geminación de la ciudad que sigue a la fusión de romanos latinos y romanos sabinos. La tradición, a partir de Varrón, es unánime a) en relacionar Quirino con Quirites ${ }^{26}$, y b) en derivar Quirites del nombre de la ciudad sabina de Cures (ver supra). Livio $(1,13,4-5)$ explica que, tras la paz que siguió a la guerra entre latinos y sabinos, ambos pueblos forman un reino común y un pueblo «geminado» y «para hacer también alguna concesión a los sabinos tomaron todos el nombre de quirites, por Cures». Y eso sucede hasta tal punto que, casi dos siglos después, Plutarco — siguiendo muy de cerca de Liviollega a hacer Quirites sinónimo de Curenses y aun a sustituir —en la fórmula ritual- el nombre de Quirites por el de Curenses, como vamos a ver más abajo. El autor griego justifica esta sinonimia de una forma que combina la arqueología con la lógica: el nombre Quirites como título genérico de los romanos nace de una planificación, sancionada en el Comicio, que es consecuencia de la geminación de la Urbe entre latinos y sabinos: Tras esa geminación latinos y sabinos deciden repartir la dignidad regia entre Rómulo y Tito Tacio; y deciden paralelamente distribuir los dos títulos eponímicos de la ciudad: El topónimo se concede a Rómulo y a los romanos (Rómulo significa el Romano), llamando a la ciudad Roma; mientras que el gentilicio se concede a Tito Tacio, procedente - como los sabinos en general- de Cures, llamando a los habitantes de Roma (en la fórmula ritual del Comicio) Quirites, y no romanos:

«Acordaron... que la ciudad se llamara Roma por Rómulo y curenses todos los romanos por la patria de Tacio, y que reinaran ambos generales en común» (PLUT. Rom 19,9).

Fijémonos de paso en el detalle de que la concesión del nombre de la ciudad a Rómulo (el romano) se instituye de forma que Roma se llama así por Rómulo27.

26 «Los quirites (Quirites) tienen su denominación por los de Cures (Curenses): de aquí vinieron en compañía del rey Tito Tacio para entrar en alianza con nuestro Estado» (VARRO De L.L. VI,68; ver también $\mathrm{V}, 51$ ).

${ }_{27}$ El mismo orden lógico aplicado por T.Livio y por Varrón: «El romano (Romanus) recibió su denominación de donde Roma, de Romulus» (VARRO Lingua Latina 5,33). 
Pero ello no equivale necesariamente a derivar etimológicamente Roma de Rómulo. Tal derivación, a pesar de que la tradición la expresa en ese orden, no es coherente, sino que lingüísticamente debe expresarse, como es lógico, en el orden inverso: Rómulo (que significa el Romano) deriva de Roma (que significa, como hemos defendido, la ciudad de las colinas-ubres) ${ }^{28}$.

Kretschmer (1920:127) objeta contra la hipótesis de Varrón (Cures>Quirites) diciendo que se trata de «una construcción histórica cuyo valor es altamente dudoso", pero no argumenta al respecto. Se precisaría al menos que alguna de las hipótesis que se oponen a aquélla demostrasen su fuerza. Las hipótesis que disputan legitimidad a Quirites<Cures se muestran aún más débiles y, desde luego, incapaces de sustituir la hipótesis varroniana. El único óbice presentado por Kretschmer (loc. cit.) contra la relación de Quirites con Cures consiste en la imposibilidad aducida por él de tal derivación (el derivado lógico sería únicamente $\mathrm{Cu}$ renses), mientras que Quirîtes habría de derivar, en su opinión, de un no existente ${ }^{*}$ Quirium, como Samnîtes de Samnium ${ }^{29}$. Pero todo se remedia tomando a Quirites como una analogía de Samnites: Ambas palabras pertenecen al mismo fondo lingüístico: Tanto el dialecto sabino —en el que nacería el término Quiritescomo el dialecto samnítico —al que pertenece evidentemente el término Samnites- se encuadran dentro del marco de lenguas umbro-sabélicas.

Tal analogía se refuerza si, como quieren algunos autores -entre ellos el mismo Kretschmer (pp. 148-149) - , hay que poner en relación igualmente la palabra Quirites con curis, el término sabino para denominar la lanza. Uno esperaría que el derivado de curis, para designar a los que luchan con lanza, contuviera un $r i$ (con - $i$ - breve en penúltima sílaba) paralelo de pedites y de equites, los que luchan «a pie» o «a caballo» respectivamente. En el caso de que Quirites derivara de curis (y no de Cures), o de ambos, Quirîtes se explicaría y sólo se explicaría como analogía de Samnîtes.

Poucet (1967:11-19) arguye contra la derivación de Quirites-Quirino a partir de Cures ( ${ }^{*}$ Quirium) objetando contra el poblamiento primitivo de Roma por los sabinos. Compara los relatos de Tito Livio y de Dionisiso de Halicarnaso relativos a la

${ }^{28}$ Ver Casquillo 2004-05 passim. Es lógico que el nombre de las naciones provenga del de sus pobladores, pero el nombre de las ciudades no proviene del de sus habitantes. De ambas partes de este principio es testigo el propio Varrón: «(1. a PARTE) Los lugares de Europa ... generalmente han sido designados o por el nombre de sus pobladores en sentido figurado, como Sabini y Lucani, o por uno resultante de la transformación del de sus pobladores, como Apulia (¿de Apulus?) y Latini, o de una y otra forma, como Etruria y Tusci. Por donde estuvo el nombre de Latinus, el territorio en conjunto recibió la denominación de Latius (sic), (2. ${ }^{a}$ PARTE) y por partes se sobrenombró según sus ciudades, como de Preneste Prenestinus, de Aricia Aricinus» (VARRO, L.L. 5,32). De donde se deduce que la tradición, al derivar Roma de Romulus (=Romanus) y no a la inversa, cometió el error de fundir la $1 .^{a}$ parte del principio (el nombre de los pobladores da origen al de los territorios) con la 2. ${ }^{a}$ parte (el nombre de los habitantes procede del de las ciudades y no a la inversa) creando un principio único y «con-fuso»: el nombre de la ciudad de Roma, como el de los territorios, procede del de su fundador-habitante (Rómulo-Romano). Pero ahora sabemos que Rómulo provine de Roma, y no a la inversa.

${ }_{29}$ Reivindican, sin embargo, la hipotética existencia de tal toponímico Quirium, como base para Quirites-QuirÎnus, Niebuhr, Birt 1887-1888, Deecke, Wissowa y O. Hoffmann 1917 (ver Kreschmer, op. cit. p. 147), a los que Kretschmer allí califica de «renovadores de la hipótesis varroniana». 
Muerte, desplazamiento y apoteosis de Rómulo: un estudio sobre la realidad...

fundación de Roma y su primer reparto territorial: Allí encuentra que la pretendida colina sabina —el Quirinal- solamente en el relato de Dionisio de Halicarnaso $(I I, 50,1)$ aparece en la Roma habitada por los hombres de Rómulo yTito Tacio tras la unión que sigue al rapto de las Sabinas, mientras que en el relato de Tito Livio $(I, 44,3)$ no entra a formar parte del territorio romano hasta el reinado del rey etrusco Servio Tulio, casi dos siglos después. Poucet concluye que la versión más antigua y auténtica es la de Tito Livio, y que el primitivo poblamiento sabino de Roma sólo puede recibir valor legendario. La argumentación de Poucet reposa en que Quirinal, Viminal y Esquilino iban juntos en la tradicional geografía romana - tal como consta en el relato de Livio-, mientras que Dionisio erróneamente separa el Quirinal, cosa aún más grave en el caso del Viminal-Quirinal que juntos formaban la regio Collina. Pero el argumento de Poucet se manifiesta como un anacoluto dialéctico: por un lado argumenta que Quirinal-Viminal-Esquilino son una inseparable unidad en cuanto «avanzadillas del vasto llano que cubre el Nord-Este de la Urbe»; y, por el contrario, añade a continuación, que "Quirinal y Viminal debían ser considerados por los antiguos como una unidad particular, puesto que formaban ellos dos solos (!) la llamada regio Collina»; es decir, que Poucet lo mismo argumenta que el Quirinal es inseparable del Esquilino por lo llano, que argumenta que es inseparable del Viminal por lo elevado. Nada permite argüir que el Quirinal no pudiera ser habitado por Sabinos antes que el Viminal y que el Esquilino: el Viminal puede ser una denominación secundaria parcial del Quirinal. El Esquilino se distingue del Quirinal (y del Viminal) no sólo en base geológica sino aun en base lingüística: los romanos llamaban collis, "colina» al Quirinal-Viminal, frente al Esquilino al que sin vacilar llamaban mons, «monte». No tenemos, pues, ninguna razón para preferir Tito Livio a Dionisio de Halicarnaso. Otros muchos autores consensúan el dato con Dionisio, lo que le concede un cierto grado de versión preferente. ¿Dónde, si no, se establecieron los sabinos que vinieron con Tito Tacio a unirse con Rómulo? Los albanos de Rómulo ya ocupaban el Palatino y el Capitolio, tal como el propio Poucet, siguiendo a Livio $(I, 7,3$ y $I, 11,6)$ reconoce. Los sabinos tenían por fuerza que instalarse en alguna colina. Tito Livio $(I, 13,5)$ los ubica en Roma sin asignarles territorio. Dionisio de Halicarnaso es perfectamente coherente en corregir la situación mal determinada por Tito Livio y asignar a los sabinos el collis Quirinalis ${ }^{30}$.

Comparemos una vez más el texto de Tito Livio con el de Dionisio de Halicarnaso: El Quirinal, según Livio, no está integrado en la ciudad de Rómulo y no es anexado a Roma hasta el reinado del rey etrusco Servio Tulio. Conclusión de Poucet: La tradición historiográfica en que bebe Tito Livio es más antigua y auténtica que la de Dionisio; la caracterización sabina del Quirinal (la pretensión de que Tito Tacio instaló allí a los sabinos) ${ }^{31}$ es pura leyenda. Pero, se puede objetar, ¿no estamos ante uno más de los excesos de la hipercrítica? Del relato de Tito Li-

30 Ver D.H. II,50,1. No hay que confundir —como Poucet !967:9-11 hace- el collis Quirinalis (VARRO L.L. V,51-52) con la regio Collina (VARRO. L.L.V,45). El collis Quirinalis existe ya en la Roma primitiva; la regio Collina, en la que se funden Quirinal y Viminal solo empieza a existir en tiempos del rey etrusco Servio Tulio.

31 Ver DIONYS.HALIC. II,50,1). 
vio no se sigue que, antes del rey etrusco Servio Tulio, el Quirinal no estuviera habitado o que, al menos, sus habitantes no fueran sabinos ${ }^{32}$. Lo único que se sigue de Tito Livio es que, si había sabinos en el Quirinal, aquél considera que no estuvieron integrados en la jurisdicción de Roma hasta después de Rómulo. Lo cual deja muy disminuida de contenido político la dimidiata urbs de la que Livio expresamente habla. Pero, en cualquier caso, los Quirites pudieron haber llegado ya a Roma - quizá desde Cures-en tiempos de Tito Tacio (y Rómulo) ${ }^{33}$. Y, si como nadie duda, Quirino está relacionado etimológicamente con Quirites, Quirino llegó a Roma con los sabinos.

Quirinus. Quirino es sin lugar a dudas una de las más antiguas divinidades romanas. Forma parte de la vieja tríada capitolina, Júpiter-Mars-Quirinus, cuya existencia antes del inicio de la República Romana es, a todas luces, incontestable para todos los autores antiguos y modernos. La importancia de la tríada desde los tiempos más antiguos viene confirmada por la existencia a su servicio de los tres sacerdotes flámines, entre ellos el flamen Quirinalis. Una fiesta dedicada a Quirino el dia 17 de Febrero, llamada Quirinalia, formaba parte del antiquísimo calendario de Numa.

Quirino, igual que su sacerdote principal, el flamen Quirinalis, es un dios estrechamente vinculado al grano del cereal (Dumézil 1944:195). Sus fiestas patronales, las Fornacalia, estaban dedicadas a la torrefacción del grano (el farreum, ibid.196). Igualmente es destacada la intervención del flamen Quirinalis en las fiestas llamadas Consualia, celebradas el 21 de Agosto, en las que el supremo sacerdote de Quirino en unión de las vírgenes Vestales ofrecía un sacrificio al dios subterráneo Consus, cuyo nombre hace alusión al soterramiento del grano en sus asilos (condere, ibid. 197).

Es sorprendente que, si el cereal como el olivo de alguna manera simboliza la paz, Quirino aparezca también en la tradición romana asociado a las armas y reciba un epíteto griego, Enyalios, que lo identifica con el dios de la guerra, Ares; y eso, aun a pesar de la relación que une a Quirino con los Quirites, nombre que los romanos reciben en cuanto meros «ciudadanos" diferenciados de los soldados armados, milites ${ }^{34}$. Pero el mismo Varrón $(L . L$. VI,88) nos recuerda que los Quirites, cuando se reúnen en el comicio centuriado, aunque ciudadanos en son de paz, responden a una convocatoria por centurias, según una clasificación que viene determinada por su armamento de guerra. A ello se añade que en las estatuas Quirino era representado armado y que el encargado de «engrasar» sus armas era el

32 Poucet 1985:83-s. no parece querer distinguir muy expresamente entre población (peuplement) e integración política (intégration) de la zona del Quirinal, sino que presupone sin razón que ambos elementos no pueden haber existido disociados: «Pendent une période assez longue, toute cette zone a eté designée par un terme général et commun, Collis, la Colline...: elle n'était pas encore considerée comme parte intégrante de la citté...; le Collis était encore, à ce moment, zone périphérique, marginale. Son peuplement et son intégration (!) récents ... dans la réorganization dite servienne (regio Collina)". Pero evidentemente poblamiento e integración pudieron no haberse producido en el mismo tiempo.

33 Ver T.LIV. I,13,5 y VARR. L.L. V,51.

34 Ver el incidente narrado por Suetonio (Divus lulius 70) en que los soldados de César rehúsan airados recibir el título de Quirites, que parecía licenciarlos del oficio de las armas (ver también TAC. Ann. I,42; y LUCAN. 5,358). Ver igualmente la oposición Marte/Quirino en VARR. L.L. V,73 y VI,88). 
Muerte, desplazamiento y apoteosis de Rómulo: un estudio sobre la realidad...

flamen Portunalis, sacerdote de Portuno, el dios de las puertas de la Urbe ${ }^{35}$. Todo ello ha llevado a Dumézil a establecer un paradigma de igualdad/desigualdad entre Marte y Quirino, oponiendo éste último al dios de la guerra como una especie de Mars Tranquillus: Quirino, pues, dios de la paz armada, es decir, las armas en su función preventiva de la guerra: «los mismos hombres ... según el tiempo, según que se estuviera en guerra o en paz, eran tanto milites como Quirites (Dumezil 1944:204). ¿Qué colegir de ahí? La derivación etimológica de Quirites a partir de ${ }^{*}$ co-virites (de vir) pierde todo su sentido, si se toma en consideración que tanto eran viri los «milites» como los «Quirites», y más aquellos, los soldados, si se piensa en la virtus como un carácter propio del hombre militar.

Se ha puesto en duda, sin embargo, su carácter de divinidad de origen sabino. Para los antiguos - historiadores y anticuarios- era claro que el nombre de Quirino, como el de los Quirites, está indisolublemente unido a los sabinos y a la villa sabina de Cures $^{36}$. Muchos autores contemporáneos se han mantenido fieles a la raíz sabina de Quirino ${ }^{37}$. Otros, que van de Dumézil al hipercrítico Poucet, ponen en duda el origen sabino de Quirino. Dumézil, no obstante, cita a Dionisio de Halicarnaso $(I I, 48)$ que adhiriéndose a la teoría de Varrón, mitad del siglo I a.C., reafirma la sabinidad del dios: "Los sabinos, y a su ejemplo los romanos, dan a Enyalios el nombre de Quirino». Pero Dumezil, como muchos de los autores modernos, cree en que es la afabulación la que ha convertido a Quirino en un dios Sabino. ¿Con qué fundamento lo cree? Sugiere que una cuestión de mera similitud fonética (Quirites ><Quirino) fue lo que confundió a los arqueólogos empezando por Varrón. A pesar de esa similitud fonética, Dumézil (1944:219) asevera que «el nombre de Quirino no tiene trazas de ser sabino». Y añade a renglón seguido: "Quirino como dios no figura, salvo una única excepción, en ninguna inscripción de la región de la Sabina» ${ }^{38}$. Pero, ¿qué otros restos epigráficos conservamos en la Sabina -o en cualquier otra región latina- de la época, s. VIII-IV a.C., que podrían testificar la sabinidad del nombre divino de Quirino? El fondo epigráfico latino más primitivo se reduce a documentos oficiales (Leges Regiae, XII Tabulae, etc.) y data de los siglos VII-V a.C.. Sólo se nutre de inscripciones de carácter cultual a partir del 400, un tiempo en el que Quirino era un dios casi olvidado, situación que cambió precisamente a partir de su rejuvenecimiento ya cerca del 200 a.C. Pero entonces Quirino se convirtió en un dios de Estado (bajo el mando de los Julios), más que un dios del culto popular.

La afirmación o negación del carácter sabino de Quirino está abocada por el momento a ser mantenida en suspenso. Es posible que todos los testimonios de historiadores (Tito Livio, Dionisio de Halicarnaso) y poetas (Ovidio) que ponen el grupo de palabras Quirites-Quirino en relación con la villa sabina de Cures dependan exclusivamente del arqueólogo Varrón. Y es posible que la autoridad de Varrón, lastrada por su presunta sabinomanía, deba quedar en entredicho. Quizás

\footnotetext{
35 Festus, s.v. persillum.

36 Ernout-Meillet (1962) en su «Dictionaire Ëtymologique» reafirma el dato (s.v. Qurinus).

37 Wagenwoort, etc. (en Poucet 1967: 22 n. 63 y 64).

38 E. C. Evans, The Cults of the Sabine territory, pp. 114 y 213.
} 
es, pues, conveniente suspender el asenso cierto a la sabinidad de Quirino y a la correlación de los Quirites con Quirino. Dado que nadie ha falsado de forma convincente las teorías de Varrón, nos basta por el momento con mantener a título de hipótesis la llegada de Quirino a Roma de mano de los sabinos. Una tesis más cierta no la ha demostrado nadie. Pero los antiguos negaban la latinidad de la etimología de Quirino (lo que abría la puerta a su sabinidad). Nadie entre los modernos ha sabido contradecirles con una argumentación concluyente.

\section{HACIA UNA INTERPRETACIÓN RITUAL DEL DESPEDAZAMIENTO DE RÓMULO}

Nuestra obligación no es, sin embargo, probar que los Quirites recibían tal nombre por Cures, ni que Quirino está relacionado etimológicamente con Quirites. Nuestra única intención reside en dejar asentado que no es cierto que Quirītes proviene de *Co-uirites, ni Quirīnus proviene de *Co-uirinus. Si ninguna nueva hipótesis se muestra más fuerte que la hipótesis tradicional de Varrón, seguiremos manejándonos con el paradigma de que Quirino es un dios sabino y que los ciudadanos romanos recibieron el título de Quirites tras la fusión de los sabinos con los latinos. El despedazamiento de Rómulo no es, pues, un ritual para significar la recuperación de la soberanía por los * co-uiri de la Roma pre- o proto-urbana puestos bajo la advocación de Quirino.

En la interpretación del despedazamiento y apoteosis de Rómulo, nos mantenemos dentro de una línea hermenéutica antropológica. Nuestra línea de investigación se desvía, no obstante, del terreno estrictamente político hacia el que la han desplazado Fraschetti y Carandini (el despedazamiento de Rómulo es, según ellos, un ritual de apropiamiento de la soberanía), y se orienta hacia el terreno más adecuadamente religioso: Si el despedazamiento y apoteosis de Rómulo continúa siendo para nosotros un ritual $-\mathrm{y}$ con ello nos mantenemos en el terreno puro de la Antropología Cultural-, se trataría más bien de un ritual religioso de afirmación del carácter regio de la autoridad de Rómulo sobre la naciente Roma. Siguiendo a aquéllos autores que, como Burkert (1962), han visto en el aniquilamiento de Rómulo no un expediente de destrucción y sustitución del poder real, sino un rito de apoteosis y fundamentación cósmico-divina del poder regio, trataremos de consolidar dos ideas sobre el despedazamiento y apoteosis de Rómulo: A) la negación de toda hermenéutica que se base en la interpretación del despedazamiento de Rómulo como un asesinato ritual, y B) la afirmación de la apoteosis de Rómulo como consecuencia del despedazamiento de Rómulo y como tránsito hacia la renovación y continuidad de una monarquía de origen divino.

\subsection{Gestación de la idea del asesinato de Rómulo}

La negación de toda hermenéutica que se base en la interpretación del despedazamiento de Rómulo como un asesinato ritual, nos conduce metodológica- 
mente hacia un estudio de la génesis del relato en que el despedazamiento de Rómulo es presentado como un verdadero asesinato histórico.

El asesinato de Rómulo no está de acuerdo con la tradición canónica, que no hubiera ignorado la muerte violenta de Rómulo, como sin duda la ignora Ennio -y de hecho la ignora Cicerón en el De Republica - ${ }^{39}$; ni la hubiera puesto en duda, como dudaba Tito Livio $(1,16,4)$; ni aún menos la hubiera negado, como la niega Ovidio (Fast. 2,497). No es correcta la contundencia en afirmar «el asesinato del primer rey» (ver, por ej. CARANDINI 2006:355). Dionisio de Halicarnaso es probablemente el primer historiador que sostiene la teoría del asesinato. ¿Qué fundamento para ese asesinato hay en el relato tradicional, anterior a la historiografía griega, si no se documenta ninguna rebelión patricia antes, y ni siquiera ningún tipo de expiación popular del crimen después? En contra, pues, del asesinato se puede argumentar en varios sentidos:

x) La sugerencia de Angelo Brelich (y en algún momento del propio Carandini) en contra del despedazamiento de Rómulo como expediente racionalizador: $\mathrm{Hu}$ biera valido un asesinato a secas, seguido de un ocultamiento del cadáver, para racionalizar el mito de la desaparición apoteósica de Rómulo. Pero se puede llegar más lejos a propósito de la tesis de Fraschetti-Carandini del despedazamiento ritual de Rómulo: Si de lo que se trataba era de recuperar simbólicamente la soberanía por parte de los senadores o jefes de cada rione de Quirites, ¿para qué hacía falta asesinar al rey? Bastaba con esperar a que la muerte natural señalase el fin de su reinado y, entonces, despedazarlo pública y ritualmente para simbolizar la devolución de la soberanía a las Curias. ¿Por qué, pues, esconder los trozos de Rómulo en las ropas de Senadores?

xx) La tesis del asesinato de Rómulo puede haber surgido de una errónea interpretación del desmembramiento de Rómulo a partir de la interpretación que los historiadores griegos, siguiendo a Dionisio de Halicarnaso, hicieron de la muerte de Rómulo en analogía con el reciente asesinato de Julio César. La gestación de este error puede desglosarse en varios pasos sucesivos: a) identificación de ciertos personajes (como Tarquino, Mario, Sila, Cicerón y Julio César) con Rómulo en su pretendido carácter de padres de la patria y refundadores de Roma. b) la evolución de algunos de éstos hacia la tiranía, lo que conlleva la recta doctrina de la insurrección contra ellos y legítimo tiranicidio. c) La analogía refundadores-Rómulo lleva a retroproyectar la teoría del asesinato en el propio Rómulo, y así reinterpretar el desmembramiento de Rómulo como anticipación del asesinato de César. d) Regresión «circular» hasta el «último» Rómulo del carácter tiránico que ahora, a ejemplo de Rómulo, se quiere punir en César, Tarquino, etc. Me ocupo uno a uno de tales pasos:

${ }^{39}$ La frase de Cicerón en que interpreta el testimonio de Próculo Julio sobre la ascensión a los cielos de Rómulo como un expediente de los senadores «para alejar de ellos sospechas por la muerte de Rómulo» (invidiam interitus Romuli, CIC. Resp. 2,10), no implica necesariamente conocimiento de una muerte violenta personal de Rómulo: Basta con que los senadores quieran evitar que la plebe vea en el caso de Rómulo una repetición de la muerte de los reyes etruscos Tarquino el Antiguo y Servio Tulio, que terminaron asesinados. 
a) Es sabido que grandes personajes de la res-pública romana, como Tarquino, Servio Tulio, Cicerón y Julio César, se arrogaron el carácter de refundadores de Roma: César no fue el primero que se tuvo por nuevo Rómulo. Mario se hizo venerar como tercer fundador de Roma. También Sila trató de presentar el aspecto de Rómulo ${ }^{40}$. Cicerón, tras desmontar la conjuración de Catilina, se hizo llamar «padre de la Patria», como es de sobra sabido; y el Pseudo-Salustio lo caricaturiza como «el Rómulo de Arpino». El mismo Pompeyo fue amenazado por compararse a Rómulo (PLUT. Pomp. 25).

Pero es, sin duda, el caso de Julio César el más notorio. Sus partidarios lo consideraban como fundador de una Roma nueva. El poeta Catulo, en una de sus varias invectivas contra César, lo llama con sorna «Rómulo marica» («cinaede Romule», CATVLL. 29,9): Teniendo en cuenta que Catulo se reconcilió con César el año 55 en la casa paterna de Verona, parece una atribución muy temprana en la biografía de César ${ }^{41}$. También Cicerón compara a César con Rómulo divinizado (de pompa Quirini) en una carta ya del 45, mismo año de la muerte de César.

César, como antes Cicerón, recibió el título de «padre de la Patria: "recepit ... cognomen Patris patriae", y se le consagró tras su asesinato una columna por el pueblo dedicada al «Parenti patriae» (SVET. 76 y 85 respectivamente). Así mismo (loc. cit. 76) se colocó una estatua suya entre la de los reyes de Roma, probablemente asimilándose así aún más a Rómulo, el primero de los reyes.

b) Sobre todo en el caso de Tarquino el Antiguo y en el de César, la evolución hacia la tiranía de éstos imitadores de Rómulo, refundadores de Roma, conlleva la recta doctrina de la insurrección contra ellos y legítimo tiranicidio: Los biógrafos de César han narrado suficientemente la gestación de la conjura que llevó hasta el día de las Idus de Marzo del año 44 a.C,

c) La analogía refundadores-Rómulo lleva a proyectar la teoría del asesinato en el propio Rómulo, y así reinterpretar el desmembramiento de Rómulo como anticipación del asesinato de César (etc.), y el asesinato de César como imitación del de Rómulo:

c.1. (los modernos): «Como los patricios habían expulsado al último rey tirano, así ellos (la aristocrcia gentilicia) debieron matar en la fantasía legendaria al fundador de Roma, construyendo su figura sobre el modelo de la de Tarquino el Soberbio, y haciendo de esa manera remontar a aquel tiranicidio imaginario la posesión exclusiva de los auspicios» (CARANDINI 2006:467).

c.2. (los antiguos): Un texto de Plutarco (no citado, por cuanto sé, por Carandini) es aún más explícito en sugerir el asesinato, en este caso de Pompeyo. Dice Plutarco (s. I-II d.C.) que, cuando Pompeyo pretendió poderes quasi-dictato-

\footnotetext{
40 Así lo testimonia Burkert 1962:357, quien cita a Alföldi 1951:203-ss. El hijo de Sila acuñó monedas de su padre en figura de Rómulo (Alföldi 1951:198). SALL. or. Lep. 5 llama a Sila scaevus iste Romulus, "ese Rómulo zurdo".

41 Ver Miguel Dolç. Catulo. Poesías. Ed. Alma Mater, Barcelona 1963, p. XIX.
} 
Muerte, desplazamiento y apoteosis de Rómulo: un estudio sobre la realidad...

riales con el proyecto de ley Gabinia contra los piratas (67 a.C.), todos los senadores, menos César — que se alió «demagógicamente» al lado del pueblo- se le enfrentaron y un cónsul le atacó con amenazas: «diciéndole que, si quería imitar a

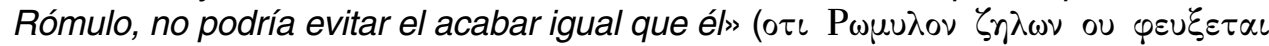

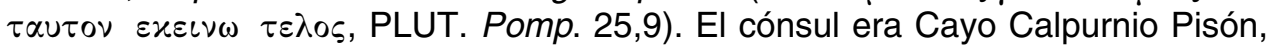
que tenía por colega a M. Acilio Glabrión (Dion Cassio, 38,24,3). La anécdota de Plutarco, si responde a los hechos - algo probable-, demuestra que en la primera mitad del siglo primero antes de Cristo el episodio del descuartizamiento de Rómulo era de conocimiento común al menos entre el orden senatorial . A este respecto, se dice que fue Pisón quien dio origen al rumor de que Rómulo fue asesinado por los senadores, algo que — habría que deducir- no se había sostenido hasta entonces ${ }^{42}$. Hasta entonces se hablaría probablemente del despedazamiento de Rómulo (que podía tener diversos sentido rituales) sin interpretarlo necesariamente como asesinato. En el futuro se entendería, el pueblo así lo entendía, que quienquiera que se tuviera por nuevo Rómulo estaba amenazado de muerte. El primero en hacerse eco del rumor ya popular fue Cicerón: Una carta del 15 de Mayo, de Cicerón a Ático, en el año 46 a.C. contiene un párrafo en que aparentemente se desea la misma muerte violenta para César: Cicerón ironiza diciéndole a Ático que prefiere a César compartiendo el templo de Quirino que el de la diosa Salud: "eum бuvvaov Quirini malo quam Salutis» (CIC. Ad At. 12,45), lo que puede interpretarse de forma natural entendiendo que Cicerón desea a César la muerte que a Rómulo-Quirino. Unos viente años después Tito Livio $(1,16,4)$ toma de Pisón la vaga noticia acerca del "oscuro rumor» que se levantó tras la desaparición misteriosa de Rómulo en la laguna de Capra. Dionisio de Halicarnaso $(2,56)$ y tras él la historiograría griega (Apiano y Plutarco) lleva la confusión (despedazamiento>asesinato) a una idea cierta acerca del asesinato de Rómulo, identificando sin vacilar el despedazamiento como un verdadero asesinato. El proceso circular (muerte al tirano>asesinato de Rómulo) queda así consolidado.

d) Regresión «circular» hasta el «último» Rómulo del carácter tiránico que ahora, a ejemplo de Rómulo, se quiere punir en Tarquinio, César, etc.

d.1. (los antiguos): Es característica de los historiadores más tardíos, y sobre todo de Plutarco la proyección a Rómulo de unos caracteres tiránicos, propios del «último» Rómulo, excesivamente minuciosos, difícilmente retenibles por la tradición histórica romúlea, y más lógicos en un refinado y helenizado César, desde el que fácilmente podían ser retrotraídos a Rómulo: así, la túnica de púrpura, el trono de oro, y los trescientos "armatos» - o celeres - a los que ya se refiere Tito Livio desde el comienzo de la monarquía de Rómulo (y que podían haber sido importados de la misma diarquía espartana $)^{43}$. Es más fácil trasladar a un asesinato meramente legendario los detalles de un asesinato históricamente acaecido que vi-

42 «Piso hatte auf die Sage angespielt, da $\beta$ Romulus, zum Tyrannen entartet, von den Senatoren in Stücke gerisse worden sei» (BURKERT 1962:358).

${ }^{43}$ Ver Plutarco, Rom. 26,2 (y el paralelo comportamiento de César en Dion Casio; XLIV,3-6). En cuanto a Tito Livio, ver I,15,7. 
ceversa. Así, es fácil retroproyectar al pasado un detalle tan concreto como que los Padres asesinaron a Rómulo «colocándose en círculo» (Plutarco, loc. cit.), si se sabe históricamente que los senadores apuñalaron a César «rodeándolo» (circumsteterunt, SVET. Caes,82), para cortarle toda posible escapatoria.

d.2. (los modernos): Por eso, es lógico que algunos autores reconozcan, como hace Fraschetti, en la caracterización tiránica del último Rómulo el efecto de un mero proceso circular por el que se retroproyectan a Rómulo los caracteres tiránicos de César ${ }^{44}$. De esta manera se está culminando el procedimiento por el que antes Cicerón y Cayo Calpurnio (entre otros que se sepa) habían amenazado a César y a Pompeyo con la misma muerte por asesinato, con la que que previamente habían reinterpretado «ad hoc» el desmembramiento de Rómulo. La sospecha de ese recurso «circular» se hace tan patente, que no es extraños que el mismo Carandini ponga en duda la fiabilidad de la caracterización tiránica de Rómulo ${ }^{45}$.

En efecto, no es en absoluto cierto que la caracterización tiránica de Rómulo pertenezca a los orígenes de la historiografía tradicional referente a Rómulo. La historia del texto muestra más bien lo contrario: la caracterización de Rómulo como dictador es un efecto de la acomodación de un texto que en su origen era totalmente antitético con esa idea. En efecto:

El relato de Cicerón sobre la muerte y apoteosis de Rómulo, tal como se nos presenta en su tratado sobre la «República» del año 52 a.C., nos muestra más bien a un rey-fundador que anticipa las virtudes políticas de la futura república romana y las mantiene hasta el momento mismo de su misteriosa desaparición. Rómulo en el relato ciceroniano evita usufructuar el carácter de señor y dominador de Roma (dominus), que parecía otorgarle su acción fundadora, comparable con la de Licurgo, y modera aquella fuerza de dominación (illam vim dominationis, Resp. 2,9), propia de Esparta pero a la que él renuncia, y que consiste en el ejercicio de la autoridad (adiuncta auctoritas, ibid.) que otorga a los optimates: Tal autoridad reside en los dos pilares de la cosa pública (duo firmamenta reipublicae, ibid. 2,10) los auspicios y el senado (auspicia et senatum, ibid.). Para administrar los auspicios, que significan el freno y control que la voluntad divina impone a la voluntad del rey, Rómulo escoge un augur por cada una de las tres tribus de la Urbe (ex singulis tribubus singulos cooptavit augures, ibid. 2,9); y gobierna apoyándose en el poder consultivo del senado (hoc consilio et quasi senatu fultus et munitus, ibid.). La acción de su gobierno no se basa en ningún momento en la coacción tiránica que se ejerce mediante la fuerza y, si ha lugar, la tortura (non vi et suppliciis coercebat, ibid.). Por el contrario, repartía bienes entre todos los ciudadanos, a los que hacía ricos, «sin llevarse a su propia casa lo mejor del botín» (cum ipse nihil ex praeda domum suam reportaret, ibid.).

44 «Non è improbabile che alcune caratteristiche della 'tiranide' del 'ultimo' Romolo, quando egli è di nuevo unico re dopo la morte di Tito Tazio (come abbiamo avuto da vedere una morte anche essa oscura e violenta), riecheggino motivi di polemica anticesariana, di polemica sopratutto contro la 'tiranide' del 'ultimo' Cesare. (...) in una sorta di procedimento circolare» (Fraschetti 105).

45 «L'abolizione stessa della monarchia ereditaria — piú che la sua degenerazione in tirania- potrebbe dunque costituire il movente per l'uccisione di Romolo da parte dei Patres» (Carandini 2006:114). 
Muerte, desplazamiento y apoteosis de Rómulo: un estudio sobre la realidad...

El «último Rómulo», ese Rómulo dictatorial que en la historiografía griega posterior a Dionisio de Halicarnaso se caracteriza por su ejercicio abusivo del poder, está totalmente ausente en el texto de Cicerón, en donde desde ese benéfico Rómulo se pasa sin solución de continuidad a narrar el fin de la vida mortal de Rómulo tras treinta y siete años de reinado uniforme (cum septem et triginta regnavisset annos, ibid. 2,10).

Tal descripción de un reinado lleno de virtudes distributivas parece estar inspirado en la figura del «rey de justicia» que inspira el relato de Ennio casi un siglo y medio antes. Es verdad que de la desaparición y apoteosis de Rómulo sólo nos ha quedado en Ennio una narración fragmentada. Pero los pocos datos que poseemos nos son suficientes para adivinar en el relato de Ennio una deuda directa a la descripción en Hesíodo del estatuto post-mortem de los reyes y de los hombres-reyes que vivieron en la Edad de Oro hesiódica. El último verso conservado del Libro Primero de los «Annales» de Ennio es una clara alusión a la desaparición de Rómulo: "Tú nos abriste el camino a los confines de la luz» (Tu produxisti nos intra luminis oras, v.59,5). Tras su ascensión a los cielos «Rómulo pasa el tiempo en el cielo con los dioses de su estirpe» (Romulus in caelo cum dis genitalibus aeuom degit, vv.57,1-s.). Los dioses de la saga («genitalibus») son una clara alusión a la estirpe regia epichthonizada, es decir, son los dioses menores o daemones en que se convierten tras su muerte los reyes - reyes a su vez identificados con los hombres de la Edad de Oro hesiódica ${ }^{46}$. Tales dioses «epichthónicos» velan por los hombres desde lo alto de la tierra (HES. Erga 121-126). Es lógico que tengan su residencia en las estrellas, tal como aparece en el texto de Ovidio, donde Rómulo demonizado en Quirino es transportado a los astros (venit in astra... astra petebat, OV. Fast. II, 478 y 496 respectivamente). Pero en los astros Rómulo-Quirino, como los démones epictónicos de Hesíodo, no lleva una existencia retirada sino que se ocupa de sus compatriotas: "Oh Rómulo, divino Rómulo, los dioses te engendraron para guardián de tu pueblo» (O Romule, die Romule, qualem te patriae custodem di genuerunt!, ibid. vv.59,2-3). Evidentemente sería absurdo que se encumbrara como protector de la patria a un rey, Rómulo, que hubiera acabado su reinado ejerciendo maneras de tirano. Eso lo sabía muy bien Ennio y no podía por menos de ponerlo en práctica en unos momentos, hacia el año 200 a.C., en que se estaba concluyendo el período más democrático de la república romana. Las dictaduras, Mario, Sila, César, vendrían un siglo después. Pero, aun en ese momento los historiadores, la historiografía griega en particular, no podía ignorar el signo exclusivamente benéfico del reinado de Ró-

46 Ver supra n. 6. La interpretación de Vernant hace expresa alusión a la identificación de los reyes con los hombres de la edad de oro (Véase VERNANT 1965 [1983] pp. 31 y 51-57) y a las virtudes que adornan a esos «reyes de justicia» (ibid. pp. 30-31 y 78-79) citando expresamente el texto de Hesíodo (Theog. 81-91). Hay que recordar que la dadivosidad de los reyes benéficos es compartida por los mismos démones, en los que tras su muerte se convierten, y que se traduce, según Vernant (op. cit., p. 30), en que «como ploutodotai, dispensadores de riquezas, favorecen la fecundidad del suelo y los rebaños" (ver HES. Theog. 123). En este contexto, probablemente, hay que situar el texto mismo de Cicerón, que atribuye a Rómulo «mucha dispensación de ovejas y bóvidos, porque entonces la propiedad se medía en ganado y posesión de tierras (in pecore et locorum possesionibus), por lo que entonces se llamaban acaudalados (pecuniosi) y ricos (locupletes)» (CIC. Resp. 2,9). 
mulo, y así le atribuye el carácter post-mortem propio de un «rey de justicia» incluso a él, a un rey al que -en flagrante anacoluto- el historiador había caracterizado de tirano al final de sus días. Así sucede expresamente en el relato de Plutarco. Alli sorprendentemente, al final de la apoteosis narrada por Julio Proclo (sic), Rómulo en persona dice que se va a convertir en un daemon protector: «Yo seré para vosotros Quirino, un demon benéfico» ( $\varepsilon \gamma \omega \delta^{\prime} v \mu \mathrm{tv} \varepsilon v \mu \varepsilon v \eta \varsigma \varepsilon \sigma o \mu \alpha l$ $\delta \alpha 1 \mu \omega v$ Kvpivos, PLUT. Rom. 28,3) ${ }^{47}$.

Es evidente que sólo el rey de justicia se convierte en demon benéfico, y que el relato tradicional, del que había bebido Dionisio de Halicarnaso, es decir, la analística griega de Fabio Píctor, caracterizaba a Rómulo de rey benéfico hasta el final de sus días. Y así debía ser, pues el texto no recoge ningún trazo del reinado de Rómulo que apunte, ni siquiera al final de sus días, a un movimiento de rebeldía contra la monarquía de Rómulo similar al que se dio cuando la monarquía cayó en Roma durante el reinado de Tarquino el Soberbio.

Los historiadores griegos que vivieron la caída en la tiranía de Julio César y los primeros movimientos de Octaviano hacia el imperio, se atrevieron a dar un paso para el que la historiografía latina no pudo encontrar fundamento. Es sólo una conjetura - ¿qué más podría ser?-, pero es lícito pensar que los historiadores griegos no vacilaron en avisar a los romanos de que en los momentos que se avecinaban no cabía más que recordar que la monarquía había estado lastrada en Roma por signos dictatoriales. Dionisio de Halicarnaso se atrevió a ser más arrojado contra Rómulo de lo que cabía esperar de un historiador romano, apegado a las tradiciones de Roma, incluso si se trataba, como en el caso de Tito Livio, de un ferviente republicano. Quizás la historiografía griega se dejó confundir por dos datos de la tradición, dos datos de peligrosa hermenéutica: El relato tradicional fabulaba sobre un desmembramiento de Rómulo. ¿No podía interpretarse como un tiranicidio? Y ¿no habría sido el final de su vida Rómulo un tirano, si el mismo Ennio no se abstenía de llamar «tirano» a Tito Tacio, que compartió el trono con Rómulo? ${ }^{48}$. Después de la tiranía de Pisístrato y de sus hijos, iba a ser imposible para un griego separar el término tyrannos del sentido neutramente benéfico que en un tiempo pudo haber tenido.

47 Recordemos los paralelos: En Ennio (59,3), Rómulo divinizado en Quirino es un dios «custodem» de todos los romanos. En Hesíodo los hombres de la edad de oro se convierten en démones guardianes (phylakes, Erga 123 ); y, según Vernant, «(el demon en que se convierten los hombres de la generación dorada y el rey muerto como "Soberano Bien") representa una categoría de demonios que vigilan, en nombre de Zeus, el ejercicio regular de la función regia» (VERNANT 1965 [1983], p. 31).

${ }^{48}$ El fragmento de Ennio es conocido: «O Tite tute Tati tibi tanta tyranne tulisti?» (ENN. 1,54). ¿A qué se refiere Ennio? No es difícil saberlo. Pero es oportuno recordar que, aun en los contextos en que el término griego tyrannos se refiere sin más al rey, como es el caso del Oedipous Tyrannos, el «Edipo Rey» de Sófocles, no resultaba fácil separar el término de su sentido peyorativo, lo que permite al coro de la tragedia de Sófocles pronunciar contra Edipo aquella sentencia acusadora: «La hybris engendra al tyranno" (SOPH. O.B., 872). 
Muerte, desplazamiento y apoteosis de Rómulo: un estudio sobre la realidad...

\subsection{Desmembramiento, no asesinato. (Despedazamiento como rito de inmortalidad regia y apoteosis)}

Pero, si nosotros hemos argumentado contra quienes interpretan la muerte de Rómulo como un asesinato y la división de su cadáver en trozos como una forma de recuperación y reparto de la soberanía, ¿que otra hermenéutica podemos aplicar al despedazamiento de Rómulo?

Como hemos visto más arriba, la tesis central de Carandini (2006: 267 y 283) propugna que el despedazamiento de Rómulo es un rito por el que el poder regresa desde el rey identificado con Marte (igual que en el regifugium, fiesta próxima a las Fordicidia o Quirinalia -15 a Abril-), a las curias de Gentes, presididas por los $\mathrm{Pa}$ dres, cuyo patrono y término de identificación es Quirino. El hecho se confirmaría en el hipotético relato paralelo de una muerte del rey Latino descuartizado por los 30 consejeros albenses - representantes de 30 distritos-y la también hipotización paralela de que el mismo rey Latino había asesinado a su hermano Agrio, igual que Rómulo a Remo (ver la «Teogonía» de Hesíodo en cuanto a Agrio y Latino, hijos gemelos (?) de Ulises y la maga Circe) $)^{49}$.

Pero Andrea Carandini no ha sido el único que ha aportado una tesis acerca del desmembramiento de Rómulo. Antes que él otros ya intentaron explicar el desmembramiento de Rómulo relacionándolo o sin relacionarlo con su apoteosis y ascensión al cielo. Jacques Poucet ha resumido certeramente la multiplicidad de enfoques y posicionamientos. Se ofrece aquí su texto íntegro no sólo por el resumen en sí de las posiciones acerca de la muerte de Rómulo, sino por la visión global de la bibliografía al respecto hasta el año 1985:

«Se conocen las dos grandes versiones (sic, contra Carandini) de la muerte de Rómulo: sea la apoteosis ${ }^{50}$; sea el desmembramiento por los senadores ${ }^{51}$. No tomaremos en consideración más que el $\delta 1 \alpha \sigma \pi \alpha \rho \alpha \gamma \mu$ o 0 descuartizamiento del rey.

Los modernos han visto allí a veces un rito de fertilidad ${ }^{52}$, otras veces un rito de comunión ligada a la magia de la lluvia ${ }^{53}$, otras veces el reflejo del asesinato del an-

49 En Carandini 2006:283 se hipotetiza una explicación del descuartizamiento de Rómulo en el sentido de que «se il sacrificio del toro sul Monte Alabano avesse corrisposto a un qualche sacrificio primordiale di un re nemorense" (cfr. Frazer, a propósito de Nemi) se explicaría por qué Rómulo fue descuartizado y sus 30 partes sembradas «e non piú mangiate, come invece era avvenuto e avveniva con le carni del toro sul Monte Albano". Esta hipótesis de Carandini presupone que los senadores intentaron apoderarse (cómo «recuperar»?) del poder regio, pero por presión de la plebe - tras el episodio de Próculo Julio?- consintieron con que se les otorgara la facultad de ejercer el interregnum previo a la elección de un rey no hereditario (Carandini 2006:114). Carandini basa este último punto en un texto del «De Republica» (CIC. Rep. II,12<23-24Carandini>) que acaba así: Nostri illi etiam tum agrestes viderunt virtutem et sapientiam regalem, non progeniem, quaeri oportere.

50 NOTA. Los textos citados por Poucet son los siguientes: LIV., 1,7,15; 15,6; 16,2ss.; 40,3; D:H., II, 56,2, et II,63; CIC., Rep., II,10,17; PLUT., Rom., XXVII; PLUT., Fort.Rom., VIII; OVID., Fast., II,491-512; SOL., I,20.

51 NOTA. Los textos citados por Poucet son los siguientes: LIV., I,15,8; 16,4; D:H., II,56,3-5; PLUT., Rom., XXVI-XXVII; VAL.MAX., V,3,1; APPIAN., B:C., II, 114.

52 A. BRELICH, Quirinus, 1960, pp. 86-119 (cfr. B. LIOU-GILLE, Cultes héroiques, 1980, pp. 177-178).

53 W. F. OTTO, «luno», Philologus, t. 64, 1905. pp. 187-190. 
tiguo rey mágico ya decrépito, una forma de regicidio ritual en que el rey era despedazado ritualmente para transmitir las fuerzas mágicas a su sucesor ${ }^{54}$, otras veces la traducción de un rito primitivo de admisión de los jóvenes al cuerpo de los Quirites ${ }^{55}$, y otras veces un símbolo cosmogónico del sacrificio del rey fundador de una ciudad, el cual representa al creador del universo y cuya muerte crea la nueva nación ${ }^{56}$.

B. Liou-Gille ha presentado muy bien, ayudado por la comparación etnográfica y bibliográfica, las múltiples significaciones (cosmogónica, social, política, agraria) que puede revestir el desmembramiento. La autora ha recordado igualmente, a propósito de la apoteosis, "las innumerables ascensiones de dioses o de héroes, de las que se conocen ejemplos a lo largo de todo el mundo"57» (Jacques Poucet 1985:289-s).

Poucet concluye el texto recién citado preguntándose si, de cara a una situación tan compleja, no es lo más razonable limitarse a poner los problemas sin pretender resolverlos. Pero resulta inevitable responder que los problemas hay que intentar resolverlos. Si el estado de la cuestión es complicado, hay que proponer nuevas vías de solución o profundizar en alguna de las vías ya abiertas. Pero la severidad de la crítica no puede encadenar al historiador y maniatarlo en una posición hipercrítica. Si la nueva vía no acaba de llevarnos a una solución cierta, bastará con haber tentado de nuevo el camino y dejarlo abierto como vía preferible a las que actualmente se transitan.

Walter Burkert (1962) había señalado un camino que —continuando la sugerencia de Schwegler (1853) - nos conviene explorar con más detalle: El despedazamiento del cadáver (no necesariamente de la persona viva) es un paso del ritual funerario regio. En el culto del soberano, según frase literal de Walter Burkert, «aniquilación de su cuerpo (no necesariamente vivo) y divinización coinciden» (Burkert 1962: 368). Y sabido es que la divinización se representa por la ascensión a los cielos, como demuestra paradigmáticamente el catasterismo de los faraones en la teología funeraria egipcia y la asumpción de Hércules en la mitología griega. En esa línea metodológica vamos a abordar lo que sigue.

No nos será necesario confrontar la leyenda del asesinato de Rómulo por los senadores con el sacrificio del toro en las «feriae Latinae» celebradas anualmente sobre los Montes Albanos. No nos será necesario, porque en los ritos de inmortalidad no resultaba esencial (aunque se da en el caso de Dióniso) la consumición del cadáver. Y sobre todo porque los autores que, como Fraschetti, citan y siguen en este aspecto a Burkert, van detrás de ver en los trozos de carne que se reparten equitativamente en el banquete - y se consumen- un reparto justo de sobe-

54 A. SCHWEGLER, Römische Geschichte, I, 1853, pp. 543-544; J. G. FRAZER, Les origines magiques de la roiyauté, Paris, 1920, pp. 306-324; J. BAYET, Histoire politique, 1957, p. 47; M. DELCOURT, Romulus et Metius Fufetius, 1960, pp. 77-82; M. DELCOURT, Le partage du corps royal, 1963, pp. 3-25.

55 J. GAGE, Témoignage de Julius Proculus, 1972, pp. 49-77.

56 B. LINCOLN, Myth of Creation, 1975-1976, pp. 121-145; J. PUHVEL, Renus et Frater, 1975-1976, pp. $146-157$.

${ }_{57}$ B. LIOU-GILLE, Cultes hëroiques, 1980, p.175. El desarrollo del tema acerca de la muerte de Rómulo se encuentra en pp. 174-179. 
Muerte, desplazamiento y apoteosis de Rómulo: un estudio sobre la realidad...

ranía entre los «populi albenses», lo que tenía como objeto «reafirmar la "parità" de los pueblos que constituían la liga, cuyos nombres eran enumerados en famosa lista proporcionada por Plinio el Viejo» (Burkert 1962: 367-369, citado en Fraschetti 2002: 105-106). Pero, como ya he dicho más arriba, la repartición de la soberanía, o el gobierno conjunto de la liga, venía dado — como en todas las «phratrías»— por el hecho mismo de comer en común, sin que sea necesaria —en todo caso constituye un mero apéndice- el descuartizamiento y consumición del soberano.

Pretendemos, pues, unir el despedazamiento de Rómulo y la apoteosis de Rómulo como dos caras de una misma moneda. A pesar de que la versión de la ascensión a los cielos ante el comicio, en la laguna de Capras, y la versión del despedazamiento a manos de los senadores en la Curia parecen en efecto antitéticas (un Rómulo querido por el pueblo e inmortalizado por sus méritos / un Rómulo tirano), no tenemos derecho a hacerlas totalmente irreconciliables, si tenemos en cuenta que autores, como Cicerón (siguiendo a Ennio) ${ }^{58}$ y Tito Livio, que debían conocer bien los términos de ambas versiones - aunque eliminen algunos datos en su relato-, las combinan en una versión mixta.

Los pasos que estamos en disposición de avanzar son los siguientes: 4.2.1. Establecer el carácter regio de Rómulo; 4.2.2. Determinar el tipo de funeral que correspondía a Rómulo (como a Osiris y a Dioniso un ritual funerario de inmortalidad); 4.2.3. Describir despedazamiento y apoteosis como un rito de inmortalidad regia; 4.2.4. Confirmar tal apoteosis mediante el carácter demónico que Rómulo adquiere tras su muerte.

\subsubsection{Carácter regio de Rómulo}

Pretendemos que el carácter regio de Rómulo pueda deducirse antropológicamente del ritual de inmortalidad regia que se le aplica a su muerte: Pero, dado que la tradición histórica procedía en otro orden (es decir, el carácter regio de Rómulo precede al culto regio que se le concede a su muerte), queremos que quede asentado el carácter regio que el relato canónico atribuía a Rómulo. Haciéndolo así, pretendemos asociar la tradición de la apoteosis de Rómulo a su carácter regio. No podemos pretender, evidentemente, que la apoteosis de Rómulo sea un hecho histórico. A los historiadores actuales que presentan la muerte y desmembramiento de Rómulo como un expediente racionalista para superar el mito de (desmitificar) la apoteosis de Rómulo, hay que replicarles que la apoteosis del rey, siendo ciertamente un elemento meramente mítico, está plenamente integrado dentro de los sistemas religiosos que superesctructuran las teocracias del antiguo régimen.

Es dato unánime de la tradición histórica romana (latina y griega) que Rómulo fue el primer rey de Roma. La cuestión disputada puede trasladarse a otro punto

58 L'apothéose (de Romule) est un motiv ancien. Elle avait eté chantée dejà par Ennius (Marcheti, 2002, p. 84 n. 37). 
distinto: ¿Fue Rómulo un rey hereditario o un rey electivo? Carandini comienza asentando que Rómulo, como los reyes alba-longanos, «siendo un príncipe... de la casa reinante de Alba, de origen divino porque descendía de Marte y de los reyes aborígenes del Lacio, que procedían también ellos de aquel dios» (CARANDINI 2006:354). Hay más, Carandini ha tratado la monarquía de Rómulo y su despedazamiento como un acontecimiento «puente» entre la sovranità ereditaria di Alba y la sovranità elettiva de Numa y restantes reyes de Roma: Según él, el final tragico-mítico de Rómulo pertenece a ambos mundos. «La monarquía se completa en Roma con el asesinato del primer rey - a lo que se añade la posible abolición o en cualquier caso transformación de la realeza en Alba- y constitución del "interrregnum"» (CARANDINI 2006:355).

Rómulo, ¿qué rey?. Según Cicerón (Rep., II,12), por voluntad del pueblo, Numa pasa a ser el primer rey electivo. Pero según Dionisio de Halicarnaso, ya Rómulo es elegido por el pueblo. ¿Cómo catalogar entonces los párrafos de Carandini en que afirma que la monarquía de Rómulo hay que situarla en la lína sucesoria de Alba?

Igual que es incierta la línea de la monarquía en Alba, después de la restauración de Numítor, es totalmente oscuro el estatuto de Rómulo en cuanto rey de Roma. Ese estatuto parece emanar simplemente de la voluntad de Rómulo de instaurar la monarquía en Roma y del asentimiento de sus compañeros de aventura ${ }^{59}$. En ningún texto se documenta que Rómulo fuera nombrado rey de Roma en su calidad de heredero del reino de Alba. ¿Era realmente Rómulo el heredero del trono de Alba? En base estrictamente antropológica debemos dejar asentado que en los reinos del Lacio la corona se heredaba por línea masculina. Sabemos, en clave meramente legendaria, que los hijos de Numítor fueron asesinados por Amulio. Pero, ¿correspondía entonces de verdad, siquiera el reino de Alba Longa, a los hijos de Rea Silvia? Hay quien lo ha puesto en duda (y ha sugerido por tanto que aquí sí, con la vista puesta en los usos etnológicos, nos hallaríamos ante un dato meramente legendario) ${ }^{60}$. Correspondiese o no a Rómulo y Remo el heredar el trono de su abuelo materno Numítor, no hay constancia de quién sucedió a Numítor

59 Los autores del relato tradicional se abstienen de mencionar cualquier rito o proceso de legitimación del poder regio por Rómulo. Tito Livio es sobrio en la forma de dar por hecho el carácter monárquico del poder de Rómulo, una vez consumado el ceremonial de fundación de la Urbe, y tras la eliminación física de Remo: Ita solus imperio potitus Romulus, «así Rómulo se apoderó él solo del mando» (T.LIV. $\mathrm{I}, 7,3)$. Cicerón se ajusta a los mismos contenidos, aunque en términos más civilizados: Quorum copiis cum se ducem praebuisset, «como quiera que él se ofreció como jefe a tales fuerzas» (es decir, a los pastores que acompañaban a Rómulo y Remo en los terrenos de Fáustulo); aequo animo libenterque illi parerent, «y ellos le obedecieron con ánimo.justo y de buen grado» (CIC. Rep. II,2). Dionisio de Halicarnaso es, por el contrario, largo y explícito en presentar el acceso de Rómulo a la monarquía de Roma como una elección en toda regla (DION.HALIC. 2, 3,8-5,1).

60 Los temores de Amulio a una posible descendencia masculina de Rhea Silvia son incompatibles con los usos hereditarios de Roma en época histórica. «En el caso de que Rhea Silvia se casara y tuviera un hijo varón, ¿en qué podría el niño obstaculizar los planes de Amulio reclamando para sí la sucesión de Numítor, dado que un nieto no podía nunca ser el heredero de su abuelo materno? Para entender la conducta de Amulio, habría que tomar en consideración un sistema de sucesión regia en que el poder fuera transmitido por las mujeres...» (Michel J.H., Mariage romain et ethnologie française, 1979, p. 109; citado en J. Poucet: 1985, p. 112). 
en Alba, y, desde luego, no consta que Rómulo fuera constituido en rey de Roma en cuanto heredero de Alba. En ese caso el trono de Alba se hubiera anexionado al de Roma, lo que va contra los datos del relato analístico. Decenios después, en tiempos de Tulio Hostilio, Alba está constituida como una polis independiente de Roma. ¿Bajo el poder de un rey soberano? El relato no es muy explícito. Cuando surge entre romanos y albalonganos el conflicto que habrá de acabar con el combate entre Horacios y Curiáceos, Tito Livio nos remite a Alba con estas palabras: Imperitabat tum C.Cluilius Albae, «mandaba entonces en Alba Cayo Cluilio» (T.LIV. $\mathrm{I}, 22,4)$. Todo nos lleva a deducir que Cluilio ejercía la potestad regia, pues el relato lo trata en paralelo a Tulo Hostilio. Y no se trata de un Silvio. Henos, pues, aquí con que, al morir Numítor sin descendencia, la monarquía albana fue heredada por una nueva estirpe...

Si, como hemos tratado de probar, la monarquía de Rómulo en Roma no es mera continuación de la monarquía albana, tal monarquía surge de un acto de libre albedrío del propio Rómulo o de los compañeros con los que fundó la nueva ciudad. Hay que probar, entonces, por qué esa nueva monarquía instaurada no continuó siendo una monarquía hereditaria como la albalongana. En ninguna parte del relato histórico tradicional se nos dice que fueron los senadores quienes, en nombre de las curias, quisieron recuperar la autoridad regia - que ellos no habían legado a Rómulo - y decidieron, por su propio arbitrio, hacer elegible el trono que había dejado Rómulo. Carandini (2006:356) quiere que sea la aristocracia senatorial la que, en el momento de la creación de la monarquía romúlea, cedió a Rómulo el poder colegiado de los senadores, dispuestos a recuperar el poder regio — simbolizado en los auspicios- a la muerte de Rómulo y a usar tal poder y autoridad en el interregnum para elegir al nuevo rey. Cicerón quiere que la monarquía post-romúlea sea hereditaria por decisión del pueblo — sabio ya entonces, aunque agreste-, que «por deseo de Rómulo» no cejó de pedir un nuevo rey y encargó a los senadores de elegir un sucesor de Rómulo (Numa) que destacase «por su virtud y su sabiduría», a pesar de la voluntad expresa de los senadores de abolir la monarquía (CIC. Rep. II,12). Pero es claro que Cicerón usa el dato — de cuya procedencia no nos informa- para exaltar la constitución política de Roma y encumbrarla por encima de la constitución que Licurgo dio a Esparta, en la cual se conformó con que los titulares de la diarquía espartana fueran descendientes de Heracles.

Según Dionisiso de Halicarnaso, son los propios compañeros de Rómulo los que lo eligen y nombran rey inmediatamente después de fundar la Urbe (DION.HAL. 2, 4,1-2 y 5,1). Lo que no precisa Dionisio es si el nombramiento de Rómulo es a título personal o implica la creación de una nueva dinastía y, por tanto, de una monarquía hereditaria. Pero en este punto es preciso echar mano de un dato, que pocas veces - quizá nunca - se tiene en cuenta y que tiene una trascendencia básica para la sucesión de Rómulo: la tradición analística no menciona nunca un hijo y posible sucesor de Rómulo. Dionisio de Halicarnaso se limita a decir lo siguiente: «Rómulo, tras fundar Roma y ser nombrado por ella rey, alcanzó la muerte sin dejar descendencia, después de haber reinado durante treinta y siete años, a los cincuenta y cinco años de edad, pues obtuvo el poder cuando era muy joven, a los dieciocho años, como todos los escritores de su historia ratifican» (ibid. 
$2,56,7)$. El dato no puede ser fruto de una mera desidia en el relato tradicional, si se piensa, por ejemplo, en el caso de Julo y en el alcance de las pretensiones dinásticas (véanse los Julios) en la tradición romana. El dato sólo se explica si tiene una sólida base histórica. Si el dato tiene base histórica, explica al menos que tras la muerte de Rómulo sin descencia, el paso a una monarquía electiva, al menos por el momento, fuera un cambio político ineludible al margen de cualquier movimiento político por parte de la aristocracia senatorial. $Y$ explica, y aun hace necesario, lo que sigue en Dionisio: «Al año siguiente no fue nombrado ningún rey por los romanos (el subrayado es evidentemente mío). Se ocupaba de los asuntos públicos un gobierno que llaman interregno (designado entre los patricios inscritos en el Senado por Rómulo)» (ibid. 2, 57,1). Ante la nueva situación, la falta de un sucesor el trono, no había más remedio que replantearse la forma de gobierno: «Entonces los senadores convocaron al pueblo... y pusieron a su consideración... si querían confiar los asuntos públicos a un rey o a magistrados anuales. El pueblo no hizo la elección por sí mismo, sino que remitió la decisión a los senadores... Todos decidieron establecer un régimen monárquico...» (ibid. 2, 57, 3-4).

Debemos concluir, pues, que el relato canónico no es ni claro ni concluyente en cuanto a la situación del trono de Roma a la muerte de Rómulo. ¿Se pasó a una monarquía electiva por decisión pactada por el pueblo y los senadores, o simplemente se pasó a elegir - de forma provisional o definitiva - un nuevo rey, porque Rómulo había muerto sin sucesor? La respuesta, que queda en suspenso, no es baladí, pues de ella dependería el que quedara pendiente un ritual funerario de transmisión del poder regio, bien al descendiente del rey (en aquel momento fallido, pero posible en el futuro), o bien al nuevo rey electo.

\subsubsection{Ritual de transmisión del poder regio}

Como ya antes han puesto de manifiesto diversos autores, como Schwegler y Burkert (véase supra), algunos elementos — quizás el total- del relato de despedazamiento de Rómulo permiten reconocer facetas de un antiguo ritual de transmisión del poder regio. Ya han sido citados (ver supra) estudios antropológicos al respecto. De todos esos estudios se puede deducir que: $y$ ) sea por comparación con el trocear de la simiente, yy) sea por comparación con el ritual de momificación del faraón, yyy) sea por eliminación (cremación?) del elemento mortal de Pandora, el despedazamiento del rey significa una apropiación de la inmortalidad. El rey se perpetúa en su sucesor, en el que sobrevive (y en toda la saga o dinastía), a la vez que z) elevado al cielo, por medio de su apoteosis, cuida de su dinastía y de su pueblo.

\section{Rey y ciclo del trigo}

En este apartado de nuestro trabajo vamos a poner en práctica un método comparativista moderado y razonable. Un preámbulo metodológico sobre el comparativismo antropológico resulta imprescindible. No creemos en un comparativis- 
Muerte, desplazamiento y apoteosis de Rómulo: un estudio sobre la realidad...

mo que se limite a sacar conclusiones de meras coincidencias en detalles aislados. Sólo podemos interpretar según el mismo paradigma dos fenómenos antropológicos cuando coinciden en tantos detalles cuantos son necesarios para formar un mismo sistema o estructura.

Debemos partir de que a comienzos del primer milenio antes de Cristo, en el que está situada la labor fundadora de Rómulo y su hipotético carácter regio, en el Mediterráneo predominaba la cultura procedente de Egipto. En ese sentido asentamos aquí como un principio metodológico las palabras de Angelo Brelich a propósito de la religión micénica, cuya vigencia nosotros ampliamos hasta el último período lacial:

«Con la difusión de las formas superiores de civilización, que, a partir de Mesopotamia y Egipto, en cualquier parte que arraiguen, llevan a nuevas y originales síntesis, surgen las religiones politeístas, igualmente diferentes entre sí, pero definidas por comunes principios estructurales»61.

La teología funeraria de Egipto — la llamada teología menfita - aplicada a la muerte del faraón y a la pervivencia de la dinastía faraónica puede enunciarse así: Osiris es asesinado por su hermano Seth, quien despedaza su cadáver (Plutarco) y lo deja expuesto a la putrefacción. Pero entonces la diosa Isis, hermana y esposa de Osiris, recompone sus miembros, reanima con su magia al impotente y concibe de él un hijo: Horus, el hijo de Osiris, venga a su padre derrotando a Seth y recupera el trono paterno. Toda esta teología funeraria de Egipto estaba relacionada con el destino del Faraón. El Faraón muerto es identificado con el Osiris mítico. Como en el caso de Osiris, nada acaba con la muerte del Faraón: Su hijo, el nuevo Faraón, es Horus, el hijo de Osiris, que venga simbólicamente la muerte de su padre. Mientras su padre, el Faraón muerto, asciende al cielo y se incorpora al ciclo solar catasterizado, el hijo real restaura el orden asegurando la continuidad en el trono.

El misterio del destino del Faraón muerto viene simbolizado en el grano de trigo. El trigo se identifica con Osiris y el ciclo vital del trigo simboliza el destino regio. Osiris, como el trigo, es desmenuzado y entregado a la tierra, pero no muere allí sino que reaparece en el trigo nuevo de la nueva cosecha ${ }^{62}$.

61 A.Brelich 1967, «Religione micenea: Ossevazioni metodologiche»; Atti del I Congresso Internazionale di Micenologia, Roma (Marazzi, M. editore, La societa micenea. Editori Riuniti [trad. castell. «La sociedad micénica», de M. Bayo, Akal 1982].

62 Henri Francfort (1948) lo ha explicado en un capítulo de su obra dedicado al Misterio de la Sucesión. El Texto Dramático de Sethe es un manuscrito en el que se dramatiza la subida al trono del faraón Sen-Usert I. La obra está fechada hacia el año 1900 a.C. y es una copia de la representación que se hacía para la subida al trono de cada nuevo rey. Una de las escenas representa la trilla; el grano de trigo es la manifestación de Osiris, que es pisoteado y golpeado por sus enemigos (los agricultores cumplen aquí la función de Seth) (Francfort 1948:150). En otra escena el nuevo rey, como Horus, recibe el espíritu del poder regio (el $\mathrm{ka}$ ) de su padre muerto, cual Osiris: «El poder divino de la realeza inmanente al antiguo gobernante es transferido a su sucesor» (ibid. p. 156). En el epígrafe dedicado a «Osiris en los cereales» (ibid. pp. 207-212) se pone de manifiesto lo que por su parte es el destino del Faraón muerto. En los textos de las Pirámides abundan los conjuros en que Isis y Nephtys, Horus y Nut $<<$ unen $>>$ los miembros de Osiris muerto (ibid. p. 223). Un texto de las Pirámides combina la identidad del rey muerto y Osiris, y su deseo de supervivencia personal. Osiris es el trigo, pero no muere en la tierra, sino que sube al cielo en las nubes de menuda paja que se levantan al aventar el grano: «Osiris es Unas (el faraón aquí aludido) en el barcia que sube al cielo...Unas va de camino al cielo con el viento» (Pyr.308-9). 
En larga historia de la hermenéutica del despedazamiento y apoteosis de Rómulo muchos y diversos autores han detectado paralelos evidentes entre la suerte de Osiris y la suerte de Rómulo-Quirino representada por el grano de cereal u otros frutos de la tierra. Frazer (1900) fue el primero, en tiempos contemporáneos, en unir la suerte de Rómulo a la de Osiris: Rómulo, primer rey de Roma, fue despedazado el 7 de Julio (ver la fecha en los «Fastos» de Ovidio) con ritos aparentemente conectados a la fecundidad artificial de la higuera (no olvidar la higuera Ruminal como símbolo y causa del carácter terrígena de Rómulo) (Frazer 1900 [1992] p. 431). Brelich (1960) intuyó la asociación que puede establecerse entre Rómulo-Quirino y la suerte de Osiris en el grano de trigo. Brelich considera a Quirino en origen una divinidad agraria. Como demuestran las funciones a las que está ligado el sacerdote de Quirino, el flamen Qurinalis, el dios está relacionado a la maduración, la recolección, la trilla y el almacenamiento del grano de trigo. Igualmente Quirino, a quien se dedican las fiestas llamadas Fornacalia, está ligado a la torrefacción del trigo (il farro), que una vez tostado supera el trance de la pudrición y pasa a un estadio que lo asimila a la inmortalidad ${ }^{63}$.

¿Cómo correlacionar la suerte del trigo con la suerte post-mortem del faraón?, ¿y cómo correlacionar paralelamente la suerte del trigo con el destino post-mortem de Rómulo convertido en Quirino? Precisamente en los «Fastos» de Ovidio, a las fiestas de Quirino en el 17 de Febrero, las Quirinalia (II, 475-512), donde el autor narra el desmembramiento (con la consiguiente muerte) de Rómulo, luego convertido en Quirino, se superponen «en días no fijos» las fiestas Fornacalia, en las que se conmemora la recolección, trilla y tostado del farro, el trigo de que se obtiene la harina para el pan (II, 512-532). Se veneran en los mismos días (!) los Manes de los muertos; las espigas de trigo (v.538) que se ofrecen a los difuntos, no pueden por menos de ponernos en contacto con Osiris y con el simbolismo de resurrección que corresponde al ciclo del trigo.

Incluso los autores que identifican el despedazamiento y apoteosis de Rómulo a la luz de paradigmas muy diferentes al nuestro, no dejan pasar inadvertido el paralelismo del destino del Osiris-cereal con la transformación de Rómulo en Quirino simbolizada en el misterio del farro. Como la muerte de Osiris y su transformación en Horus, la apoteosis de Rómulo en Quirino simboliza en la persona del fundador de Roma el destino del rey. Para Carandini (2006) los Quirites ritualizan la unión de las 30 curias de Roma «consumiendo el farro representado por el rey despedazado, enterrado (=sembrado) y divinizado ${ }^{64}$. El paralelismo se enriquece

63 Ver la crítica de Momigliano 1963:110 n. 63. y el relanzamiento de la tesis de Brelich con algunas modificaciones en Coarelli,F. 1983:188-189 y 192. El desdoblamiento de personalidad entre el grano despedazado (Rómulo) y el grano que renace (Quirino) ha sido dotado de una explicación, acorde a su tesis, en Carandini (2006): «Quirino, divinità agraria, aveva in origine un mito di morte (e di sbranamento) che lo colegava al farro...; a demitizzazione avvenuta, il colegamento con farro gli è restato, mentre il tema dell'uccisione e dello sbranamento gli è stato sostrato ed è stato trasferito sul personagio 'storico' Romolo" (Carandini 2006:393).

64 "Consumendo il farro, rappresentato anche dal re smembrato, seppellito (=piantato) e divinizzato, I Quirites se affratellano in una sorta di communione collettiva, organizzata per gruppi, collegata ... a un progetto civico... 30 curie» (Carandini 2002: 205s.). 
Muerte, desplazamiento y apoteosis de Rómulo: un estudio sobre la realidad...

con la gemelaridad Rómulo/Remo puesta en relación con la pareja de hermanos Osiris/Set, que como en el caso de los gemelos romanos termina con el asesinato de uno de ellos ${ }^{65}$.

Lo que realmente importa en el ciclo del grano es ver en él la ritualización del destino del rey. Lo que en los años 60 Angelo Brelich puso de manifiesto en relación al destino de algunos grandes personajes dema, cuyo despedazamiento y cuya siembra estaba destinada a asegurar la fertilidad de los campos y de las cosechas, Dario Sabattucci ha querido ponerlo en los años 80 más en relación con el destino del rey. Como los campos, es el faraón primeramente en la teología menfita, y luego el rey en la tradición greco-latina el que se renueva cíclicamente al renacer en cada uno de sus descendientes que forman parte de la dinastía.

Rey y sucesión dinástica: Osiris, Dioniso, Quirino

Rómulo despedazado es el dios (Osiris) que muere; en buena lógica el Quirino resultante de la apoteosis de Rómulo es el nuevo rey (Horus), que como el farro representa el futuro de la dinastía y de su pueblo (que por él es alimentado).

En esa dirección hay que tratar hermenéuticamente las alusiones al desmembramiento y apoteosis de otros héroes (-dioses) de la mitología clásica. Entre éstos destaca Dioniso. Ya a Brelich (1960) no le pasaba inadvertido el destino de Dioniso, pisado y desmenuzado en la uva generadora del vino, de la misma forma que otros grandes fundadores de civilización antiguos, caracterizados por Brelich —siguiendo a Jensen- como demas, o personajes extraordinarios, mágicos, míticamente elaborados en el contexto de civilizaciones politeísticas superiores. ¿Por qué en el caso de estos héroes divinizados, apoteosizados como Rómulo, surge siempre la contradicción entre en dios que muere y renace cíclicamente, a pesar de la inmortalidad que estatutariamente corresponde a los dioses? Algo tiene que ver con la suerte de la persona del rey y su dinastía que se renueva cíclicamente.

Dioniso es un dios cuyo carácter regio es puesto de manifiesto, más y más, progresivamente. Incluso los autores que interpretan el despedazamiento y apoteosis de Rómulo a la luz de paradigmas muy diferentes al nuestro, no dejan pasar inadvertido el paralelismo del destino de diferentes divinidades egipcias y griegas con la transformación de Rómulo en Quirino. Así sucede también en el caso de Dioniso. Carandini lo ha puesto en evidencia con palabras que vamos a recordar en su tenor literal: En el mito de Dioniso la muerte por despedazamiento es el presupuesto de su resurrección (CARANDINI 2002: 204). Pero, como vamos a tratar de poner de manifiesto, esa resurrección no carece de relación con el destino del rey. Dioniso, en efecto, es rey. Podemos rastrear las huellas de tal afirmación tanto a nivel histórico (a), como a nivel mítico (b).

65 «Set ... Osiride ...(questa lotta tra gemelli ricorda ... quella fra Remo e Romolo. (...) Osiride sepolto equivale al seme sepolto nella terra, tanto che durante la semina venivano sepolte nei campi effigie di Osiride. (...) $\dot{E}$ possibile che in epoca preistorica gli stessi re recitassero il ruolo del dio e venissero uccisi e smembrati» (Carandini 2002:212). 
a) Dioniso, rey de Atenas. A propósito de Rómulo, «despedazado como un héroe o como un dios", Carandini (2006:320) menciona a Dioniso y su probable conexión con la monarquía de Atenas. Es posible, recuerda Carandini (2006:315) que el rey de Atenas fuese identificado con este dios. Los indicios de esta función regia de Dioniso puede rastrearse ya en edad alto-arcaica. No faltan datos de carácter arqueológico. Textos que pueden reflejar estratos más antiguos del folklore regio ateniense presentan a Dioniso como el fundador (?) y, seguramente, el renovador de la dinastía regia de Atenas. Su culto parece ineludiblemente conectado a la mansión ateniense del «arconte rey» (CARANDINI 2006:56). El basileionboukoleion puede ser caracterizado arqeueológicamente como sede de los reyes de las tribus de Atenas, del arconte rey y quizá del culto regio de Dioniso (ibid., p. 62). En el Boukoleion la esposa del arconte rey (= Ariadna) se unía anualmente a Dioniso en una forma de matrimonio sagrado (ibid. p. 76). Dado que el ritual se celebraba en el Boukoleion (literalmente «mansión del pastor de toros») y dado que era habitual la identificación de Dionsio con el toro - icomo Osiris!-, la unión del arconte rey y de su esposa podría fácilmente interpretarse como una repetición de aquellas hierogamias que en el mundo antiguo estaban meramente dedicacas a simbolizar y ritualizar la fecundidad y la fertilidad de la naturaleza, incluyendo a las mujeres y los campos. Pero en el caso del boukoleion de Atenas esta hierogamia va más allá. Como dice literalmente Carandini, en el caso del arconte rey "se trata de la pareja divino-humana que engendra reyes» (ibid.). Para entender el sentido histórico de tal acontecimiento ritual, hay que remontarse mitológicamente al momento fundacional del encuentro de Dioniso y Teseo en la isla de Naxos. Ariadna, la hija de Minos y hermana del minotauro de Creta, que había ayudado a a Teseo en su aventura del Laberinto, es abandonada por el príncipe ateniense Teseo (a la vez mítico refundador de Atenas e hijo de Egeo, primer rey de la ciudad), cuando dormía en la playa de Naxos; allí es desposada por el dios Dioniso, que venía desde Oriente en su ruta de regreso hacia Tebas. Pausanias $(1,3,1)$ en el siglo II sigue aún testimoniando que Ceramos, epónimo del barrio Cerámico de Atenas, fue el fruto de los amores de Dioniso y Ariadna. Este acontecimiento inaugura un matrimonio sagrado, en el que Dioniso y Teseo parecen intercambiarse mutuamente el estatuto de reyes de Atenas y consortes regios de Ariadna (la reina). Nos sumamos a la conclusión que de todo ello obtiene Andrea Carandini: «En Atenas el papel de procreador de los príncipes de sangre real corresponde a Dioniso" (CARANDINI 2006:56).

b) Dioniso, el hijo de Semele. Zagreus. El farro de Quirino. Pero el paso importante a dar es que a Dioniso en Atenas corresponde no sólo el papel de generador del nuevo rey en el aspecto biológico, sino el de regenerador de la potestad regia a la muerte del viejo rey. Dicho de otro modo, Dioniso genera al nuevo rey no sólo en la carne, sino - lo que es más importante- también en la dignidad regia ${ }^{66}$. Esta dualidad estatutaria del carácter regio de la persona del rey está crípticamente expresada en el mito del doble nacimiento de Dioniso:

${ }^{66}$ Un ejemplo de esta dualidad puede estudiarse en el caso de Heracles: ....en el mito de la Vía Láctea (apoteosis en la carne) ... y en la leyenda de la pira del monte Oeta... 
Muerte, desplazamiento y apoteosis de Rómulo: un estudio sobre la realidad...

b’) En el prólogo de su tragedia, en las «Bacantes», Eurípides nos ha dejado constancia de la incardinación de Dioniso en la antigua saga regia de Tebas. Dioniso está enraizado en la dinastía cadmea como hijo de la princesa Semele, hija mayor de Cadmo. Aún más, Dioniso está destinado a fundar una nueva estirpe como hijo directo de Zeus y de Semele. Su mayor parentela con Zeus -el dios que funda la soberanía - se significa en el mito por el hecho de que Dioniso nace directamente del muslo de Zeus, que recoge el feto aún inmaduro de Baco del vientre de Semele herida de muerte por el propio rayo de Zeus.

b") Al mito de este primer nacimiento de Dioniso —nacimiento a la sangre dinástica- se añade el mito de su segundo nacimiento, que hemos anticipado como nacimiento a la dignidad regia. Más que la dignidad regia de Dioniso como rey de Atenas encontramos testimoniado el destino de Dioniso a un reino futuro: el reino del cielo y el reino de las ciudades griegas en el período helenístico. Fueron los órficos quienes crearon el mito de Dionysos Zagreus y su destino al trono del cielo: Un segundo Dioniso (que en algunos relatos se mitifica como concebido de Zeus y Perséfone $)^{67}$ es despedazado por los «pérfidos» Titanes, que según reza una interpretación órfico-tardía, querían impedir su acceso al trono ${ }^{68}$.

Es claro que la tradición órfica no tenía más que recoger toda la mitología que de forma equívoca, como más abajo veremos, desarrollaba en un sentido maléfico el tema del despedazamiento ritual (diasparagmòs). Eran conocidos los antiguos relatos referidos a Licurgo, a Penteo, a Pelias y, lo que afectaría más a los órficos, al mismísimo Orfeo. Licurgo, rey de Tracia, y sobre todo Penteo son castigados por oponerse a las delirantes y frenéticas ceremonias del ritual báquico. Licurgo maltrata y expulsa de Tracia a Dionisos Bacchos, que venía desde la India a Grecia con la firme intención de instaurar sus sagrados misterios; Licurgo es milagrosamente enloquecido (¿manía dionisíaca?) por Baco, que le hace perecer despedazado por sus propios caballos ${ }^{69}$. Penteo, regente de Tebas, perteneciente como el mismo Baco a la dinastía regia de Cadmo, es despedazado por las hermanas de Sémele, que lo identifican con un cachorro de león, posible víctima del diasparagmòs dionisíaco. El descuartizamiento de Penteo constituye, como es sabido, la trama de la tragedia de «Las Bacantes» de Eurípides. Pelias, rey de Yolco en Tesalia, sufre la venganza de Jasón, que — por medio de las artes mágicas de Me-

67 La distinción entre Semele y Perséfone puede paliarse si se atiende al dato, ofrecido por la tradición mitográfica, de que ambas son personificaciones de la Tierra. En cuanto a Perséfone-Tierra baste recordarse su filiación a partir de Deméter, la madre Tierra. En cuanto a Semele y a su identificación con la Tierra-Koré, ver HARRISON 1903:404 y HARRISON 1911:91 y 168.

${ }_{68}$ La tradición oficialista olímpica (y de ella la tradición cristiana) había recogido el episodio destacando, como es natural, la forma criminal y, sobre todo, subrepticia de conducirse los Titanes con respecto al futuro rey: La diosa Hera, irritada por los amores adulterinos de su esposo Zeus con Perséfone (o con la misma Sémele), preparaba asechanzas contra el niño Dioniso, destinado al trono (de Atenas o) al trono celeste, y, llegado el momento oportuno para ponerlas en práctica, coloca a los Titanes, satélites suyos, en el interior del palacio y les encarga hacer regalos al niño, para que, colmados sus caprichos infantiles, pudiera ser conducido al lugar de las asechanzas en las desiertas estancias reales (FIRMICUS MATERNUS, De errore profanae religionis, 6, O.F. 214). Ver también CLEM. ALEX. Protrept. II,17,2-18 (O.F. 34).

69 El relato es conocido ya por Homero (II. VI, 130-140) y por Sófocles (Ant. 955-965). 
dea - impele a sus hijas, las Pelíades, a trocear a su padre y a hervirlo en un caldero con la fallida intención de sacarlo de allí rejuvenecido ${ }^{70}$. Y el mismo Orfeo, decidido a no amar a otra mujer tras la definitiva pérdida de su adorada Eurídice, sufre también en Tracia el rencor de las mujeres Basárides que lo descuartizan a dentelladas como a una víctima más del diaparagmòs báquico ${ }^{71}$.

El mito órfico de Dionysos Zagreus es un mito tardío. Pero en diferentes pasos, en sucesivos estratos de la tradición mitográfica (tanto a nivel sincrónico como diacrónico), se deduce que precisamente tal rito de despedazamiento debía entenderse como una condición de la sucesión regia. El mito de despedazamiento de Dioniso por los Titanes se carga de un sentido fisiologizante: El vegetal simbolizado no es el cereal, sino la vid, el vino. Sin duda, aquí, como en el caso del cereal, del farro que simbolizaba a Quirino en las fiestas Fornacalia de Roma, se pone de manifiesto el aspecto positivo que el despedazamiento tiene. Diódoro Sículo, ya en el siglo I a.C., describe los diferentes nacimientos de dios «physiológicamente» identificado con la naturaleza diciendo a propósito del que él llama tercer nacimiento o génesis: «el dios nacido de Zeus y Deméter fue despedazado $(\delta 1 \alpha \sigma \pi \alpha \sigma \theta \eta v \alpha \mathrm{l})$ y cocido ( $\kappa \theta \varepsilon \varepsilon \psi \varepsilon \theta \eta v \alpha \mathrm{l})$ por los hijos de la Tierra $(\eta \gamma \varepsilon v \varpi v)$ y, habiendo sido articulados otra vez sus miembros por Deméter, renació otra vez desde el principio» (DIOD. III,62 $<$ O.F. 301>). Según Diódoro, los mitógrafos aplicaban estos relatos a ciertos procesos físicos: Evidentemente el despedazamiento de Dióniso se refiere al acto de cortar y pisar las uvas y la cocción hace alusión a la fermentación y maduración del mosto; la labor armonizadora de Deméter define los pasos que sigue el vino de lágrima en su tránsito por el lagar y los toneles, que dan al vino su esencia definitiva.

Esta representación fisiológica del mito de Dioniso en clave agrícola hace patente el sentido creador y benéfico que en el proceso funerario, como en el de la vinificación, pueden tener las operaciones de «descomposición» y de «recomposición». Los hijos de la tierra de la versión fisiologizante del mito se corresponden con los Titanes de la versión teomórfica $(\sigma \omega \mu \alpha \tau o t \delta \eta \theta \varepsilon \varpi v$, DIOD. III,63) en el propio Diódoro y en el resto de la tradición mitográfica. $Y$ es evidente que esos terrígenas o agricultores ( $\gamma \varepsilon \rho \rho \gamma \varpi v$, DIOD. III,62,7 <0.F. 301>), que despedazan y cuecen al dios del vino, no son malditos agresores ni asesinos, sino fraternales amigos de Baco, al que conducen a bien morir, para renacer a la vida que Deméter, la Tierra, le ha proporcionado.

Ahora bien, tanto en los relatos acerca de Osiris, cuanto en los relatos acerca de Dioniso, hemos de afirmar que su aspecto funerario y su a aspecto agrícola son facetas de un mismo tema mítico, como sucedía en Roma a propósito de RómuloQuirino en el paso sin solución de continuidad desde las fiestas Quirinalia a las Fornacalia. Las peripecias agrícolas del grano (Osiris, Perséphone, Qurinus) y de la vid (Dionysos) no son sino el reflejo de su propio ciclo funerario, y viceversa, en su

70 La muerte de Pelias es relatada sólo a partir del período helenístico: DIOD. SIC. VI,53; APOLLOD. I,9. Pero el despedazamiento de Esón, padre de Pelias, es aludido en EURIP. Med. p. 137, 12-16 Schwartz; y una representación del «asesinato» de Pelias por sus hijas, las Pelíades, en un mármol de Pentélico, datable en época clásica, se conserva en el Museo Lateranense de Roma.

${ }^{71}$ El testimonio más antiguo en ERATOSTH. Catast. 24. 
Muerte, desplazamiento y apoteosis de Rómulo: un estudio sobre la realidad...

doble vertiente de muerte y regeneración perpetua. Así lo aclara el propio Diodoro (III,62,8 <O.F. 301>) protestando en tal sentido que él no ha inventado nada acerca de Dioniso por seguir el modelo egipcio, sino que todo lo que él dice «está de acuerdo con los poemas órficos y lo que se celebra en los ritos iniciáticos (teletàs), sobre los cuales no se puede contar más detalles a los no iniciados". No es que los comentaristas griegos identificaran por su cuenta arbitrariamente a Dioniso con el Osiris griego. Sucede otro tanto a la inversa. Ya Heródoto $(I I, 42)$ nos informa de que los egipcios de su tiempo (ca. 500 a.C.) identificaban a Osiris con el Dioniso griego, un dios despedazado, que pasaba al mundo de los muertos y a la vez era llamado a una nueva vida.

c) Las Pelíades. El natron de Egipto. Diríase que toda la labor de embalsamamiento se concibe como un proceso dedicado a devolver mágicamente al cadáver la vitalidad que había perdido, es decir, a operar una reconstitución del difunto. Ahora bien, la teología funeraria egipcia realizaba en este punto una sutil distinción entre la labor ejercida por Isis, a quien competía «la reunión de los miembros", y la labor ejercida por su madre Nut, a quien competía la revivificación del difunto. El renacer era para los egipcios el único camino para la inmortalidad. Por eso, es natural que la fe en la inmortalidad se fundamente en Egipto, como en Creta y en Grecia, con los mitos de renacimiento cíclico en la naturaleza (el grano, la vid). Y, dada la asimilación de la leyenda Osiriana al ciclo solar a partir de la V Dinastía $^{72}$, el renacimiento en la madre se combina muy frecuentemente con el tema del circuito solar y la transformación de Osiris se da sobre todo cuando éste se eleva con el Sol naciente ${ }^{73}$. Y, dado que el circuito celeste pasa por la tierra (con el sol que muere) y sube al cielo (con el sol naciente), parece natural que sea la diosa Nut, el Cielo, la que asume el papel preponderante en este renacer, que en categorías griegas prehelénicas corresponde más bien a la diosa madre identificada con la Tierra, madre de todos los seres chthónicos. Si Nut es representada como vaca, el transfigurado es concebido como «becerro de oro, nacido del Cielo» (Pyr. 1028-30). Por otro lado, de Osiris muerto nace, en unión mágica con su hermana Isis, un hijo póstuno, Horus, que es la verdadera reencarnación del ka (hálito vital) de Osiris en la tierra (en el nuevo Pharaón), mientras su ba (alma individual) recorre el país de los muertos.

¿No es esta misma revitalización del carnero Ammón-Osiris, identificado con el faraón muerto, que renace como becerro rejuvenecido en nuevo faraón, Horus, la que sucede en el caso del caldero a cuyos efectos mágicos Medea invita a las Pelíades? El anciano Pelias, padre de las Pelíades, sufre la venganza de Jasón muriendo cocido en la versión novelada (más reciente) del mito del caldero. Pero Medea había dado antes una prueba de la eficacia del caldero de inmortalidad rejuveneciendo a diferentes seres, entre otros un viejo carnero que sale del agua hirviendo resucitado como un tierno corderito. Entre los experimentos que Medea realiza, para convencer a las hijas de Pelias (perversamente, en la versión desfi-

\footnotetext{
72 Jacques Pyrenne. Historia de la civilización del Antiguo Egipto. I, Barcelona 1971, p.114 s.

73 «Has venido a ser, estás en lo alto, has sido transformado» (Pyr. 207-212). «Sales en el lado oriental del Cielo, renovado en tu tiempo, rejuvenecido en tu hora» (Pyr. 882-883).
} 
gurada del mito) de la eficacia del ritual, se incluye -además de la cocción e inmortalización de Esón, padre de Jasón $-{ }^{74}$ un relato en que son precisasmente las nodrizas de Dioniso (a quien estará unido indeleblemente el ritual del caldero de inmortalidad) las que son cocidas o rejuvenecidas ${ }^{75}$. ¿No queda así reflejada y confirmada la versión más antigua (ritual) del mito? No faltan indicios de que el caso de Pelias el ritual del caldero conseguía una verdadera «daemonización» del troceado anciano. En ese sentido debe ser valorada la noticia de que se celebraron unos juegos funerarios en Yolco (o en Corinto) en honor del difunto Pelias ${ }^{76}$. Es claro que el testimonio de Estesícoro demuestra que la propaganda oficial no pudo borrar totalmente el recuerdo de los efectos inmortalizadores del caldero. Por eso, es justa la sorpresa de los mitólogos que no pueden explicarse la presencia en los juegos de aquéllos a quienes la tradición olímpica calificaba de asesinos de Pelias (APOLLOD. V,17-10): Jasón entre los participantes en la lucha; como espectadoras las mismas hijas de Pelias; y como organizador de los juegos Acasto, a quien precisamente la versión oficial tachaba de haber aprovechado el engaño por Medea de sus hermanas las Pelíades, para acceder al trono de su padre. "Sin embargo - como dice Ruiz de Elvira (1975:292)—, no hay noticias de que Pelias muriera de otro modo».

El episodio de los juegos en honor de Pelias demuestra que el despedazamiento (y la posterior cocción) de un rey podían ser interpretados de forma constructiva, y no como un crimen. Caminamos, pues, en la misma dirección que Tito Livio y que Ovidio, cuando consideraban oscuro o falso que Rómulo hubiera sido descuartizado criminalmente. La eficacia del despedazamiento y del caldero de inmortalidad hemos de investigarla en dirección de Osiris y de Egipto.

El recurso técnico fundamental de la momificación egipcia era la sustracción de la humedad del cadáver. Al parecer ya en la época de la III Dinastía, al inicio de la época de las Pirámides, antes de que se desarrollara la leyenda de Osiris, todo el ritual funerario se reducía a la extracción de las vísceras, "que eran lo primero que se corrompía» (BLÁZQUEZ 1984:61), por lo que se las reemplazaba con bandas de resina. Luego fueron añadidos nuevos pasos en el ritual funerario, hasta llegar a la sofisticación técnica del embalsamiento de Amenophis III, en el que culmina todo el proceso de momificación, tal como lo describe por ejemplo Heródoto $(I I, 86)$ en el siglo $V$ a.C. El historiador griego cuenta cómo la disección de las entrañas sólo se hacía en los embalsamamientos más caros (inicialmente sólo en el del faraón). El proceso de deshidratación se hacía introduciendo al muerto en un baño de sosa cáustica o natron, que se mantenía durante setenta días. Cocido por la sosa, el ca-

74 Nostos fr. VI Allen ap. Argum. EURIP. Med. p. 137, 12-Schwartz, y schol. ARISTOPH. Equ. 1321. Precisamente en este último texto la broma aristofánica de cocer al «Demos» para devolver a la Democracia su vigor juvenil demuestra que en tiempos del poeta cómico aún se podía imaginar la utopía del caldero de inmortalidad.

75 AESCHYL. Nodrizas de Bacchos fr. 56 Nauck (426 Mette).

76 El primer testimonio sobre los juegos funerarios en honor del «inmortalizado» padre de las Pelíades se remonta ya a Estesícoro, que floreció alrededor del 590 a.C. (STESICH. fr. 176-178 Page, ap. Etym.Magn. 544,54, y ap. ATHEN. IV, 17,9-10), según el cual en tales juegos participaron Cástor y Pólux en la carrera hípica, Amphiaraos en el salto, y Meleagro en la jabalina. Apolodoro (III, 9,2) y Pausanias $(\mathrm{V}, 17,9-10)$ añaden que también participó Atalanta en la lucha venciendo a Peleo. 
dáver se convierte en una masa sólida y dura de piel y huesos capaz de resistir sin cambio externo el paso del tiempo. Tratándose de evitar la putrefacción de las vísceras, la disección del cadáver era el sistema más «preciado» de asegurar la perennidad del difunto. No obstante, la apariencia de agresión dañina que la disección del cadáver llevaba consigo, justificaba un rito ancestral de Egipto en que los sacerdotes disectores - benéficos Titanes- habían de arrojar su bisturí y abandonar corriendo la sala de disección, mientras los asistentes les arrojaban piedras.

Las estructuras del mito de Dioniso despedazado por los Titanes se han mostrado capaces de ser interpretadas con coherencia desde el hipotético influjo del mito egipcio de Osiris. Es difícil asegurar apodícticamente un influjo, mediato o inmediato, de los ritos funerarios egipcios en el mito de la muerte y restauración de Dioniso. Todavía faltan pruebas directas, aparte de los debatidos viajes de Orfeo, Pitágoras, y Platón a Egipto y otros como Melampo, según el más o menos fidedigno testimonio de Heródoto (II, 46 y 81). Los helenistas tienden a sobrevalorar la originalidad de la cultura griega y a tachar de «espejismo egipcio» todo lo que pretenda ser estimado como deuda de Grecia al país del Nilo ${ }^{77}$. Los historiadores en general y, sobre todo, los egiptólogos tienden más bien a hacer justicia al hecho de la gran irradiación de la cultura de Egippto en todo el Mediterráneo durante el segundo y primer milenio antes de Cristo ${ }^{78}$. Pero Andrea Carandini, que no niega una

77 Es un clásico en este asunto FROIDEFOND, Christian, Le mirage égyptien, Université d'Aix en Provence 1971.

78 Jacques PIRENNE constituye una muestra notable en el recto aprecio del influjo de la cultura religiosa egipcia. A propósito de Dionysos Zagreus, versión cretense de Dioniso, el dios despedazado por los Titanes, del que aquí estamos tratando, podemos argüir que Pirenne cree sin vacilaciones en el influjo egipcio sobre la Creta del segundo milenio antes de Cristo, de donde debió pasar a Atenas el culto de Dionysos Zagreus. La religión cretense es todavía un territorio por explorar. La religión de Creta es una especie de monoteísmo dualista — según Pirenne (1951:140-ss.) - basado en el culto a una divinidad madre, diosas de la fecundidad, y a un dios paredro de la gran diosa, que aparece indistitamente como su hijo y/o su amante. Pues bien, ese dios está dotado de los atributos propios del Osiris egipcio y, a la vez, del Dioniso griego. Se trata de un dios toro (muchas veces antropomórfico y zoomórfico), como el Minotauro y como su abuelo el raptor de Europa. Es un dios al que hay que poner sin duda en relación, como a Osiris-Minotauro, con su hermana Ariadna, a la que sabemos que Dioniso desposó en la isla de Naxos y a la que sabemos (ver supra) que la esposa del arconte-rey de Atenas se unía hierogámicamente en el basileion-boukolion. Las «corridas de toros» tan representadas en el arte minoico pertenecen a este mismo culto del toro. El sacrificio (por despedazamiento) y la muerte de ese toro significan un destino al que no puede escapar el propio dios: «muere en otoño para renacer en primavera entre la algazara de las fiestas y las danzas» (ibid. 141) de la misma manera que muere y resucita Dionysos Zagreus, y de forma semejante a como muere el faraón (Osiris) y renace en el nuevo faraón (Horus). No tenemos una documentación muy precisa y cierta sobre el pensamiento de los cretenses acerca de la ultratumba. Pero sí que hay ciertos testimonios que apuntan en el sentido de que la teología funeraria cretense (el Laberinto es un edificio funerario según Heródoto) incluía la existencia de una vida post-mortem para el rey, Minos (Minotauro), que aseguraba la continuidad de la dinastía minoica. «Se ha querido ver en el sarcófago de Hagia-Tríada la representación del viaje del alma (=ba) hacia el país de los bienaventurados, lo que parece más que probable, pues uno de los oferentes lleva en sus brazos la maqueta del barco que en Egipto se usa para el viaje de ultratumba. Efectivamente, los egipcios expedían aceites a Creta, destinados a embalsamar a los grandes personajes" (ibid.). Entre tales personajes debió estar antes que nadie el rey de Creta, el Minos. La muerte del Minos y su hipotético despedazamiento (a imagen de Zagreus) no podían menos que estar relacionados con Osiris y Dioniso, si tenemos en cuenta que en el sacrificio que se representa en el sarcófago de Hagia-Tríada los sacerdotes oficiantes van vestidos con las mismas pieles de pantera que caracterizan no sólo a los sacerdotes funerarios egipcios, sino también a quienes ofician el diasparagmòs báquico. 
posible influencia de lo egipcio en lo mediterráneo, aduce una razón específica para excluir cualquier influjo en Roma del mito y rito de Osiris: las formas políticas totalitarias de Egipto y de Creta excluyen cualquier contacto cultural religioso con las monarquías de Grecia y de Roma en la alta edad arcaica. Carandini lo dice al final de capítulo y como dejando asentado un axioma. Haciendo un uso discutible de la base arqueológica, pone en relación las opciones religiosas de cada pueblo mediterráneo con las dimensiones de las ruinas de sus palacios ${ }^{79}$. No sé por qué ignorar que, en la edad alto-arcaica y siempre, las mismas monarquías han persistido (v.gr. los monarcas macedonios en Grecia o en Egipto) con diferentes bases mítico-religiosas; y que, a la inversa, la misma base religiosa (el Cristianismo actual) ha sido capaz de adaptarse a todas las formas políticas (a la teocracia medieval, al ancien régime, al fascismo, al nacional-catolicismo español, a la democracia) sin merma de sus esencias dogmáticas ni de su práctica sacramental o ritual. Carandini abrenuncia de Egipto y atribuye a los senadores de Roma el despedazamiento de Rómulo, proyectando al siglo VIII a.C. un reparto quasi-democrático de la soberanía en nombre del «dios de los ciudadanos» ( ${ }^{\star}$ Co-uirinus); y se olvida de que la gran mitografía de Quirino se pone de manifiesto en Roma siete siglos después cuando Cayo Julio César empieza a transpirar aires de dictadura. Y lo mismo pasó en Grecia. Dioniso, un dios que el ateniense Eurípides en las «Bacantes» por boca de Tiresias y Cadmo considera tan liberal (y democrático) -y Penteo anatematiza por su carácter disolvente de la polis-, encuentra su época de mayor florecimiento en Atenas bajo la tiranía de Pisístrato.

d) Píndaro o la verdad sobre el despedazamiento de Pélope. El caldero al que fue arrojado Dioniso operó efectos benéficos, su revitaliación (anabiôsis), y no su preparación para un banquete caníbal. Los más antiguos relatos (s. III a.C.) del «asesinato» de Dioniso aluden con claridad a Delfos. Un escolio de Licofrón dice así: «También Dioniso es venerado en Delfos y de la siguiente manera: Después de haber despedazado los miembros de Dioniso, los Titanes los entregaron a Apolo, que es hermano suyo (de él), introduciéndolos (ellos) en el caldero que estaba colocado junto al trípode, según afirman Calímaco (fr. 374) y Euforión (fr. 12 Scheidw.) diciendo: "Pusieron en el fuego al divino Baco sobre una copa"» (Schol. ad LYCOPHR. 208, P. 98,5 Scheer <O.F. 210>). Esta versión extraoficialista -precipitadamente atribuida sin dudarlo por Kern a los órficos-, lejos de considerar el

79 «Purtroppo — dobiamo qui ricordare - la regalità alto-arcaica dei Greci e dei Romani ha caratteristiche formali del tuto originali, che nulla hanno che vedere con la regalità assoluta in Egitto" (CARANDINI 2006:393). Con la aseveración de que la monarquía griega y romana tiene características de todo originales Carandini sienta un principio, quizás un postulado, difícil de compartir. «Le considerazioni sin qui fatte consentono di distanziare i re omerici e i primi sovrani di Roma dalle dispotie egizia (sic), vicino-orientale e cretese, che per quanto diverse fra loro si differenziano tutte da quelle mediterranee all'origine dell'età classica, associate sovente a costituzioni 'miste'. In Oriente sovrano e governo equivalgono a 'palazzo'». (CARANDINI 2006:365). Carandini procede a poner al descubierto las medidas de superficie de los grandes palacios de Creta, de Micenas, en comparación con los palacios romanos, para colegir el grado de populismo democrático de cada uno de los regímenes políticos a que se está refiriendo. ¡Tan absurdo como medir el sentido democrático de la monarquía española o de la monarquía británica por la magnitud de sus respectivos palacios! Olvida, además, Carandini que en Italia aun una humilde vivienda de «condominio» es un palazzo. 
trípode de Delfos una mera tumba, lo consideraba soporte del caldero de inmortalidad. En efecto, Filodemo, filósofo epicúreo de tiempos de Cicerón, comentando la triple génesis de Baco, sitúa «la tercera cuando, despedazado por los Titanes, Rhea reunió sus miembros y lo revivió» (PHILOD. de pietate 44, p.16 Gomp. $<$ O.F. 36>). Según Filodemo (ibid.), «Euforión en la "Mopsopia" está de acuerdo con esto...» Cook (1925:217) relacionaba el simulacro de ebullición a que se sometían los iniciados órficos con la célebre frase de las tablillas del sur de Italia: «Soy un cabritillo que se ha caído en la leche» (O.F. c) 11 y f) 4). La leche, cuya blancura recuerda la sosa cáustica, según Cook habría cocido a Dioniso en la intervención de los Titanes, que previamente habrían despedazado al dios como a un macho cabrío ${ }^{80}$. Sigue sin tener sentido despedazar criminalmente al alguien para que renazca. Por eso, Guthrie (1935:235) se extraña de la buena intención del «crimen» de los Titanes, que tuvo como resultado la resurrección de Dioniso. Guthrie (ibid.) resuelve su extrañeza conjeturando razonablemente que, como supone el profesor Cook, el crimen de los Titanes no es más que «un vestigio desfigurado de una versión desaparecida» en que la intención de los Titanes no era matar, sino restaurar al muerto, como a un Osiris místicamente asesinado: el faraón muere ordinariamente de forma natural (el malvado Seth no aparece en los primitivos textos de la teología funeraria menfita).

Pero este malentendido en el despedazamiento de Osiris-Dioniso-Rómulo no lo han descubierto Cook ni Guthrie, ni antes que ellos Filodemo. Mucho antes que Filodemo, ya Píndaro lo había tratado de desenmascarar. En su primera Olímpica el poeta Píndaro celebra la victoria de Hierón de Siracusa en la carrera ecuestre en el mismo escenario donde otrora había vencido el mítico Pélope. Píndaro reelabora la famosas leyenda de Pélope cocido y servido a los dioses por su padre Tántalo: El poema empieza con una alusión nítida a los efectos que la versión olímpica atribuía al perfido banquete: el «hombro refulgente de marfil» con que la diosas Deméter tuvo que subsanar los efectos del presunto banquete caníbal. Pero ya entonces Pindaro anticipa el desenmascaramiento que él se ha propuesto hacer del mítico banquete y así se refiere paradójicamente a un "caldero purificante» ( $\kappa \alpha \theta \alpha \rho \circ \nu \lambda \varepsilon \beta \eta \tau o \zeta, 40)$. Y enseguida se abre a la luz la tesis de Píndaro: «A mí me resulta imposible llamar comilón ( $\gamma \alpha \sigma \tau \rho \mu \alpha \rho \gamma o v)$ a ninguno de los bienventurados

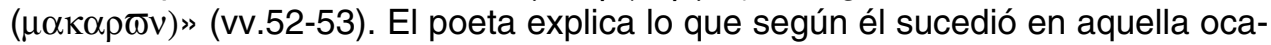
sión: Pélope no desapareció por haber sido consumido, sino porque Poseidón, enamorado, se lo llevó como cuando Zeus raptó a Ganímedes. Un vecino envidioso sugirió furtivamente que Pélope había sido hervido en el caldero, cortado a trozos, y que los dioses, a instancias de su padre Tántalo, se lo habían comido sacrificalmente. Y no es el único mito - sugiere Píndaro- en que se falsean las tradiciones. "A menudo las palabras de los hombres van más allá de la verdad. Mitos construidos con pintorescas falsedades nos confunden» (vv.28a-29). Entendemos nosotros que también los Titanes han de ser contados entre los «bienaventurados" a los que no se puede acusar de canibalismo horrendo. $Y$ entendemos la

80 La misma conjetura mantiene Guthrie (1935:233) citando a Cook: «Supposons donc que les anciens 'rois' thraces et phrygiens (les Titans du mith) après avoir égorgé Dionysos comme un chevreau, l'aient mis dans un chaudron de lait et l'aient fait bouillir pour qu'il renaisse». 
actitud -ya no nueva después de Píndaro- que Tito Livio y Ovidio mantienen al calificar de «rumor confuso» y de «falsedad» la opinión de los que interpretaban como un crimen de los senadores romanos el despedazamiento de Rómulo. ¿Cuál es, entonces, la explicación verdadera de lo que ocurre en el caldero de inmortalidad? Píndaro explica de otra manera el caldero de Pélope y por otras razones el castigo de su padre: Tántalo era tenido por hijo de Zeus y de Pluto, ella misma una Titánide nacida de Cronos o de Atlas. Había, pues, heredado el carácter regio por parte de padre y madre. Reinaba en Asia Menor (en Frigia o en Lidia, sobre el monte Sípilo). Era titular de una estirpe regia, en la que había de sucederle su hijo Pélope. Tántalo, aunque nunca es tenido por un dios, poseía de pleno derecho la inmortalidad, que a los reyes de la Grecia micénica seguramente les confiere en el mito la sangre de Zeus, en el rito el caldero de inmortalidad. «Robó a los dioses y entregó a los comensales de su tiempo el néctar y la ambrosía que a él le habían convertido en inmortal» (PIND. OI. I, 60-63). Tántalo quiso así ampliar a los hombres la inmortalidad de ultratumba que los ritos funerarios concedían solamente a los miembros de las dinastías regias ${ }^{81}$. Y, por eso, los dioses no demoraron su castigo: a Tántalo le hicieron padecer tormento. Pero el castigo de Tántalo —como afirma Píndaro, y contra lo que dice Homero_-82 no es pasar hambre en los infiernos por haber entregado a Pélope a un banquete canibalístico, sino sostener sobre su cabeza una enorme piedra (el sol), por malversar la inmortalidad que e él le correspondía únicamente entregar en herencia a su hijo. Repartir la ambrosía (=athanasía) es función que corresponde primigeniamente a Deméter, la madre Tierra, y delegadamente a sus hijos los Titanes. El propio Tántalo, que «robó» a los inmortales el néctar y la ambrosía, era un Titán, como Prometeo (que «robó» el fuego), pues era identificado con Atlas, el titán de la Arcadia. Píndaro, presionado por la tradición, se contradice al caracterizar a Tántalo como un mortal ( $\theta v \alpha \tau o v, v .54)$ $y$, a la vez, como gozando de una inmortalidad con la que — dice Píndaro- los dioses lo dotaron (vv.63-s.). Igual que Prometeo era hijo del titán lápetos, Atlas Helios era para Hesíodo hijo del titán Hiperión ${ }^{83}$. La inmortalidad era un atributo propio de

81 FRANKFORT (1948:219) trata en Egipto durante el Primer Período Intermedio el tema de la supresión de la barrera que separaba la suerte post-mortem del rey de la de sus súbditos: «el pueblo... usurpó ... la prerrogativa real y aspiró a un entierro osiriano con la esperanza de conseguir la resurrección».

${ }_{82}$ El castigo digno de un coloso (de un Titán) a que se refiere Píndaro (OI. I, 56-63) diverge del que le asigna Homero (Od. XI, 582-92), quien por cierto coloca a Tántalo en un Hades completamente distinto del de los versos anteriores, que lo era de sombras evanescentes. Éste Hades, en que se mueven figuras titánicas como Orión (-Osiris), Ticio y Sísifo, está presidido por el cretense Minos, antitipo de Osiris, que como aquél preside una ultratumba también corpórea (de cuerpos embalsamados), que como el propio Tántalo famélico y sediento de Homero necesitan comer, según demuentra el ajuar funerario de las tumbas egipcias -y de otras muchas del área mediterránea contemporánea-

83 HES. Theo. 371-ss. Ver DIONYS.HALIC. Arch. I,6 y Schol. ad EURIP. Or. 981. Mayer (1887:87) avala la etimología Tántalos <Táltalos <Tálaos <Tálos = Helios, el Sol. Este sol es la piedra (a lo Anaxágoras) que Tántalo sostiene sobre su cabeza, como Atlas sostiene el Cielo. Dumezil (1924:121) identifica arcadio Atlas $=$ argivo * Táltalos $>$ Tántalos. A la identidad Tálos $=0$ ஸे $\lambda$ ıo $(\mathrm{HESYCH}$.) conviene

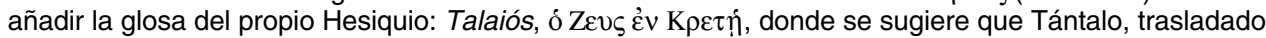
a la Arcadia desde la cultura micénica, no es sino uno de los nombres del Zeus cretense. Dada la relación que, por medio de Creta, puede establecerse con el mundo egipcio y semítico, no es de extrañar que Atlas-Tántalo emigrara, como el fenicio Melqart, hasta los límites de la Tierra; y más allá de las columnas de Hércules sostuviera la «piedra» que caía sobre el horizonte cada atardecer (mientras que en el extremo oriental Sísifo debía hacerla remontar en cada amanecer). 
Muerte, desplazamiento y apoteosis de Rómulo: un estudio sobre la realidad...

Tántalo ${ }^{84}$. ¿Y Pélope?, ¿los dioses castigan a Pélope, que no había cometido, él, ningún delito? No, Pélope paga meramente las consecuencias de la acción impropia de su padre: «y de nuevo (los dioses) enviaron a su hijo (Pélope) junto a la especie de fugaz destino de los hombres» (ibid. vv.65-67). Dicho de otra forma, Pélope no pudo disfrutar del caldero de inmortalidad, que su padre había ultrajado, y perdió el derecho divino a la sucesión en el trono. Por eso (ibid., vv. 69-ss.) tuvo que pensar en una boda ventajosa que le devolviera el carácter regio: el trono de Pisa (junto a Olimpia) y la mano de Hipodamía, que su padre Enómao había ofrecido al vencedor en la carrera ecuestre. Y así termina la primera Olímpica de Píndaro.

La reflexión de Píndaro nos impele a rechazar la consumición del cadáver cocido como parte sustancial del ritual del caldero de inmortalidad. Ya hemos anunciado más arriba nuestra renuncia a interpretar el mito de Dioniso dentro de cualquier esquema de banquete y cultura, como el de la oposición crudo/cocido, renuncia que nos viene impuesta porque el trazo culinario del mito de Dionysos Zagreus (y el de cualquiera otro de los mitos de devoración caníbal) sólo aparece en las últimas versiones ya de la época neoplatónica ${ }^{85}$. Por el contrario, aquí conjeturamos que el despedazamiento y la (hermenéuticamente abordable) cocción de Dioniso, como antes la de Osiris y, más tarde, el despedazamiento y la fulminación de Rómulo debe ser interpretada en el marco de un «mito de sucesión». De hecho, así hay que abordar aquellos relatos en los que el despedazamiento y/o la cocción de un héroe conduce a su posterior exaltación. Aquí y ahora abordaremos como relatos paradigmáticos de ese mito de sucesión aquellos en que el despedazamiento-cocción conduce a un desenlace positivo, como son el relato de la cocción de Demofonte y la fulminación de Heracles.

El primer Himno Homérico a Deméter relata —como sabemos- que la diosa madre, disfrazada de anciana, llegó a Eleusis, junto a Atenas, buscando a su hija Perséfone, raptada por el dios Poseidón. Encontró allí, junto a un pozo de agua a las hijas de Celeo y Metanira, que le propusieron cuidarse de su hermanito, llamado Demofonte. La diosa llevada por su amor al niño quiso privarlo de vejez y de muerte. Para eso, ella «a espaldas de sus padres embadurnaba con ambrosía al niño Demofonte cada noche y después lo sometía al fuego que había de inmortalizarlo» ${ }^{86}$. Una noche Metanira observa cómo la «anciana» somete al fuego a su hi-

${ }^{84}$ Se dice que Tántalo tuvo el don de la inmortalidad porque lo recibió y, luego, lo robó a los Olímpicos. Seguramente nos hemos topado otra vez con una aplicación de la célebre «teoría del rapto»: Es el mismo tratamiento que la propaganda «Olýmpica» dio en Hesíodo al don del fuego que Prometeo primero robó y luego donó a los humanos.

85 En esto discrepo de Detienne (1977:131), quien haciendo remontar el orfismo y el mito de Zagreo hasta el s. VI a.C. afirma: «Desde entonces el mito de Dioniso matado por los Titanes pasará a ser, en sus diversas secuencias, el motivo de una serie de preguntas sobre el sacrificio sangriento de tipo alimentario, sus modalidades y su estatuto en la sociedad y en el pensamiento griegos". La existencia en época clásica del mito de Zagreo devorado por los Titanes es rechazada unánimemente por la crítica filológica actual, al menos desde Wilamowitz-Möllendorf, Der Glaube der Hellenen, 1932, p. 373 n. 4.

${ }^{86}$ HYMN.HOM. ad Dem. (I),236-ss. Véase también APOLLOD. 1,5,5. Lo mismo hacía Thetis, de la que Apolodoro en su Biblioteca Mitológica $(3,13,6)$ dice que «acostumbraba a sumergir por la noche en el fuego (a Aquiles) para destruir lo que había en él de mortal heredado de su padre (Peleo), pero de día lo ungía ( $\chi \chi \rho \imath \varepsilon v)$ con ambrosía». 
jito y, desconfiada, trata de arrebatarlo de los brazos de la que ella ignora ser una diosa. Irritada la diosa, detiene a medias su operación y echa al niño a tierra, donde queda muerto, como los antiguos comentaristas interpretaron ${ }^{87}$. La diosa protesta que, si Metanira le hubiera dejado hacer, «ella hubiera concedido al niño una promoción u honor imperecedero ( $\alpha \phi \theta \imath \tau o v \tau \mu \eta \nu)$, pero que ahora ya no es posible que él escape al destino de la muerte» (vv.261-2). La expresión timé áphthitos (v.263) recuerda demasiado a la que emplea Hesíodo para caracterizar a los reyes y a los démones en que se convierten los hombres de la regia generación dorada, para que no nos veamos obligados a pensar que lo que realmente Deméter quiso hacer del niño Demofonte fue convertirlo en un miembro de la generación dorada, en un rey ${ }^{88}$. La datación antigua del Himno a Deméter, siglo VI a.C., nos permite tender este puente con Hesíodo. Tanto el Himno Homérico con respecto a Demofonte, cuanto Apolodoro con respecto al niño Aquiles, expresan claramente que la ambrosía operan como una unción o embalsamamiento que otorga la vida tanto al vivo como al muerto ${ }^{89}$.

Por otro lado, el texto está cargado de alusiones a la teología funeraria y a la generación titánica. Las hermanas de Demofonte toman en sus brazos al niño y, reanimando el fuego que había encendido Deméter, tratan de devolverle la vida. En las funciones que ellas desempeñan se descubren funciones básicas del vocabulario funerario. Las hermanas de Demofonte no sólo alejan a Metanira del «incensado tálamo» ( $\theta \nu \omega \delta \varepsilon \circ \varsigma \varepsilon \kappa \theta \alpha \lambda \alpha \mu$ oto, v.288) —lo cual, sobre todo tratándose de un niño ajeno al tálamo parece aludir a una fórmula ritual de luto más que al perfume que ha dejado la diosa-, sino que siguen todos los pasos de un auténtico

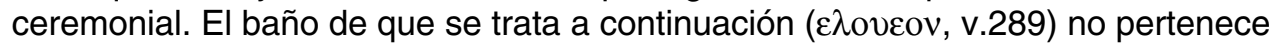
a la parte lustral del rito funerario, sino que debe entenderse como el bautismo de fuego (¡reanimado!), que en intención de las hermanas, había de revitalizar al niño. Pero no lograron su propósito: «Tan inferiores a la diosa eran», dice el texto

${ }^{87}$ El niño resultó muerto, o bien porque «había sido consumido por el fuego» ( $\tau$ ov $\mu \varepsilon v \beta \rho \varepsilon \phi о \varsigma ~ v \pi \mathrm{o} \tau \mathrm{\tau ov}$ $\pi \cup \rho \circ \varsigma \alpha v \varepsilon \lambda \mathrm{o} \theta \varepsilon$, APOLLOD. 1,5,1), o bien porque, como dice el Segundo Mitógrafo Vaticano, "Demeter in her rage killed it» (G.FRAZER 1921:312).

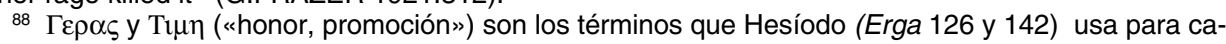
racterizar a los hombres de la generación dorada y su estatuto post-mortem. Lo típico de esta generación dorada es su carácter regio, igual que es lo típico de los dioses que crean y promocionan (ver VERNANT 1960:29-31). El epíteto áphthitos, «imperecedero», parece enunciar el carácter indeleble del alma del rey (igual que el ka del faraón), que se transmite a la dinastía y que persiste de generación en generación. El autor del Himno Homérico a Deméter no sabe entender la literalidad de la expresión e ignora ya el sentido que los términos pudieron haber tenido en un pasado no tan remoto. Lo demuestra el hecho de que el autor paradójicamente concreta en una deplorable guerra de Eleusis contra Atenas tal «honor imperecedero", por haber reposado el niño en sus rodillas (!).

${ }_{89}$ En el área prehelénica la ambrosía, con la que se frota (se unge) al vivo o muerto, crea la inmortalidad del daemon destinado a la «función regia», como la unción crea al rey de Israel. El fundamento para ambas prácticas podría estar en Egipto. El embalsamamiento preserva la naturaleza inmortal y divina del Faraón; y así lo que en Egipto eleva al inmortal y regio en vida y tras la muerte, ¿en Grecia conserva sólo tal valor en el estatuto póstumo de la generación dorada? En Israel se recalca su influjo en la vida presente como unción de reyes y profetas (curiosamente en una etapa histórica en que la vida de ultratumba se reduce a la existenca en el sheol de meras sombras, como en la antropología indoeuropea de los Olýmpicos): véase, en los LXX, Jos 8,10; 3 Reg 19,16; Jud 9,15. Véase también en el Nuevo Tes-

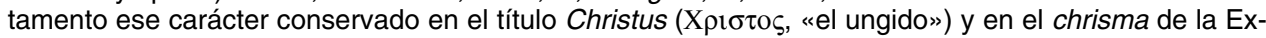
trema Unción. 
(v.291). Es más, el relato presenta al niño ahora «resistiéndose» (aspaironta, v.289) al baño, lo que no se explicaría si se tratara de un mero baño lustral a un niño ya medio muerto o totalmente cadáver (el episodio vacila entre la descripción de un mito de resurrección y uno de inmortalización fallida de un niño vivo). El fracaso ritual de las hermanas las hijas de Metanira es descrito metafóricamente: «No

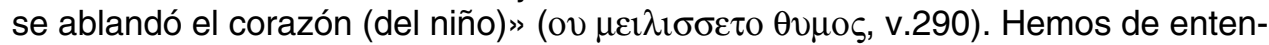
der que el ablandarse de corazón tiene un sentido ritual. En efecto, el verbo «ablandar» pertenece al vocabulario funerario ${ }^{90}$. En el contexto de un proceso de «revitalización», ablandar el corazón (thímós, principio de vida) puede significar simplemente revivificar al muerto. De hecho el término podría estar relacionado con el efecto que el fuego, sobre todo si se trata de cocción, produce en las carnes del muerto devolviéndole la suavidad de la primera juventud ${ }^{91}$.

e) Hércules: el rayo de Zeus, rayo de apoteosis. En el episodio de Deméter en Eleusis, la suspendida revitalización de Demofonte pudiera haber sido efecto tanto de la cocción en el caldero cuanto de la aplicación directa a las llamas. Estamos ante un texto de transición al ritual del puro fuego, tal como se entendía practicar en época histórica. Así podemos observarlo en el mito de Heracles, cuya cronología mítica se sitúa ya al final de la edad micénica, al borde de la era dórica (los reyes de Esparta se autoproclamaban heráclidas): Heracles en la pira, fulminado por los rayos de Zeus, igual que Sémele en el nacimiento tebano de Dioniso, nos transporta hacia Rómulo, cuyo despedazamiento podría no ser una versión aparte - más antigua- de su muerte, sino que podría correr paralelo de la tormenta de fuego que Júpiter envía sobre él en el momento de su apoteosis.

La historia final de Hércules es de sobra conocida. Heracles ve llegar su hora final al no poder resistir el dolor causado en sus carnes por los efecto mágicos de la túnica envenenada del centauro Neso. Celosa del nuevo amor de Hércules por Yole y engañada por el centauro que la había intentado violar a la vista del héroe, Deyanira, la penúltima esposa de Heracles, le había regalado esa túnica esperando recobrar su amor. Heracles decide vencer a la muerte quemando sobre la pira del monte Oeta lo que de mortal había en él y así subir a formar parte del número de los dioses Olímpicos. Tal es la historia final de Heracles. Pero, ¿qué podía esperar el héroe del fuego de la pira sino la muerte? Como ya hemos visto más arriba, el fuego (con caldero - Pelias y Pélope - o sin caldero -Demofonte-) daba ya la inmortalidad; pero en el caso de Hércules el efecto regenerador del fuego es reafirmado por el rayo de apoteosis de Zeus.

En Eleusis se conservaba una sagrada tradición prehelénica, según la cual el fuego concedía la inmortalidad. Precisamente el nombre de Eleusis aparece en la

90 Sobre $\mu \varepsilon 1 \lambda \imath \sigma \sigma \omega$, «ablandar», véase CHANTRAINE, Dictionnaire Étymologique de la langue grecque, s.v. $\mu \varepsilon \imath \lambda \imath \alpha, \mu \varepsilon \imath \lambda \imath \chi o \varsigma$.

91 Véase APOLLOD. 1,9,27 y PAUS.8,11,2 a propósito de Pelias cortado en trozos por sus hijas con la intención de regenerarlo. De hecho, en el ritual funerario egipcio el término se usa a propósito de los efectos del natron, de la resina y de los aceites y bálsamos, que agilizan y ablandan los miembros de Osiris embalsamado y destinado a la resurrección. 
etimología del nombre enelysioi, que recibían aquellos que eran alcanzados por el rayo de Zeus ${ }^{92}$; incluso el simple nombre de elysia era dado a los lugares que habían sido señalados por el fuego divino ${ }^{93}$. Se creía que los hombres tocados por el rayo, como los que eran conducidos a los Campos Elíseos (de ahí la hipotética relación etimológica entre ambas palabras), quedaban inmortalizados. Paradójicamente la fulminación era considerada por los más antiguos una verdadera apotheosis acompañada de lo que llamaríamos en algún sentido euthanasia. La lista de los hombres inmortalizados de esa manera es larga: Además de Heracles (y Rómulo) son inmortalizados por el rayo, entre otros, Asclepio, Erecteo y Capaneo. El caso de Capaneo es paradigma de los efectos del rayo en la edad micénica.

Capaneo, uno de los «Siete contra Tebas», fue golpedado por el rayo (AESCHYL. Sept. 444-ss.): su cadáver quedó quasi-divinizado (EURIP. Supplic. 935) y su tumba sacralizada (ibid. 981). Siendo uno de los enêlysioi, su pira era exhibida en Eleusis, según Eurípides, a la derecha del templo de Deméter Eleusinia; e igualmente se mostraba su cámara funeraria y el sepulcro sagrado, al que el poeta trágico (ibid. 1010) llama «pira, tesoro de Zeus». Es claro que tales piras, como otras hogueras funerarias que se levantaban en los alrededores de Eleusis, no eran meros dispositivos donde practicar el rito indoeuropeo de la incineración. Así lo cree Picard, quien piensa en Capaneo y su esposa Evadné, que se arrojó a la pira de su marido, como una pareja prehelénica divinizada en Eleusis ${ }^{94}$. Pero quizás no es necesario llegar a tanto. Si fulminación y cremación tienden a fundirse en Eleusis, es probablemente porque el rayo de Zeus simboliza —en categorías griegas, es decir, propias de los dioses Olímpicos- el mismo efecto inmortalizador que antes —en categorías prehelénicas, es decir, propias de los dioses chthónicos—95 realizaba el fuego de la pira o el caldero de inmortalidad ${ }^{96}$.

Desde este punto de vista la fulminación de Sémele, la madre de Dioniso, por el rayo de Zeus, como la de su propio hijo, adquiere un nuevo sentido. La versión clásica de Eurípides representaba esa fulminación como castigo perpetrado por

92 Vésae Picard 1933:153, y Chantraine, s.v. Eגvoiov.

93 «Fenced about from the foot of common mortals and reserved for Zeus himself, they were both in name and in nature so many "Elysian fields"» (COOK 1925:22). En cuanto a la etimología de Elysion discrepan quienes siguiendo a L.Mayer Handb.d.gr.Etym. conectan elysion con enelysios (de $\varepsilon \lambda \varepsilon v \sigma o \mu \alpha \mathrm{l}$ y $\varepsilon \lambda v \theta 0 v$, "venir (el rayo sobre alguien»), y aquellos otros — más dignos de crédito en mi opinión- que siguiendo a Malten (1913:39) afirman que la palabra es minoica y conectan Elysion con Eleusis. Veáse

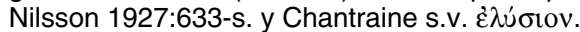

${ }_{94}$ Picard (loc.cit.) cita a Nilsson (1932:118), quien estudiando el mito de Capaneo lo considera «a precious testimony as to Mycenaean funeral costums". Para la procedencia de Capaneo, véase Nilsson (ibid.), que hace notar, por un lado, que su patria y su genealogía eran desconocidas, pero, por otro lado, que en una fuente tardía para un personaje minoico-micénico (HOM. II. 2,564) se dice que «los de Argos iban mandados por Estenelo, hijo del gran Capaneo». Pero su esposa Euadné lleva en el nombre la misma raíz que la cretense Ariadné (cfr. Chantraine s.v. adnon); ella, como Ariadna, es aveces confundida con Perséphone (véase Picard 1933: 138 n. 5, y Nilsson 1927:527-s.).

${ }_{95}$ Para la distinción entre categorías religiosas de origen prehelénico (en las que dominan los dioses de la Tierra, ge o chthon, los dioses chthónicos) y categorías de origen helénico (en las que dominan los dioses del cielo, o dioses Olímpicos) puede verse Angel Luis Casquillo Fumanal, Naturaleza Titánica, U.A.M. Madrid 1991.

96 «Le rite du Bûcher est venu a Eñeusis aaux temps intermédiaires oú la religion de la Terre subit l'eclipse connu: rattachée, en gros et en general, à l'invasion des Doriens» (Picard 1933:35). 
Muerte, desplazamiento y apoteosis de Rómulo: un estudio sobre la realidad...

Hera haciendo que la adúltera Sémele quisiera recibir a Zeus en toda su gloria (EURIP. Bacch. 9), o como castigo decidido por el mismo Zeus, según pregonaban las hermanas de Sémele, por haber inventado ella, una mortal, nupcias divinas (ibid. 28-ss). Pero ya Píndaro (OI. II, 25-s) negaba la crueldad divina, como en el caso de Pélope, y presentaba la fulminación de Sémele como una auténtica apoteosis. E, igual que su madre, Dioniso fue divinizado por el rayo: según testimonio de Diodoro Sículo $(\mathrm{V}, 52)$, los habitantes de Naxos creían que Sémele fue golpeada por el rayo antes de dar a luz, para que ella dejara de ser una mortal y Dioniso, siendo hijo de dos seres inmortales, fuera ya inmortal desde el momento mismo de su nacimiento ${ }^{97}$. Vistas así las cosas, cabe preguntarse cuál fue el proceso mitográfico - y a qué época histórica corresponde- por el que una fulminación, la de los Titanes que despedazan a Zagreo, como más adelante la del rey romano Tulo Hostilio (a diferencia de la de Rómulo), pasa a ser un mero castigo vaciado de todo contenido positivo. La respuesta está, en este momento, por encima de nuestras posibilidades.

No debe, pues, extrañarnos, que el mismo decantamiento de lo positivo a lo negativo se dé (como se dará en el despedazamiento de Rómulo) también en el caso del fuego que consume a Heracles en la pira. Ya en época histórica una sucesiva declinación del poder regenerador del fuego puede observarse en el lapso que transcurre desde el relato de Teócrito en su poema bucólico «Heraclisco» (s. III a.C.) hasta la tragedia de Séneca (s. I d.C.) «Hércules en el monte Eta». En ambos casos la hazaña de Heracles en la pira transporta al héroe desde los límites de la mortalidad a los cielos y a las estrellas (THEOCR. XXIV,79). Pero la diferencia sustancial está en que en el texto de Teócrito la apoteosis se debe a la eficacia positiva del fuego de la pira traquinia, que «se lleva todo lo que de mortal» hay en Heracles ((THEOCR. $X X I V, 83)$; mientras que para Séneca «las llamas no son nada» y Hércules queda inmortalizado por el hecho de que él solo sale triunfante de «el único mal que en la tierra aún no había vencido, la llama» (SEN. Herc. in Oeta, 1610-15).

Hércules en la mitología no pasó de ser rival de Euristeo, rey de Micenas. Históricamente hablando habríamos de remontarnos a los reyes dorios de Esparta, quienes se consideraban hijos de Heracles retornados a Grecia, los Heráclidas. Dioniso, un cadmeo por línea materna, no llegó nunca a rey de Tebas. Pero los órficos, antes, y luego los reyes de las ciudades helenísticas -incluido Marco Antonio en Alejandría- consideraban los primeros a Dioniso destinado al trono del cielo y los últimos se consideraban a sí mismos personificación de un nuevo Dioniso (Neós Diónysos). Los perversos Titanes del mito órfico — que despedazaron a Dioniso Zagreo- eran considerados diversos de los benéficos hermanos de Cronos, Titanes reyes de la Edad de Oro hesiódica. Quizás no desentone aquí, con la «navaja de Ockham» que Píndaro ha puesto en nuestras manos, purificar a los Titanes órficos de la maldad que la propaganda Olímpica les atribuye, y conjeturar en ellos Titanesreyes como los del relato hesiódico empeñados aplicar al niño Dioniso el ritual de despedazamiento que lo había de hacer apto para ocupar el trono del cielo.

${ }_{97}$ Sobre las fuentes antiguas de Diodoro, véase Schwartz, s.v. «Dionysos», R.E. Pauly-Wissowa, t.V c.678. 


\section{EPÍLOGO}

La cremación y apoteosis de rayos de Heracles cierra, en el tiempo inmediatamente anterior a la invasión doria, una larga serie de episodios de la era minoicomicénica en la que, de acuerdo con el paradigma de Osiris, un héroe griego (a veces siguiendo ritos claramente pre-helénicos) concluye un proceso de apoteosis generalmente relacionado con la función regia.

En el caso de Osiris, su despedazamiento parece no ser otra cosa que la traducción a lenguaje mítico del ceremonial de embalsamamiento del faraón. La misma situación se da en Grecia de forma hiperbólica, si hemos de creer ya a Frazer (1922), quien no tenía ninguna repugnancia en entender realísticamente el esquema egipcio y aplicar al ritual de sucesión al trono cualquier mito de despedazamiento: «Pudo suceder que, en épocas prehistóricas, fuesen justamente los reyes los que simbolizaban al dios (Osiris,Dioniso) y, como tales, eran sacrificados y hechos pedazos» (Frazer, 1922 [1992]: 431). Lo que, según Frazer, fue en época prehistórica un rito fáctico y cruel, en época histórica no pasa seguramente de ser mitología y simbolismo ritual, como a mi entender no pasó de ser en Egipto.

Rómulo se adapta a las líneas maestras de ese paradigma. Su muerte es consecuencia de un despedazamiento ritual. Se excluye un asesinato físico en busca de una recuperación de la soberanía o en busca de la usucapión de los auspicios por parte de los senadores de Roma, como querían Fraschetti y Carandini. Ambos episodios, apoteosis celeste y despedazamiento, lejos de constituir dos variantes autoexcluyentes, una antigua (mítica) y otra reciente (desmitificadora) de la desaparición de Rómulo, pueden hipotéticamente ser entendidas como una doble versión del ritual de inmortalidad y deificación del rey muerto.

Hemos de atender finalmente a una doble objeción:

1. Una primera objeción es propuesta por Dumézil (1924): Rómulo no aparece en ningún desarrollo del mito como perpetuándose en el nuevo rey, ni como rey del Hades en el plano de los muertos, al contrario que Osiris; y, a su ejemplo Minos en Creta (rey del muertos con su hermano Radamanthys) y en época griega Dioniso, divinidad chthónica, que como Heracles desciende triunfante a los infiernos, aquél para introducir a Ariadna (HOM. Od. XI, 324-s.) y rescatar a su madre Sémele (PAUS. II, 31,2 y 37, 5-6), éste para doblegar al can Cerbero ${ }^{98}$.

98 «J'ai pensé d'autre part que c'est qu'en tant que maître du sous-sol (voir JMQ, pp. 94-95; y JMQ II p.197) que Quirinus avait pu se fondre avec Romulus, le 'premier roi mort': en effet, chez un grand nombre de peuples, indoéuropéens ou non, le 'premier roi mort' devient aisément le roi d'outre-tombe avec les prérogatives agraires que decoulent de ce qualité. La première explicatión est évidemment très verbale et la seconde se heurte au fait qu'aucun document ne permet de voir en Romulus, ni en Qurinus, un 'roi des morts'. De plus l'un et l'autre négligent deux aspects du service du dieu (ici custodia, là imperium) qui, étant essentiels dans le résultat, doivent avoir joué un rôle important dans le processus même des assimilations» (Dumézil 1944: 204). 
Muerte, desplazamiento y apoteosis de Rómulo: un estudio sobre la realidad...

2. La segunda objeción es propuesta por Carandini (2006): Tras la muerte de Rómulo ya no se trata de generar físicamente ni regenerar místicamente al rey exaltando una dinastía de reyes divinos, sino de elegir un nuevo rey ${ }^{99}$.

Contra tales objeciones se puede argüir que el rey muerto, identificado con Osiris rey de los occidentales, es decir del cortejo de los muertos, es la cara oculta del nuevo rey, Horus, en el que pervive el ka del faraón muerto. Es cierto que cualquier episodio de Rómulo en los infiernos nos es desconocido. Pero puede abrirse un camino a la investigación relativa a Quirino en cuanto personificación divina del nuevo rey, que mantiene vivo el espíritu del antiguo rey. De hecho, Cayo Julio César se atribuyó el título de Quirino: ¿podemos dudar de que César se autoproclamó Quirino en su calidad de aspirante a un poder faraónico con capital en Alejandría? Sabemos también que de hecho Rómulo murió sin descendencia. No sabemos cómo hubieran ido las cosas, si un hijo de Rómulo hubiera recibido en herencia el trono y el reino. A la muerte de Rómulo se convierte inmediatamente en electiva una monarquía que por el momento no tenía futuro como monarquía hereditaria. Los senadores exigen una monarquía electiva, que el pueblo concede. Sin embargo, no es claro que una monarquía electiva no requiera, en cada interregno, una fundamentación divina además, y más allá, de favorables auspicios. ¿Acaso la tradición histórica, demasiado atenta en poner de relieve los poderes del senado durante el interregno, no nos ha hurtado el rito religioso de transición de un rey a otro?

La leyenda de Tulo Hostilio ha mantenido una réplica de tormenta de rayos igual que la apoteosis de Rómulo. Hemos argumentado más arriba la buena lógica de entender positivamente rituales como el caldero de inmortalidad, la cremación y el reyo de apoteosis, que la tradición convirtió en castigo. Así se debió hacer en el caso del rey Tulo Hostilio, cuya fulminación pasó a entenderse como castigo por una vida excesivamente belicosa. Tito Livio aduce que Tulo Hostilio celebró de forma poco adecuada ciertos rituales de Júpiter Elicio, por lo que dice que «la ira de Júpiter, provocada por la impiedad de Tulo, hizo que el rey fuera herido por el rayo y muriese quemado en su palacio» (T.LIV. I,31,8). Por el contrario, Cicerón -en testimonio conservado por San Agustín (de civ.Dei 3,15) - argumenta que «la razón por la que no se creyó que con tal muerte (Tulo Hostilio) había sido recibido entre los dioses, es quizá porque a aquello que en el caso de Rómulo había probadamente persuadido a todos, no quisieron los romanos quitarle precio ni vulgarizarlo, como sucedería si fuese fácilmente atribuido también a otro» (CIC. de re publ. II,17). No estaría de más conjeturar que a otros reyes de Roma se les hubiera quitado a la hora de la muerte más de lo que se quitó al propio Tulo Hostilio.

Puedo concluir de acuerdo con Burkert (1962) admitiendo que la sugerencia de que el despedazamiento de Rómulo —igual que su ascensión al cielo- no puede

99 «Il fallo custodito dalle Vestali (...) quello dello sposo sopranaturale (...) scaturisce del focolare regio (...) possedere la vergine principessa-sacerdotessa scelta per procreare l'eroe. II mitico evento - tipicamente indigeno - non si verifica piú dopo Romolo e l'abolizione della monarchia ereditaria ad Alba e a Roma, per cui la demitizzazione appare dalla fine dell'VIII secolo a.C., in sintonia con l'interrregnum, nel senso che non sarà piú questione di generare prodigiosamente re semidivini ma di eleggere re umani, salvo l'eccezione di Servio Tullio, non a caso il rifondatore di Roma» (Carandini 2006: pp. 79-80). 
aspirar más que a ser una sólida conjetura, referida a un tiempo, la primitiva monarquía de Roma, del que faltan testimonios contemporáneos ${ }^{100}$. Partimos aquí del principio de Karl Popper de que toda ciencia, sin excluir la ciencia histórica (y menos aún cuando la historia se practica con un método antropológico), es un sucederse de conjeturas abierto a inacabables refutaciones.

Hemos pretendido aquí cotejar dos teorías sobre el significado histórico del despedazamiento de Rómulo. La teoría de Augusto Fraschetti (2002) y Andrea Carandini (2006) -el despedazamiento de Rómulo responde a la repartición de la soberanía y a la conquista de los auspcicios por los senadores de Roma- se nos ha mostrado, en la primera parte de este trabajo, dotada de una verosimilitud débil. Hemos contrastado la teoría de Fraschetti-Carandini con la teoría más tradicional, que la nueva teoría trataba de sustituir. La teoría tradicional, la teoría de que el despedazamiento de Rómulo puede entenderse desde el paradigma del despedazamiento de Osiris (y los correspondientes prototipos griegos), teoría que atribuimos provisionalmente a Angelo Brelich (1960), se nos ha mostrado más sólida que la de Fraschetti-Carandini, sobre todo al contemplarla desde una base antropológica más amplia. Los hechos de esa base antropológica, a los que hemos aplicado una metodología comparativista no de detalles sueltos, sino de estructuras rituales complejas, permiten seguir los pasos de Brelich y de Sabatucci: El despedazamiento de Rómulo, como el de Osiris y Dioniso, está rodeado de una serie de «enunciados verdaderos» más extensa que la de Fraschetti-Carandini, y permite ser entendido como un rito de sucesión.

De paso hemos aprendido que el método comparativista, en antropología, puede ser sometido a los principios gnoseológicos de Karl Popper y que la comparación antropológica es más sólida cuanto mayor sea el grado de verosimilitud de los enunciados (o hechos) que contribuyen al universo comparativo.

Otros intentos de interpretar el despedazamiento de Rómulo sucederán al de Fraschetti-Carandini. Quizás alguno refutará pronto la hipótesis tradicional. Mientras tanto, sigue en pie la conjetura de que Rómulo, como Osiris, y como muchos reyes del antiguo mundo mediterráneo, fue despedazado en el momento de su muerte para ritualizar su inmortalidad y la de la monarquía romana.

\section{BIBLIOGRAFÍA}

ALFÖLDI, A. «Der neue Romulus», MusHelv 8, 1951, pp. 190-215.

ASSMAN, J. Potere e salvezza. Teologia politica nell'antico Egitto, in Israele e in Europa. Einaudi, Torino 2002.

BENVENISTE, Emile. «Symbolisme social dans les cultes gréco-italiques», en Revue d'histoire des réligions 129, 1945, pp. 5-16.

BLÁZQUEZ, José M. ${ }^{a}$ (Introducción). El Libro de los Muertos. Traducción de F. Lara. Editora Nacional, Madrid 1984.

100 «No se necesita recalcar que todas estas interpretaciones no pasan de conjeturas (Vermutungen) no estrictamente demostrables (beweisbar), pues se remontan a un ámbito prehistórico, que precede a aquella época en que venció la verdadera representación de Roma» (BURKERT 1962:270). 
Muerte, desplazamiento y apoteosis de Rómulo: un estudio sobre la realidad...

BÖMER, F. Ahnenkult und Ahnenglaube im altem Rom, Leipzig 1943.

BRELICH, Angelo. Tre variazioni Romane sul tema delle origini, Roma 1955.

- Gli Eroi Greci. Edizione dell'Ateneo. Roma 1958.

- «Quirinus. Una divinità romana alla luce della comparazione storica», en Studi e Materiali di Storia delle Religión,39, 1960, pp. 153 ss.

BRIQUEL, D. «Perspectives comparatives sur la tradition relative à la disparition de Romulus», en Latomus 36, 1977, pp. 253-282.

BURKERT, "Caesar und Romulus-Quirinus», en Historia. Zeitschrift für alte Geschichte. 11, 1962, pp. 356-376.

- Griechische Religion der archaischen und klassischen Epoche. Verlag W. Kohlhammer, Stuttgart 1977.

- Homo Necans. The Anthropology of Ancient Greek Sacrificial Ritual and Myth. University of California Press, 1983.

CARANDINI, Andrea.

2002 Archeologia del mito. Emozione e ragione fra primitivi e moderni. Einaudi editore, Torino 2002.

2006 Remo e Romolo. Dai rioni dei Quiriti alla città dei Romani (775/750-700/675 a.C.). Einaudi, Torino 2006

2007 Cercando Quirino, Einaudi, Torino 2007.

CARTER, B. s.v. «Romulus», en W. H. Roscher Lexicon der griechischen und römischen Mythologie, Druck und Verlag von B. G. Teubner, Leippzig 1909-1915: «vede nel regicidio una affabulazione razionalizzante resasi necessaria quando l'apoteosi avrebbe perso credito».

CASQUILLO FUMANAL, Ángel Luis. Naturaleza Titánica: Poder y Disidencia en la Mitología Clásica. Microfichas. Universidad Autónoma de Madrid 1991.

COARELLI, Filippo. II Foro Romano. Periodo arcaico. Roma 1983.

CORNELL, Timothy J. The Beginnings of Rome. Italy and Europe from the Age of Bronze to the Punic War (c.1000-264 b.C.). London-New York, 1995.

DETIENNE, Marcel. Dionysos mis à mort. Paris, Gallimard 1977 (trad.castell. de J.Herrera en ed. Taurus, Madrid 1983).

DUMÉZIL, Georges. Le festin d'immortalité. Paul Geuthner, Paris 1924.

- JMQ = Jupiter, Mars, Quirinus. Essai sur la conception indo-européenne de la societé et sur les origines de Rome. Paris 1941.

- JMQ II = La naissance de Rome (Jupiter, Mars, Quirinus II). Gallimard, Paris 1944.

ELIADE, Mircea. Der Mythos der ewigen Wiederkehr. Düsseldorf 1953.

ELLUL, Jacques. Histoire des institutions, Presses Universitaires de France 1958 (trad. cast.: «Historia de las instituciones de la antigüedad», Aguilar, Madrid 1970).

FRANCFORT, Henri. Kingship and the Gods. University of Chicago 1948 (trad. castell.: «Reyes y Dioses», Alianza, Madrid 1983).

FRAZER, Georges. he Golden Bough. London 1911-1918².

- «Putting children on the fire», en Apollodorus, (traducción, notas y apéndices por G. FRAZER) Heinemann, Cambridge-London $1979^{6}$.

- The Golden Bough (edición reducida): traducción italiana «ll ramo d'oro», ed. Newton, Roma 1992.

- The Golden Bough IV: Adonis, Attis, Osiris. London.

FRASCHETTI, A. Romolo il fondatore, ed. Laterza, Roma-Bari, 2002, p. 96.

GUTHRIE, M.W.K. Orpheus and the Greek Religion, 1935 (trad. franc.: S. M. Guillemin, «Orphée et la Religion Grecque», Payot, Paris 1956).

GOLDSCHMIDT, Victor. "Theologia», Revue des études grecques LXIII,1950, pp. 33-39.

KRETSCHMER, Paul. «Lat. quirites und quiritare», en Glotta 10, 1920, pp. 147-157.

HARRISON, Jane Ellen. 1903 Prolegomena to the Study of Greek Religion. Merlin Press, London 1903.

- Themis. A study of the Social Oriigins of the Greek Religion. Merlin Press, London 1911. 
LATTE, K. Römische Religiongeschichte, München 1960.

MAGDELAIN, A. «Auspicia ad Patres redeunt», en Hommage J.Bayet. Bruxelles, 1964.

MALTEN, L. «Elysion und Rhadamanthys», Arch. Jahrb. XXVIII, 1913, pp. 35-44.

MARCHETTI, Patrick. «Autour de Romulus et des Lupercalia», en Les Ëtudes Classiques LXX, 2002

MAYER, Maximilian. Die Giganten und Titanen in der Antike Sage und Kunst. Berlin, Weidmannsche Suchandlung 1887.

MOMIGLIANO, Arnoldo. «An Interim Report of the origins of Rome», en The Journal of Roman Studies, t.53, 1963, pp. 95-121.

NILSSON; Martin. Minoan-Mycenaean Religion and its survival in Greek Religion. Gleerup, Lunds 1950.

- The Mycenaean origin of Greek Mythology. Norton Company, New York 1932.

PALMER, Robert E. A. The Archaic community of the Romans. Cambridge University Press 1970.

PICARD, Ch. «Les bucher sacrés d'Éleusis», Révue d'histoire des Réligions, 1933, I, pp. 137-154.

PIRENNE, Jacques. Civilisations Antiques. Éditions Albin Michel, 1951 (trad. castell.: Mariano G. Sanz. Caralt ed., Barcelona 1976).

POUCET, Jacques. Recherches sur la légende sabine des origines de Roma. Éditions de l'Université de Lovanium, Kinshasa 1967.

- Les origines de Rome. Publications des Facutés Universitaires Sant-Louis, Bruxelles 1985.

RUIZ DE ELVIRA, Antonio. Mitología Clásica. Gredos, Madrid 1975.

SABBATUCCI, Dario. 1984 Da Osiride a Quirino. Roma 1984.

- La religione di Roma Antica, Milano 1988.

SCHWEGLER, A. Römische Geschischte I, Lepizig 1853.

VERNANT, Jean-Pierre. «El mito hesiódico de las razas. Ensayo de análisis estructural» en Revue de l'Histoire des Réligions (1960); artículo contenido en Mythe et pensée chez les grecs, ed. Maspero, Paris 1965 (ver la edición castellana: «Mito y pensamiento en la Grecia Antigua", ed. Ariel, Barcelona 1983).

WÜST, E. «Titanes», R.E. Pauly Wissowa, serie II, 12, cc. 1491-1506. 